\title{
Estudo do volume pulmonar fetal na predição dos resultados perinatais de fetos com derrame pleural "isolado"
}

Dissertação apresentada à Faculdade de Medicina da Universidade de São Paulo para obtenção do título de Mestre em Ciências.

Programa de Obstetrícia e Ginecologia Orientador: Prof. Dr. Rodrigo Ruano

São Paulo 
Dados Internacionais de Catalogação na Publicação (CIP)

Preparada pela Biblioteca da

Faculdade de Medicina da Universidade de São Paulo

Creprodução autorizada pelo autor

Freitas, Rogério Caixeta Moraes de

Estudo do volume pulmonar fetal na predição dos resultados perinatais de fetos com derrame pleural "isolado" / Rogério Caixeta Moraes de Freitas. -- São Paulo, 2011

Dissertação(mestrado)--Faculdade de Medicina da Universidade de São Paulo. Programa de Obstetrícia e Ginecologia.

Orientador: Rodrigo Ruano.

Descritores: 1.Derrame pleural 2.Hidrotórax 3.Feto 4.Pulmão/crescimento \& desenvolvimento 5.Terapias fetais 6.Ultrassonografia pré-natal 7.Quilotórax

USP/FM/DBD-372/11 
Dedico este trabalho:

A Deus, razão de tudo o que somos e fazemos.

Aos meus pais, Renato e Luzia, meus verdadeiros mestres, modelos reais de perseverança, parceria, dedicação, paciência e ética.

Aos meus irmãos, Fabíola, Rafael e Renata, que são pessoas incondicionais, os quais me incentivaram a buscar os melhores caminhos e me ensinaram com os seus exemplos.

À minha grande companheira, Clarissa, pessoa que, mesmo de longe, acompanhou todos os passos dados para a realização deste trabalho e me ajudou nos momentos mais difíceis. Obrigado pelo amor, incentivo, companheirismo, sacrifícios e concessões. 


\section{AGRADECIMENTOS}

Ao Prof. Dr. Marcelo Zugaib, Professor Titular de Obstetrícia do Departamento de Obstetrícia e Ginecologia da Faculdade de Medicina da Universidade de São Paulo, pelo apoio e oportunidade a mim dada em participar de um grupo seleto e acolhedor.

Ao Prof. Dr. Rodrigo Ruano, meu orientador e grande incentivador na vida científica, pela amizade, ensinamentos e por não poupar esforços para a conclusão deste trabalho.

Ao Prof. Dr. Anselmo Veriangieri Carmo, professor do Departamento de Ginecologia e Obstetrícia da Universidade Federal de Mato Grosso, grande responsável pelos meus primeiros passos na Medicina Fetal.

Ao Prof. Dr. Victor Bunduki, pela amizade, apoio, orientação profissional e sugestões valiosas para a finalização deste trabalho.

Ao Prof. Dr. Antonio F. Moron, Prof. Dr. Luciano M. M. Nardozza e Prof. Dr. Edward Araujo Júnior, professores do Departamento de Obstetrícia da Universidade Federal de São Paulo, pela amizade e ensinamentos em Medicina Fetal.

Ao Prof. Dr. Seizo Miyadahira e Prof. Dr. Roberto E. Bittar, pela atenção dispensada na qualificação, com contribuições preciosas para a conclusão deste trabalho. 
Ao Prof.Dr. Marco Antônio B. Lopes e Prof. Dr. Adolfo W. Liau, por sua vocação inequívoca em facilitar os ensinamentos em Medicina Fetal.

Ao Prof. Dr. Cláudio R. Pires, Prof. Dr. João Bortoletti Filho e Prof. Dr. Jurandir P. Passos, professores da Universidade Federal de São Paulo, pelo exemplo de profissionalismo e pela valiosa contribuição no meu aprendizado.

Ao Alan S. Ramalho e Ana Karina S. Cardoso, acadêmicos da Faculdade de Medicina da USP, pela contribuição na execução deste trabalho.

À Juliana A. D. B. Campos, professora do Departamento Social da Universidade Estadual de São Paulo, pela contribuição na análise estatística e a Sra.Mitsuko Miyadahira, pelo auxílio na correção e revisão gramatical.

Aos colegas de pós-graduação, Eduardo Pimenta, Gustavo Pereira, Rimena Melo, Lorena Caldas, Priscila Beirigo e Letícia Paiva, pela amizade e companheirismo.

Às Sras. Soraia Silva, Claudia Vieira, Miriam Souto, Marina Silva, Maria Aparecida Domingues, Fátima Abdul e ao Srs. Amadeu Santos, Alan Garcia, William Santos, pela amizade, respeito e carinho.

Aos demais colegas, professores, assistentes e funcionários da Clínica Obstétrica do Hospital das Clínicas da Faculdade de Medicina da Universidade de São Paulo, pelo coleguismo, respeito e apoio profissional. 
Esta tese está de acordo com as seguintes normas, em vigor no momento desta publicação:

Referências: adaptado de International Committee of Medical Journals Editors (Vancouver)

Universidade de São Paulo. Faculdade de Medicina. Divisão de Biblioteca e Documentação. Guia de apresentação de dissertações, teses e monografias. Elaborado por Anneliese Carneiro da Cunha, Maria Julia de A. L. Freddi, Maria F. Crestana, Marinalva de Souza Aragão, Suely Campos Cardoso, Valéria Vilhena. $3^{\text {a }}$ ed. São Paulo: Serviço de Biblioteca e Documentação, 2011.

Abreviaturas dos títulos dos periódicos de acordo com List of Journals Indexed in Index Medicus 


\section{SUMÁRIO}

Lista de abreviaturas, siglas e símbolos

Lista de figuras

Lista de tabelas

Lista de gráficos

Resumo

Summary

1. Introdução 01

2. Revisão da literatura

2.1. O desenvolvimento pulmonar 08

2.2. A pleura e o líquido pleural 10

2.3. Ducto torácico 11

2.4. Derrame pleural fetal

2.4.1. Definição, incidência e diagnóstico 12

2.4.2. Fisiopatologia do derrame pleural fetal

2.4.2.1. Fisiopatologia do derrame pleural "isolado" 15

2.4.2.2. Fisiopatologia do derrame pleural secundário 17

2.4.3. A história natural do derrame pleural "isolado" 18

2.4.4. Repercussões clínicas do derrame pleural na mãe e no feto 20

2.4.5. Mortalidade perinatal e fatores prognósticos 22

2.4.6. Tratamento fetal 24

2.4.6.1. Tratamento conservador 26

2.4.6.2. Toracocentese 27

2.4.6.3. Derivação tóraco-amniótica 27 
2.4.7. O derrame pleural "isolado" no período pós-natal 34

2.5 - A hipoplasia pulmonar fetal e a sua estimativa por meio do volume pulmonar 35

2.5.1. Avaliação pulmonar fetal pela ultrassonografia bidimensional 37

2.5.2. Avaliação pulmonar fetal por técnicas tridimensionais: a ressonância magnética e a ultrassonografia tridimensional 38

3. Objetivos 42

4. Casuística e método

4.1. Local do estudo 45

4.2. Coleta de dados 45

4.3. Casuística 46

\subsection{Método}

4.4.1. Estimativa do volume pulmonar fetal total pela ultrassonografia em três dimensões (US 3D) e outros parâmetros ultrassonográficos

4.4.2. Procedimentos fetais invasivos 51

4.4.3. Assistência ao parto 53

4.4.4. Cuidados neonatais imediatos 54

4.4.5. Variáveis analisadas 54

4.4.6. Análise estatística 56 
5. Resultados

5.1. Resultados gerais 60

5.2. Caracterização da amostra estudada 62

5.3. Predição da mortalidade perinatal em fetos com derrame pleural "isolado" pelo volume pulmonar 66

5.4. Predição da necessidade de UTI Neonatal / Suporte Ventilatório pelo volume pulmonar em fetos com derrame pleural "isolado" 74

5.5. Volume pulmonar fetal e outros fatores preditores do prognóstico perinatal em fetos com derrame pleural "isolado" 79

6. Discussão 81

7. Conclusão 96

8. Anexos 98

9. Referências bibliográficas 


\section{LISTA DE ABREVIATURAS, SIGLAS E SÍMBOLOS}

\begin{tabular}{|c|c|}
\hline ANOVA & Análise de Variância \\
\hline ANVISA & Agência Nacional de Vigilância Sanitária \\
\hline CAPPesq & Comitê de Ética em Pesquisa \\
\hline $\mathrm{cm}^{3}$ & centímetros cúbicos \\
\hline $\mathrm{Co}$ & coração \\
\hline DP & derrame pleural \\
\hline et al & e colaboradores; e outros \\
\hline GE & General Electric \\
\hline HCFMUSP & Hospital das Clínicas da Faculdade de Medicina da \\
\hline $\operatorname{IgG}$ & $\begin{array}{l}\text { Universidade de São Paulo } \\
\text { imunoglobulina G }\end{array}$ \\
\hline $\operatorname{IgM}$ & imunoglobulina $\mathrm{M}$ \\
\hline IOT & intubação oro-traqueal \\
\hline LHR & relação pulmão / circunferência cefálica - "Lung head ratio” \\
\hline $\mathrm{mg}$ & miligramas \\
\hline $\mathrm{MHz}$ & Megahertz \\
\hline $\mathrm{mL}$ & mililitros \\
\hline $\mathrm{n}$ & número de casos \\
\hline $\mathrm{OK}-432$ & derivado de Streptococcus pyogenes \\
\hline$p$ & nível de significância \\
\hline PCR & reação em cadeia da polimerase \\
\hline PD & pulmão direito \\
\hline PE & pulmão esquerdo \\
\hline p. ex. & por exemplo \\
\hline RNM & ressonância nuclear magnetic \\
\hline RR & $\begin{array}{l}\text { Rodrigo Ruano (prof. Dr. da Clínica Obstétrica do Hospital das } \\
\text { Clínicas da Faculdade de Medicina de São Paulo) }\end{array}$ \\
\hline SPSS & Statistical Package for Social Sciences \\
\hline US 2D & ultrassonografia bidimensional \\
\hline US 3D & ultrassonografia tridimensional \\
\hline UTI & Unidade de Terapia Intensiva \\
\hline VDRL & Venereal Diseases Research Laboratory \\
\hline VPO o/e & $\begin{array}{l}\text { razão entre o volume pulmonar observado e o volume pulmonar } \\
\text { esperado para determinada idade gestacional }\end{array}$ \\
\hline VOCAL & Virtual Organ Computed Aided Analysis \\
\hline
\end{tabular}


Figura 1: Imagem ultrassonográfica bidimensional de feto com 32 semanas com derrame pleural bilateral

Figura 2: Cateter "double pigtail”

Figura 3: A imagem tridimensional do volume pulmonar de feto com derrame pleural e idade gestacional de 28 semanas obtida nos três planos ortogonais

\section{LISTA DE TABELAS}

Tabela 1: Taxa de sobrevivência de acordo com a terapêutica escolhida para tratamento do derrame pleural primário - Revisão da literatura

Tabela 2: Características do grupo de estudo

Tabela 3: Características obstétricas e ultrassonográficas de acordo com a sobrevida perinatal em fetos com derrame pleural "isolado"

Tabela 4: Características obstétricas e perinatais relacionadas à 78 morbidade pós-natal em 15 recém-nascidos com derrame pleural "isolado"

Tabela 5: Associação entre o volume pulmonar fetal próximo ao parto e outros achados ultrassonográficos em 19 fetos com derrame pleural "isolado" 
Gráfico 1: Distribuição dos 132 fetos com derrame pleural de etiologia não imune encaminhados ao HCFMUSP entre janeiro de 2005 a julho de 2010

Gráfico 2: Volume pulmonar total mensurado (no diagnóstico e próximo ao parto) utilizando o US 3D em fetos com derrame pleural “isolado" plotados na curva de normalidade para volume pulmonar fetal em cada idade gestacional publicada por Ruano et al.

Gráfico 3: Evolução da razão entre o volume pulmonar observado sobre o volume pulmonar esperado (VPT o/e) estimados pela US 3D no momento do diagnóstico ( $1^{\mathrm{o}}$. VPT o/e) e próximo ao parto $\left(2^{\circ}\right.$. VPT o/e) em fetos sobreviventes, fetos com óbito intra-útero e neonatal portadores de derrame pleural "isolado"

Gráfico 4: Evolução da razão entre o volume pulmonar observado sobre o volume pulmonar esperado (VPT o/e) estimados pela US 3D no momento do diagnóstico ( $1^{\circ}$. VPT o/e) e próximo ao parto $\left(2^{\circ}\right.$. VPT o/e) em fetos sobreviventes e não sobreviventes portadores de derrame pleural "isolado"

Gráfico 5: Dispersão da razão entre o $2^{\circ}$ volume pulmonar observado /esperado ( $2^{\circ}$ VPT o/e) pela idade gestacional e o desfecho perinatal em fetos portadores de derrame pleural "isolado" 
Página

Gráfico 6: Diferença numérica entre o $2^{\circ}$ VPT o/e do $1^{\circ}$ VPT o/e

$(\Delta \mathrm{VPT}$ o/e) nos fetos com derrame pleural "isolado"

Gráfico 7: Variação do volume pulmonar observado /esperado em

fetos com derrame pleural "isolado" associados à morbidade respiratória

Gráfico 8: Dispersão da razão entre o $2^{\circ}$ volume pulmonar observado /esperado ( $2^{\circ} \mathrm{VPT}$ o/e) pela idade gestacional e mortalidade perinatal em fetos portadores de derrame pleural "isolado" 


\section{RESUMO}

Freitas, RCM. Estudo do volume pulmonar fetal na predição dos resultados perinatais de fetos com derrame pleural “isolado" [dissertação]. São Paulo: Faculdade de Medicina, Universidade de São Paulo; 2011. 125p.

OBJETIVO: O objetivo deste estudo foi predizer o prognóstico perinatal em fetos com derrame pleural "isolado" por meio da medida do volume pulmonar estimado pela ultrassonografia tridimensional. MÉTODO: Estudo retrospectivo, entre julho de 2005 e julho de 2010, com 19 fetos com derrame pleural "isolado" (ausência de causas infecciosas, imunes, anomalias cromossômicas ou estruturais associadas) acompanhados no Hospital das Clínicas da Faculdade de Medicina da Universidade de São Paulo. Os volumes pulmonares foram obtidos pela ultrassonografia tridimensional (Voluson 730 Expert, GE Medical System, Kretzechnick, Áustria) em dois períodos, no momento do diagnóstico (20 - 26 semanas) e próximo ao parto (duas semanas antecedentes ao parto ou até 36 semanas), e mensurados pela técnica VOCAL ("Virtual Organ Computer Aided Analysis") com rotação de 30". Os volumes obtidos (observados) foram comparados com valores esperados para idade gestacional, e a razão entre o volume total fetal observado/esperado (VPTo/e) foi avaliada de acordo com a mortalidade perinatal e morbidade neonatal (necessidade de ventilação mecânica por mais que 48 horas). RESULTADOS: Dezenove fetos com derrame pleural "isolado" foram analisados no período do estudo. Doze $(63,2 \%)$ crianças sobreviveram. Dos sobreviventes, sete $(58,3 \%)$ apresentaram morbidade respiratória. O VPTo/e no primeiro exame ultrassonográfico não se associou significativamente com mortalidade (VPTo/e: 0,42 $\pm 0,19$ nos sobreviventes contra $0,30 \pm 0,08$ nos não sobreviventes, $\mathrm{p}=0,11$ ). No segundo exame, por outro lado, VPTo/e foi significativamente menor nos casos que faleceram $(0,24 \pm 0,08)$ em relação aos sobrevivente $(0,58 \pm 0,21 ; p<0,01)$ e nos que necessitaram de ventilação mecânica prolongada $(0,35 \pm 0,08)$ comparados aos que não necessitaram $(0,68 \pm 0,10$; $p<0.01)$. CONCLUSÃO: O volume pulmonar fetal medido pela ultrassonografia tridimensional pode ser utilizado para predizer o prognóstico de fetos com derrame pleural "isolado".

Descritores: 1.Derrame pleural 2.Hidrotórax 3.Feto 4.Pulmão/crescimento \& desenvolvimento 5.Terapias fetais 6.Ultrassonografia pré-natal 7.Quilotórax 


\section{$\underline{\text { SUMMARY }}$}

Freitas, RCM. Three-dimensional ultrasonographic assessment of fetal lung volume as a prognostic factor in "isolated" pleural effusion [dissertation]. São Paulo: Faculdade de Medicina, Universidade de São Paulo; 2011. 125p.

OBJECTIVE The aim of the present study was to predict the perinatal outcome in "isolated" pleural effusion using fetal lung volumes assessed by three-dimensional ultrasonography. METHODS: A retrospective study conducted between July 2005 and July 2010, in which 19 fetuses with isolated pleural effusion (absence of infection, immunological causes, chromosomal anomalies and associated structural anomalies) at Hospital das Clínicas da Faculdade de Medicina da Universidade de São Paulo. Fetal lung volumes were assessed by three-dimensional ultrasonography (Voluson 730 Expert, GE Medical System, Kretzechnick, Áustria) in two periods: at diagnosis (20-26 weeks) and nears the delivery (2 weeks before delivery or at 36 weeks), by VOCAL technique ("Virtual Organ Computer Aided Analysis") with rotation of $30^{\circ}$. The observed volumes were compared to expected values for determine gestational age, and the observed/expected total fetal lung volume ratio (o/e-TFLV) was evaluated according to perinatal death and neonatal morbidity (need for mechanical ventilation longer than 48 hours). RESULTS: A total of 19 fetuses with "isolated" pleural effusion were evaluated during the study period. Twelve (63.2\%) infants survived. Among the survivors, seven (58.3\%) had severe respiratory distress at birth. The o/e-TFLV at the first ultrasound examination was not associated statistically with mortality (o/e-TLFV: $0.42 \pm 0.19$ in survivors x $0.30 \pm 0.08$ among those that died, $p=0.11$ ). On the second ultrasound examination, on the other hand, the o/e-TFLV was significantly reduced in those cases that died $(0.24 \pm 0.08)$ whilst in survivors $(0.58 \pm 0.21 ; \mathrm{p}<0.01)$ and in those that needed mechanical ventilation $(0.35 \pm 0.08)$ when compared to those that did not need it $(0.68 \pm 0.10 ; \mathrm{p}<0.01)$. CONCLUSION: Fetal lung volumes measured by three-dimensional ultrasonography may be useful to predict perinatal outcome in fetuses with primary pleural effusion.

Key words: 1 . Pleural effusion 2.Hydrothorax 3.Fetus 4.Lung/growth \& development 5. Fetal therapies 6. Ultrasonography, Prenatal 7. Chylothorax 
INTRODUÇÃO 


\section{INTRODUÇÃO}

A Medicina Fetal apresentou grande avanço nas últimas décadas, principalmente com a melhoria da qualidade das imagens ultrassonográficas, conhecimento da anatomia normal e das patologias fetais. O feto tornou-se acessível a diversos métodos diagnósticos e, consequentemente, a inúmeras abordagens terapêuticas. Entre essas, destaca-se o tratamento invasivo nos fetos portadores de derrame pleural com o objetivo de descomprimir os pulmões e minimizar o risco da hipoplasia pulmonar.

Estimar o prognóstico nos fetos que apresentam esse risco é um desafio. Talvez, a ultrassonografia tridimensional do volume pulmonar fetal possa predizê-lo.

Dessa forma, nasceu o interesse em se estudar o derrame pleural fetal, descrito pela primeira vez, no ano de 1977, pela pesquisadora californiana Barbara $\mathrm{Carrol}^{1}$, a qual publica o diagnóstico ecográfico desse sinal clínico, ao verificar o óbito fetal em uma gestação de 36 semanas.

O derrame pleural (DP) fetal ou hidrotórax fetal é uma manifestação clínica rara, com incidência de 1 em cada 15.000 gestações ${ }^{2,3}$. É caracterizado pelo acúmulo inespecífico de líquido no espaço pleural e diagnosticado durante o prénatal por meio da ultrassonografia obstétrica, a qual evidencia uma área anecoica (acúmulo de líquido) unilateral ou bilateral circundando os pulmões (Figura 1). 


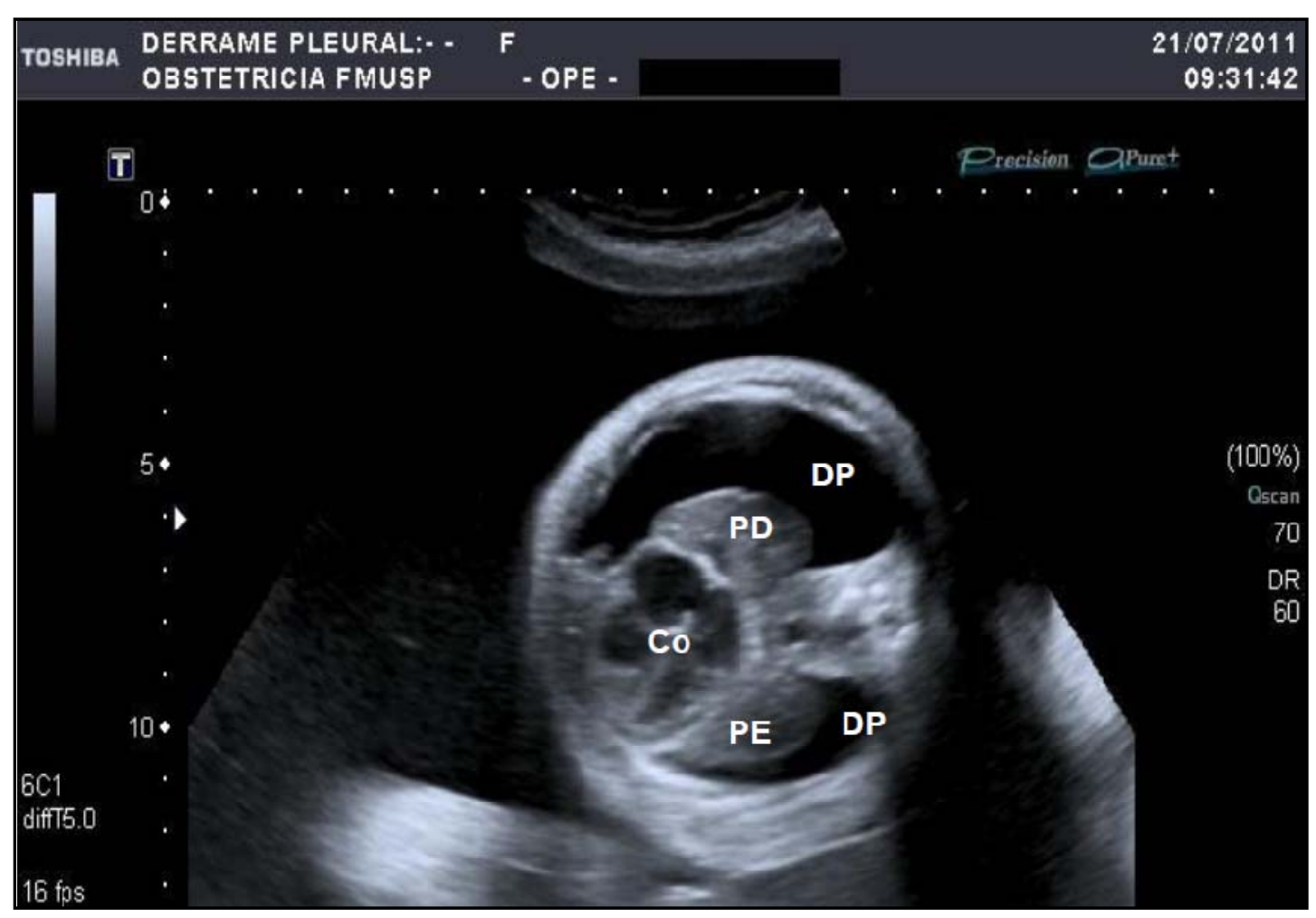

Figura 1: Imagem ultrassonográfica bidimensional de feto com 32 semanas com derrame pleural bilateral. Corte transversal torácico. DP (derrame pleural); PE (pulmão esquerdo); PD (pulmão direito); Co (coração).

O derrame pleural pode apresentar diversas etiologias, embora nem todas sejam devidamente conhecidas. Há descrições de sua associação com tumores (mediastinais, pulmonares, cardíacos ou pleurais); patologias cardíacas (malformações cardíacas, distúrbios do ritmo cardíaco); doenças infecciosas (toxoplasmose, citomegalovírus, parvovírus B19, herpes vírus, sífilis); anormalidades cromossômicas (p. ex. Síndrome de Down, Síndrome de Turner); entre outras menos frequentes, tais como a hérnia diafragmática, o diabetes materno, o uso de 
indometacina e traumas torácicos fetais (geralmente resultantes de trauma obstétrico). ${ }^{4}$

Porém, em uma pequena parcela de fetos que apresentam derrame pleural não se encontra nenhuma causa estrutural, infecciosa, cromossômica ou imune associada, sendo então, denominado, durante a vida fetal, derrame pleural "isolado" ou hidrotórax "isolado" ${ }^{,-9}$. Diversos modelos teóricos tentam explicar a origem do hidrotórax "isolado", os quais indicam que os derrames são formados a partir do extravasamento de linfa para o interior da cavidade torácica, devido à falha de conexão entre os múltiplos segmentos linfáticos com o ducto torácico ${ }^{8,9}$. Dessa forma, haverá predomínio de linfócitos no líquido pleural. Se a quantidade de linfócitos for superior a $70 \%$ do total de células, na amostra de líquido pleural, na ausência de infecções maternas ou fetais, o derrame será classificado como primário3, $10-13$

O derrame pleural fetal apresenta curso clínico variado, indo desde a sua resolução espontânea até complicações pelo aumento progressivo, resultando na hidropisia, na hipoplasia pulmonar e na morte no período perinatal ${ }^{3,5,14}$. Por sua etiologia e evolução incerta, apresenta amplo intervalo na taxa de mortalidade, variando de 22 a $75 \%{ }^{3,14-17}$. Recentes estudos têm mostrado que a presença de anomalias cromossômicas ou estruturais está associada aos piores resultados perinatais ${ }^{3,14,16,18}$. Entretanto, a predição dos resultados perinatais em fetos com derrame pleural "isolado" ainda não foi pesquisada.

Estabelecer o prognóstico pós-natal dos fetos com derrame pleural nos casos sem etiologia aparente é fundamental para selecionar os fetos que poderão se 
beneficiar de intervenção precoce ou até mesmo da antecipação do parto. Diversas propostas terapêuticas foram descritas, porém, até o momento, nenhum tratamento ideal foi estabelecido.

Dentre os fatores prognósticos do hidrotórax fetal, sabe-se que a hipoplasia pulmonar e a hidropisia fetal são os principais desfechos a serem evitados, pois se associam à alta mortalidade perinatal, atingindo cifras de 50 a $70 \%$ quando esses fetos não são tratados. ${ }^{3}$

Assim, em 1982, Petres et al. propuseram, pela primeira vez, a toracocentese como forma de tratamento para o derrame pleural fetal, porém o procedimento mostrou-se bastante limitado em virtude do rápido reacúmulo de líquido em $76 \%$ dos casos. $^{3,19,20}$

Em 1986, Seeds e Bowes $^{21}$, posteriormente Rodeck et al. ${ }^{22}$,em 1988, apontaram as primeiras evidências de que o tórax precisava ser continuamente descomprimido. Esses autores sugeriram que o tratamento com a derivação tóracoamniótica poderia ser mais efetivo. ${ }^{23-25}$

Além desses tratamentos, outras estratégias terapêuticas como a pleurodese com sangue materno ou outras substâncias irritativas, tais como o derivado de Streptococcus pyogenes encubados com benzilpenicilina (OK-432), têm sido descritas, mas o seu real benefício não foi comprovado. ${ }^{26-29}$

Em que pesem às estratégias terapêuticas mencionadas, o sucesso da intervenção fetal está relacionado com o diagnóstico precoce, o volume do derrame, o seu reacúmulo, o grau de compressão pulmonar, a existência de hidropisia e de outras alterações estruturais e/ou cromossômicas associadas ${ }^{7}$. Dessa forma, mais 
importante do que escolher a melhor estratégia terapêutica é avaliar o tipo do derrame e o grau de agressão ao órgão principal. Com base nesse princípio, alguns autores têm buscado estimar o grau de comprometimento pulmonar como forma indireta de avaliar o prognóstico e o sucesso do tratamento escolhido em fetos com alterações pulmonares ${ }^{30-36}$. Para essa finalidade, esses autores sugerem avaliar o volume pulmonar fetal pela ultrassonografia tridimensional (US 3D) e relacionar os seus achados com os resultados pós-natais em fetos com risco para a hipoplasia pulmonar. ${ }^{30-36}$

Recentemente, Vergani et al. $^{37}$ mostraram que a US $3 \mathrm{D}$ é superior à ultrassonografia bidimensional (US 2D) para a predição da hipoplasia pulmonar em 35 fetos com alto risco para hipoplasia, incluindo sete com derrame pleural.

Entretanto, até o momento, não existe estudo que avalie a estimativa do volume pulmonar fetal pela US 3D na predição do resultado perinatal nos casos com derrame pleural "isolado". Além disso, não há, na literatura, estudos que avaliem o resultado perinatal após a derivação tóraco-amniótica relacionados ao cálculo do volume pulmonar, estudos esses de suma importância, visto que a hipoplasia pulmonar fetal é uma das principais causas de morte perinatal.

Por isso, o presente estudo tem como finalidade avaliar o volume pulmonar fetal, por meio da US 3D, como método preditor do resultado perinatal em fetos com derrame pleural "isolado". 
REVISÃO DA LITERATURA 


\section{REVISÃO DA LITERATURA}

\section{1 - O desenvolvimento pulmonar}

O desenvolvimento pulmonar inicia-se por volta do $26^{\circ}$ ao $28^{\circ}$ dia embrionário, a partir do crescimento caudal do tubo laringotraqueal (quarto par das bolsas faríngeas). $\mathrm{O}$ endoderma que reveste o sulco laringotraqueal originará a laringe, a traqueia, os brônquios e o epitélio pulmonar; enquanto o mesênquima esplâncnico formará o tecido conjuntivo, as cartilagens e os músculos lisos dessas estruturas. $^{38}$

Apesar de dinâmico, alguns autores ${ }^{39-43}$ dividem didaticamente o desenvolvimento pulmonar em até cinco períodos: embrionário, pseudoglandular, canalicular, sacular e alveolar.

O período embrionário (4 a 8 semanas) é caracterizado pelo surgimento do broto pulmonar, na quarta semana de gestação, o qual se dividirá formando dois brônquios principais. Da quarta a sexta semana, os brônquios principais irão se diferenciar e ramificar, dando origem aos brônquios lobares e, em seguida, os segmentares, por sucessivas dicotomizações. Ao final da sétima semana, o pulmão apresentará a mesma segmentação encontrada no do adulto. ${ }^{41}$

No período pseudoglandular (8 a 16 semanas), ocorrem sucessivas divisões para a formação dos bronquíolos terminais e a migração das estruturas vasculares. No sentido anelar, crescem a cartilagem e a musculatura lisa brônquica. Nesse período, as trocas gasosas ainda não são possíveis. ${ }^{43}$ 
No período canalicular (17 a 24 semanas), surgem os bronquíolos respiratórios, os ductos alveolares e os alveólos primitivos (pneumócitos tipo I e tipo II). Inicia-se a produção de surfactante pelo pneumócito tipo II. A luz dos brônquios e dos bronquíolos terminais torna-se mais ampla devido à circulação de líquidos intraluminal, e o tecido pulmonar fica altamente vascularizado, tornando possíveis as trocas gasosas ao final desse período. ${ }^{41}$

O período do saco terminal ou período sacular (de 25 semanas ao nascimento) é caracterizado pela mudança dos canalículos pulmonares para os sacos terminais e aumento da superfície alveolar funcional, do afilamento da membrana do epitélio de revestimento e intensa vascularização. Há o crescimento exponencial do número de alvéolos e dos pneumócitos tipo II, que permite a sobrevida do recém-nascido prétermo. $^{43}$

No período alveolar (da 32a semana à pré-adolescência), os grupos saculares terminais se diferenciam em ductos alveolares e os alvéolos primitivos se desenvolvem até o $8^{\circ}$ ano de vida. Há maior adelgaçamento do epitélio pulmonar, aumento da vascularização perialveolar, resultando no aumento do mecanismo de trocas gasosas (amadurecimento alveolar) ${ }^{44}$. Também há proliferação do número de alvéolos que chegam a contabilizar 50 milhões, próximo ao nascimento. Após esse período, continuam a se multiplicar, podendo chegar a 300 milhões de alvéolos na vida adulta. ${ }^{43}$

Laudy e Wladimiroff $(2000)^{45}$ descreveram a importância em se compreender os períodos do desenvolvimento pulmonar e tentar identificar o momento em que ocorre a interferência em seu crescimento. Esses autores sugerem que as 
interferências no desenvolvimento, antes do término da fase canalicular (antes da $24^{\mathrm{a}}$ - 26 $6^{\mathrm{a}}$ semana), costumam trazer maiores repercussões clínicas.

\section{2 - A pleura e o líquido pleural}

A pleura é um folheto contínuo, formado por uma camada única de células mesoteliais, firmemente unidas, apoiadas sobre a membrana basal e uma frouxa camada de tecido conjuntivo. ${ }^{46}$

A pleura visceral é formada pelo folheto que recobre os pulmões, e a pleura parietal, pelo folheto em contato com a caixa torácica. O espaço virtual entre as duas pleuras é chamado de espaço pleural ${ }^{46}$, o qual apresenta certa quantidade de líquido em seu interior que favorece o deslizamento entre os folhetos pleurais e as estruturas adjacentes nos movimentos respiratórios.

O líquido pleural entra no espaço pleural a partir dos capilares da pleura parietal e é removido pelos vasos linfáticos, os quais fazem a drenagem para os linfonodos mediastinais. ${ }^{47}$

Embora menos frequente, geralmente associado a processos patológicos, o líquido pode penetrar no espaço pleural, a partir dos espaços intersticiais dos pulmões, por meio da pleura visceral ou então por pequenos orifícios no diafragma, sendo também removido desse espaço pelos linfáticos parietais. ${ }^{47}$

A circulação do líquido pleural é um processo dinâmico, mantido pelo equilíbrio entre a sua produção e drenagem, além de um balanço contínuo entre as pressões hidrostáticas e osmótica da microcirculação e do espaço pleural. ${ }^{47}$ 


\section{3 - Ducto torácico}

O ducto torácico origina-se na cisterna do quilo, estrutura abdominal que drena os vasos linfáticos das extremidades inferiores, pelve e intestino, sendo, na vida extrauterina, a principal via de escoamento da gordura alimentar absorvida nos intestinos.

O ducto torácico penetra no tórax por meio do hiato aórtico em direção ao lado direito, em posição retroaórtica, situando-se entre a veia ázigos e a aorta, na porção inferior do tórax, posteriormente ao esôfago. Ascende pelo mediastino posterior, cruzando lateralmente para o lado esquerdo no nível de T4, correndo atrás do arco aórtico, do lado esquerdo do esôfago, e, mais superiormente, atrás da artéria subclávia esquerda. Após sua entrada no pescoço, ele se curva anteriormente, na borda do músculo escaleno anterior, e se liga na junção das veias jugular interna e subclávia esquerda. Ao longo desse trajeto, existe uma rede de anastomoses linfáticovenosas que formam vias colaterais, permitindo a ligação do ducto torácico ao sistema venoso e linfático em vários pontos. ${ }^{48}$

Entender a anatomia do ducto torácico e sua interação com o sistema venoso - linfático pulmonar é fundamental para a compreensão do possível mecanismo fisiopatológico do derrame pleural primário. ${ }^{8,49}$ 


\section{4 - Derrame pleural fetal}

\subsection{1 - Definição, incidência e diagnóstico}

Derrame pleural fetal ou hidrotórax fetal é uma condição clínica rara, cuja incidência é de uma em cada 15.000 gestações ${ }^{10,11}$, sendo caracterizado pelo acúmulo inespecífico de líquido no espaço pleural, podendo ser diagnosticado durante o pré-natal por meio da ultrassonografia obstétrica.

Os achados ecográficos são típicos, caracterizados por área anecoica (acúmulo de líquido) unilateral ou bilateral circundando os pulmões. A apresentação bilateral é a forma mais frequente ${ }^{4,14,50}$. No derrame pleural unilateral não se verifica o predomínio no acometimento de qualquer dos lados, embora poucos estudos apontem haver maior frequência do acometimento do lado direito. ${ }^{14}$

Quando analisada a sua distribuição em relação ao sexo fetal, alguns trabalhos apontam haver maior predomínio do derrame no sexo masculino (2 masculino : 1 feminino $)^{51}$, embora não haja consenso na literatura. ${ }^{50}$

O diagnóstico ecográfico é realizado geralmente entre o $2^{\circ}$ trimestre e o início do $3^{\circ}$ trimestre de gestação ${ }^{3}$. Porém, tem-se verificado que com a melhoria das imagens ultrassonográficas, associada à ampliação dos programas de rastreamento fetal no $1^{\mathrm{o}}$ trimestre, tem-se realizado o diagnóstico mais precocemente. Nas primeiras revisões feitas sobre o assunto, Aubard et al. ${ }^{14}$ (1998) e Weber et al. ${ }^{17}(1992)$ constataram que a idade gestacional média do diagnóstico oscilava entre 
a $27^{\mathrm{a}}$ e $30^{\mathrm{a}}$ semana, respectivamente. Entretanto, em séries de estudo mais recentes, essa idade gestacional foi descrita por volta da $20^{\mathrm{a}}$ semana. ${ }^{52}$

Embora não seja frequente, há relatos na literatura do diagnóstico de derrame pleural em idade gestacional ainda mais precoce, ou seja, no primeiro trimestre de gestação. Isso pode ser confirmado pelo estudo publicado por Medina et al. ${ }^{53}$ (2002), que relata um caso de derrame pleural com apenas 08 semanas e 04 dias, ou pelos trabalhos de Shimizu et al. ${ }^{54}$ (1997) e Hashimoto et al. ${ }^{55}$ (2003), os quais descrevem a associação entre o derrame pleural bilateral, diagnosticado no primeiro trimestre, com a morte embrionária ou o risco para cromossomopatia.

Apesar de o diagnóstico ecográfico do derrame pleural fetal ser aparentemente de fácil execução, o diagnóstico etiológico nem sempre será dessa maneira. Assim, o primeiro passo, após a identificação do derrame pleural pela ecografia, é determinar se ele ocorre de maneira isolada, ou seja, não associado à alteração estrutural, cromossômica, imune ou infecciosa (derrame pleural “isolado"); ou, então, identificar a doença de base (derrame pleural secundário) ${ }^{19}$. Essa diferenciação é fundamental para estimar o prognóstico fetal, bem como estabelecer quais fetos poderão se beneficiar com o tratamento invasivo. ${ }^{16,50,56}$

Para a diferenciação entre o derrame pleural "isolado" e o secundário deve-se realizar rastreamento detalhado das alterações estruturais, cromossômicas, imunes e infecciosas fetais. Como método de rastreio, diversos autores propõem que ele seja semelhante ao que é realizado nos fetos com hidropisia e iniciado assim que o derrame pleural for identificado ${ }^{16,50,56}$. Deve-se pesquisar: a) alterações estruturais fetais, por meio do exame morfológico e do ecocardiograma fetal; b) alteração 
cromossômica, por meio da pesquisa do cariótipo fetal; c) infecção materna e congênita, tais como toxoplasmose, rubéola, citomegalovírus, sífilis, herpes vírus e parvovirose B19; d) etiologias imunes ou anemia fetal, realizada pela pesquisa da tipagem sanguínea materna, teste de Kleihauer-Betke ${ }^{57}$ (em casos selecionados) e pela dopplerfluxometria da velocidade máxima do pico sistólico da artéria cerebral média para excluir anemia fetal. ${ }^{58}$

Apesar desse rastreamento, haverá casos nos quais a etiologia do derrame permanecerá desconhecida, até mesmo após a avaliação detalhada no período pósnatal $^{29,}$, 59 . Na tentativa de estabelecer o diagnóstico, alguns autores sugerem pesquisar a celularidade total do líquido pleural. Embora não seja específica (patognomônica $^{13}$, uma contagem de linfócitos superior a $70-80 \%$ do total de células do líquido pleural, na ausência de processo infeccioso materno ou fetal, seria sugestiva de um defeito local na remoção do líquido linfático, caracterizando o derrame pleural primário ${ }^{7,19,60}$. É importante destacar que, na literatura, muitos artigos acabam referindo o derrame pleural "isolado" por derrame pleural primário, mesmo sem realizar a contagem da celularidade do líquido pleural.

A raridade do derrame pleural associada à dificuldade em se identificar a etiologia e a outros vieses literários (p.ex. interrupção da gestação, publicação apenas dos dados favoráveis, casuística oriunda de poucos centros) torna os dados epidemiológicos confusos e discrepantes.

Entre os derrames pleurais de etiologia não imune, estudos apontam que 25 a $40 \%$ estão associados com alterações estruturais (40\% desses com cardiopatias) ${ }^{15-17}$, 5 a $41 \%$ estão associados com cromossomopatias $10,16,52,61,62$ e $25 \%$ são derrames 
pleurais "isolados" ". Portanto, pode-se afirmar que o hidrotórax fetal "isolado" é um diagnóstico raro e de exclusão. ${ }^{16,63}$

\subsection{2 - Fisiopatologia do derrame pleural fetal}

\subsubsection{1 - Fisiopatologia do derrame pleural “isolado"}

Trabalhos na literatura apontam que o acúmulo de líquido no espaço pleural de fetos com derrame "isolado" seria resultado de provável defeito local (primário) no processo de drenagem. Assim, o hidrotórax "isolado" seria formado pelo extravasamento de linfa para o espaço pleural devido à falha na conexão entre os múltiplos segmentos venosos-linfáticos com o ducto torácico 3, 10-12, 47, 64 ou, simplesmente, por aumento da pressão no sistema venoso, levando a rupturas do ducto torácico e de suas circulações colaterais. Diversos experimentos e até mesmo a laceração iatrogênica do ducto torácico, em uma cirurgia torácica infantil, comprovam esses achados. ${ }^{65,66}$

Apesar da etiologia incerta, alguns autores sugerem que a fragilidade na ligação entre os vasos linfáticos e o ducto torácico se deva a algum dos seguintes mecanismos: ${ }^{29,59,67}$

a) Processo inflamatório local (derrame pleural "isolado" de origem inflamatória), no qual os linfócitos presentes no líquido pleural perpetuariam a agressão local, contribuindo para a fragilidade entre as conexões linfáticas-ductais; 
b) Mecanismo genético (derrame pleural "isolado" de origem genética), no qual a mutação em alguns lócus genéticos favoreceria alterações no sistema linfático local, levando a rupturas nas conexões linfáticas.

A possível explicação para esses dois mecanismos pode ser sugerida por trabalhos experimentais, os quais demonstram que apenas parte dos derrames pleurais "isolados" responde ao tratamento com a pleurodese, quando se utilizam substâncias com propriedades anti-inflamatórias, como o OK-432. Esse estudo, ao investigar o grupo que não respondeu ao mesmo tratamento (com OK-432), investigou alguns lócus genéticos que pudessem estar associados à fragilidade linfática e encontrou, nesses pacientes, quatro possíveis lócus genéticos (VEGFR3, FOXC2, PTPN11, ITGA9) ligados a uma herança autossômica recessiva, semelhante ao que é observado em alguns casos de linfangiectasia ${ }^{68,69}$. Esses autores sugerem que o grupo que não respondeu ao $\mathrm{OK}-432$ apresenta derrame pleural de maior gravidade (geralmente associado à hidropisia) por um provável mecanismo genético associado. Nesse grupo, o tratamento mais indicado é o invasivo descompressivo (toracocentese ou derivação tóraco-amniótica) ${ }^{56,} \quad 59,68, \quad 69$. Outros modelos experimentais em ratos, demonstraram que a falta da integrina alfa-9 $\beta 1$ pode alterar os receptores linfáticos e, dessa forma, contribuir para a sua ruptura e o desenvolvimento do hidrotórax "isolado". ${ }^{70}$ 


\subsubsection{2 - Fisiopatologia do derrame pleural secundário}

O derrame pleural fetal de origem secundária é consequência da retenção hídrica generalizada, devido ao desequilíbrio entre as pressões hidrostáticas e coloidosmóticas ocasionadas pela causa base. ${ }^{10,12}$

Para se determinar a causa base, deve-se pesquisar alteração estrutural, cromossômica, infecciosa ou imunológica fetal ${ }^{19}$. Entre as principais alterações estruturais associadas ao derrame pleural secundário temos: a) as lesões compressivas dos pulmões e mediastino, tais como: a malformação adenomatoide cística $^{71,72}$, a hérnia diafragmática ${ }^{73}$, o sequestro pulmonar ${ }^{72}$, a linfangiectasia, o teratoma da tireoide, o bócio congênito e o hamartoma da parede torácica ${ }^{74}$; b) as cardiopatias, tais como: as malformações cardíacas, os tumores, as cardiomiopatias e as arritmias cardíacas. ${ }^{75}$

Quanto às anomalias cromossômicas encontradas no hidrotórax secundário, as principais são a trissomia do cromossomo 21 (Síndrome de Down) ${ }^{62}$ e a monossomia do cromossomo X (Síndrome de Turner) ${ }^{62}$. Porém, também é descrita sua associação com outras síndromes, tais como a trissomia do cromossomo 18 (Síndrome de Edwards) ${ }^{16}$ ou a Síndrome de Klinefelter (47, XXY). ${ }^{16}$

Em relação às causas infecciosas associadas, destacam-se o citomegalovírus ${ }^{76}$

e a parvovirose $\mathrm{B} 19^{77,78}$, embora o herpes simples tipo $1^{79}$, a sífilis e a toxoplasmose já tenham sido descritos. 
Outras causas mais raras de derrame pleural relatadas são: a) síndromes genéticas (Síndrome de Noonan ${ }^{80}$, Síndrome Opitz-Friasand - hipertelorismo e hipospádia ${ }^{81}$, a Sialidosis, entre outras); b) doenças metabólicas (doença de armazenamento do glicogênio ou de depósito lisossomal ${ }^{15}$ ); c) diabetes materno; d) uso de indometacina; e) traumas torácicos fetais (geralmente resultantes do trauma obstétrico). ${ }^{16,82}$

Estudos apontam que o desequilíbrio entre as pressões hidrostáticas e coloidosmóticas pode ocorrer por algum dos seguintes mecanismos: obstrução na drenagem linfática pleural (p.ex. nos tumores, massas intratorácicas), aumento da pressão vascular sistêmica (p. ex. nas cardiopatias), aumento do líquido intersticial pulmonar (p. ex. nas infecções congênitas), aumento da permeabilidade capilar (p. ex. processo inflamatório local nas infecções congênitas, cromossomopatias), por passagem de líquido a partir do espaço peritoneal (p. ex. nas volumosas ascites por causa infecciosa) ou diminuição da pressão coloidosmótica na microcirculação vascular (p. ex. nas anemias fetais). ${ }^{47}$

\subsection{3 - A história natural do derrame pleural "isolado"}

O derrame pleural fetal "isolado" apresenta curso clínico variado, desde resolução espontânea ${ }^{14,50,52}$ até complicações pelo aumento progressivo, resultando na hidropisia, na hipoplasia pulmonar, no poli-hidrâmnio e na morte perinatal $^{3,5,8,14}$. Existem poucos estudos que avaliam a evolução do derrame pleural, fazendo com que a sua história natural seja difícil de predizer. 
Aubard et al. ${ }^{14}$ (1998) realizaram uma revisão com 204 fetos com derrame pleural primário e observaram a regressão espontânea em $22 \%$ deles. Klam et al. ${ }^{15}$ (2005) descreveram que a referida regressão é mais comum nos fetos cujo derrame surge após a $26^{\mathrm{a}}$ semana de gestação, sendo pouco frequente em fetos hidrópicos. Porém, Yinom et al. ${ }^{56}$ (2010) demonstraram, em sua série de 88 casos (59 hidrópicos), que essa regressão é possível em até $47 \%$ dos fetos quando submetidos ao tratamento. Mesmo assim, esses autores são categóricos em afirmar que é difícil predizer a evolução favorável.

Em contrapartida, Longaker et al. ${ }^{3}$ (1989) observaram, em sua série de 32 casos, os fetos que não eram hidrópicos, no momento do diagnóstico, e que se tornaram hidrópicos ao final da gestação, somente 38\% sobreviveram sem receber o tratamento.

Dessa forma, pode-se dizer que o derrame pleural "isolado" apresenta curso clínico incerto, o qual pode ir desde a sua regressão espontânea até complicações clínicas, tais como a hidropisia, a hipoplasia pulmonar e o poli-hidrâmnio, que apresentam elevadas taxas de mortalidade. ${ }^{4,16,56}$ 


\subsection{4 - Repercussões clínicas do derrame pleural na mãe e no feto}

Compreender a história natural e as alterações que o derrame pleural pode ocasionar sobre os órgãos adjacentes é imprescindível para melhor entender as suas repercussões clínicas sobre a mãe e o feto, bem como avaliar como a intervenção fetal pode reduzir as complicações frente a uma evolução desfavorável.

Dessa forma, o derrame pleural pode ser entendido como uma lesão expansiva no interior da caixa torácica, o qual pode alterar os mecanismos de desenvolvimento pulmonar e hemodinâmico fetal. ${ }^{49}$

Assim, os fetos com derrame pleural podem ter pulmões menores do que os normais. A compressão ocasionada pelo líquido pleural sobre o tecido pulmonar pode levar à diminuição das ramificações das vias aéreas, dos alvéolos de cada bronquíolo terminal e da produção de surfactantes. ${ }^{83,84}$

A gravidade desse quadro é diretamente proporcional à precocidade em que surge, ao tempo de permanência e ao volume do derrame. Estudos apontam que o desenvolvimento do pulmão é mais prejudicado quando as agressões externas ocorrem antes do término da fase canalicular (antes de 24 semanas), período no qual as vias aéreas e os alvéolos começam a sofrer diferenciação. ${ }^{4,19,84,85}$

Com isso, qualquer derrame pleural antecedente a esse período pode ser considerado de maior gravidade e risco para o desenvolvimento da hipoplasia e hipertensão pulmonar, caso não receba tratamento ${ }^{3,85}$. A combinação desses dois fatores pode ter como consequência clínica a insuficiência respiratória grave e complicações com a morte após o nascimento ${ }^{3,19,86,87}$. Estudos apontam que a 
hipoplasia e a prematuridade são as principais causas de mortalidade no período pósnatal. $^{3,88}$

Da mesma forma, o aumento da pressão intratorácica ocasionado pelo derrame pleural pode repercutir sobre o aparelho cárdio-circulatório fetal. $\mathrm{O}$ derrame pleural pode comprimir a área cardíaca, causando a diminuição do volume dos seus ventrículos, sem alterar o padrão de contração do músculo cardíaco (efeito semelhante ao tamponamento cardíaco), diminuindo o retorno venoso ${ }^{89}$, além de causar o desvio do mediastino ${ }^{90}$. O mecanismo exato para a progressão do derrame pleural para a hidropisia não é completamente conhecido, mas estudos apontam que o desvio do mediastino contribuiria de forma maior para o desenvolvimento da hidropisia, quando comparado com a compressão das estruturas cardíacas ${ }^{89}$. Com a sobrecarga no sistema cardiovascular, associada à redução do débito cardíaco, começa a haver acúmulo de líquido em outras cavidades corporais, surgindo a hidropisia fetal. ${ }^{49,91}$

A hidropisia fetal é definida pela presença de edema de subcutâneo e acúmulo de líquidos em cavidades corporais (derrame pleural, derrame pericárdico ou ascite) ou acúmulo de líquidos em duas cavidades corporais. ${ }^{9}$

A sua presença está associada a altas taxas de mortalidade $(69 \%)^{3,17}$, sendo considerada uma variável independente e principal fator prognóstico negativo para os fetos com derrame pleural ${ }^{15}$. Estudos demonstram que a relação entre a área do derrame pleural com a área da circunferência torácica acima de $40 \%$ apresenta boa correlação com o aumento da pressão intratorácica e risco de mortalidade. ${ }^{49}$ 
Embora rara, tem-se descrito, na literatura, como possível repercussão clínica materna secundária à hidropisia, a maior probabilidade do desenvolvimento da préeclâmpsia e da síndrome em espelho. ${ }^{56,92}$

Outra repercussão clínica que pode ser ocasionada pelo derrame pleural refere-se ao acúmulo de líquido amniótico. Baseado no mesmo princípio referido para os casos anteriores, o aumento da pressão intratorácica ocasionado pelo derrame pleural, pode causar a compressão esofágica e dificuldades na deglutição fetal. Dessa maneira, ocorre desequilíbrio na dinâmica do líquido amniótico, levando ao acúmulo do seu excesso. ${ }^{4}$

O poli-hidrâmnio é definido como o excesso na quantidade de líquido amniótico, caracterizado quando o volume é superior a $2000 \mathrm{~mL}^{93}$ Entre as repercussões fetomaternas, destaca-se o risco para o trabalho de parto prematuro, amniorrexe prematura, descolamento prematuro da placenta, atonia uterina, entre outras. $^{40}$

\subsection{5 - Mortalidade perinatal e fatores prognósticos}

A mortalidade perinatal de fetos com derrame pleural é extremamente alta e variável de acordo com diferentes publicações. Estudos apontam que ela oscila entre 25 a $75 \%$ dos derrames pleurais fetais ${ }^{16}$. Essa variação está associada a diversos fatores, tais como: a presença de malformações estruturais, alteração cromossômica, hidropisia fetal, hipoplasia pulmonar, prematuridade, bilateralidade do derrame 
pleural, entre outras ${ }^{16}$. Desses fatores, a presença de anomalias estruturais ou cromossômica está associada à maior taxa de mortalidade perinatal, atingindo, em alguns trabalhos, cifras próximas a $75 \%{ }^{16}$

Já para os fetos com derrame pleural “isolado”, essa taxa de mortalidade pode ser reduzida com o tratamento fetal em casos selecionados. Poucos estudos avaliaram os fatores prognósticos nos fetos com derrame pleural "isolado", mas sabe-se que o surgimento precoce, a hidropisia fetal, a hipoplasia pulmonar, a prematuridade e a bilateralidade do derrame estão relacionados aos piores prognósticos. ${ }^{3,5,8,14}$

Tal fato pode ser comprovado no estudo de Longaker et al. ${ }^{3}$, que descreve que o parto prematuro e o surgimento precoce do derrame pleural podem estar associados como marcadores de diminuição da taxa de sobrevivência.

Da mesma forma, Weber e Philipson ${ }^{17}$ apontaram numa revisão, que o parto, após a $31^{\mathrm{a}}$ semana, não acompanhado de hidropisia e com a terapia antenatal empregada, apresentaria bons resultados. Esses autores também reportaram que o sexo fetal, o poli-hidrâmnio, a bilateralidade do derrame e a via de parto não foram fatores preditores do resultado neonatal. ${ }^{17}$

Apesar de o poli-hidrâmnio não predizer diretamente o resultado, alguns estudos afirmam que a sua presença aumenta a probabilidade de trabalho de parto prematuro, estando esse último associado a piores resultados. ${ }^{56}$

Em outra análise, Aubard et al. ${ }^{14}$ descrevem como fatores preditores de pior resultado: a presença do derrame pleural bilateral, a hidropisia, a não regressão do derrame e o parto prematuro. Também referem que o sexo fetal, a idade gestacional do diagnóstico e o poli-hidrâmnio não são fatores preditores de pior prognóstico 
perinatal. Em uma análise multivariada, esses mesmos autores observaram que a hidropisia é um fator independente dos outros, capaz de predizer o prognóstico desfavorável fetal.

Klam et al. ${ }^{15}$ avaliaram fatores preditores do prognóstico fetal em 18 casos de hidrotórax primário. Os fetos com piores prognósticos apresentavam progressão do derrame pleural, parto prematuro e menor Apgar do $5^{\circ}$ minuto, quando comparados com os que apresentaram melhores resultados. Esses fetos também apresentavam maiores razões entre a área do derrame pleural e a área torácica ${ }^{49}$ 15, 49, ${ }^{94}$ para o derrame e maior probabilidade de serem hidrópicos ${ }^{15}$. Não se observou importância para o prognóstico fetal a idade gestacional do diagnóstico, a bilateralidade do derrame ou a presença do poli-hidrâmnio. Numa análise multivariada, somente a razão entre a área do derrame pleural e a área da circunferência torácica e a hidropisia foram independentes do pior resultado.

\subsection{6 - Tratamento fetal}

Não há consenso, na literatura, a respeito do melhor tratamento para fetos com derrame pleural "isolado". A dificuldade na escolha da melhor terapêutica se deve à raridade dessa doença e de seu curso incerto, trazendo limitações para que sejam realizados estudos clínicos randomizados. ${ }^{\text {4, } 56}$

Entre as diversas condutas descritas, encontrou-se, na literatura, a interrupção da gestação (nos países onde esse procedimento é permitido) ${ }^{3}$, a conduta expectante com acompanhamento ultrassonográfico seriado e a terapia fetal invasiva. ${ }^{3,5,7,50,56,95}$ 
Em 1992, Weber e Philipson ${ }^{17}$ realizaram a primeira metanálise que analisou as diversas formas de tratamento. Esses autores observaram que a terapia fetal invasiva apresentava os melhores resultados quando comparada com o acompanhamento ultrassonográfico seriado.

A partir de então, diversas publicações têm demonstrado que o tratamento fetal melhora o prognóstico em casos selecionados ${ }^{4,15,56,95}$, baseado nos seguintes princípios:

- A descompressão pulmonar melhora as condições para o desenvolvimento pulmonar e auxilia as manobras de ressuscitação neonatal;

- A descompressão pulmonar melhora ou reverte a hidropisia e/ou polihidrâmnio, diminuindo a morbidade e a mortalidade perinatal e os riscos para o parto prematuro.

Entre as propostas terapêuticas fetais invasivas destacam-se: a toracocentese, a derivação tóraco-amniótica ou a pleurodese. Não existe, na literatura, estudo randomizado comparando as diferentes intervenções fetais e os seus resultados ${ }^{14,50}$. Os estudos se limitam a comparar séries ou relato de casos descritos por poucos centros. Mesmo assim, em análises retrospectivas, parece haver superioridade da derivação tóraco-amniótica em relação à toracocentese de repetição para os casos de derrames graves acompanhados de hidropisia ${ }^{4,50,56}$. Para os fetos não hidrópicos, esse benefício ainda não é bem estabelecido ${ }^{4,96}$. Não existem estudos que comparem as técnicas de drenagem ("shunt" ou toracocentese) com os métodos adesivos (pleurodese). ${ }^{14,50}$ 


\subsubsection{1 - Tratamento conservador}

Diversos trabalhos apontam que o tratamento conservador é indicado apenas para os casos de derrame pleural "isolado" de pequeno volume, sem hidropisia, visto que a regressão espontânea pode ocorrer. Nesse grupo, deve-se realizar o acompanhamento ultrassonográfico seriado, avaliando o volume do derrame pleural e suas repercussões. ${ }^{50}$

O tratamento dietético materno com triglicerídeos de cadeia média, ainda durante o pré-natal, tem sido proposto por alguns autores como tratamento adjuvante ao tratamento conservador, embora não existam estudos em longo prazo que comprovem esses resultados e nem que os diferencie da história natural do derrame pleural. Porém, esses autores são categóricos em afirmar que esse tratamento dietético materno é experimental e não deve retardar o início da terapêutica fetal quando for preciso. ${ }^{97}$

Não havendo alterações no quadro inicial que permitam realizar o tratamento conservador, o prognóstico fetal é bom, com taxa de sobrevivência variando entre 73 a $100 \%$ dos casos (Tabela 1$).{ }^{14,50,63,98}$

Já para os fetos hidrópicos ou com derrame pleural volumoso, o tratamento conservador não é indicado. Dados na literatura apontam para altas taxas de mortalidade, oscilando entre 45 a 100\% dos casos (Tabela 01). ${ }^{14,50,63,98}$

Para os casos em que foi proposto um tratamento conservador durante o prénatal e que apresentam derrame pleural moderado a volumoso no final da gestação, a toracocentese prévia ao parto deve ser considerada como medida adicional aos fetos que poderão necessitar de manobras de ressuscitação neonatal. ${ }^{18,99}$ 


\subsubsection{2 - Toracocentese}

A toracocentese foi o primeiro procedimento fetal invasivo proposto para realizar a descompressão torácica ocasionada pelo derrame pleural, descrita, pela primeira vez, em 1982. Inicialmente pareceu um procedimento bastante promissor, porém, observou-se que, em $76 \%$ dos casos, o líquido reacumulava entre 1 hora ao $10^{\circ}$ dia após o procedimento. ${ }^{3,19,20}$

Apesar dessa limitação, alguns autores têm defendido o seu uso para os casos em que o derrame pleural é diagnosticado tardiamente (após a $32^{\mathrm{a}}$ ou $36^{\mathrm{a}}$ semana) ${ }^{4}$, ${ }^{50}$ ou como procedimento auxiliar na tentativa de expansão pulmonar prévia ao $\operatorname{parto}^{18,99}$.

Outras indicações para o uso da toracocentese são: a coleta do líquido pleural para a realização de cultura, a contagem celular ${ }^{13}$ e a pesquisa do cariótipo fetal ${ }^{100,}$ 101 ou como estratégia terapêutica (toracocenteses de repetição) quando o "shunt" tóraco-amniótico não puder ser realizado. ${ }^{102}$

Estudos apontam para a taxa de sobrevivência publicada entre 50 a $86 \%$ para os fetos sem hidropisia e de 10 a $50 \%$ para os fetos com hidropisia (Tabela 01$)^{14,50,}$ 63,98 .

\subsubsection{3 - Derivação tóraco-amniótica}

A derivação tóraco-amniótica foi descrita, pela primeira vez, em $1986^{21}$ como estratégia terapêutica para a descompressão contínua do tórax em fetos com derrame pleural. Teve sua técnica adaptada ${ }^{22,103,104}$ ao longo dos anos, buscando-se 
cateter mais fino e flexível, além de trocater com menor diâmetro para diminuir os riscos inerentes ao procedimento. ${ }^{4}$

A derivação tóraco-amniótica consiste na inserção de um cateter tipo “duplo pigtail" (Figura 02) na cavidade torácica fetal, sob orientação contínua da ultrassonografia, fazendo com que a extremidade distal do cateter fique no espaço pleural e a sua extremidade proximal fique na cavidade amniótica, drenando o derrame de forma contínua. ${ }^{22}$

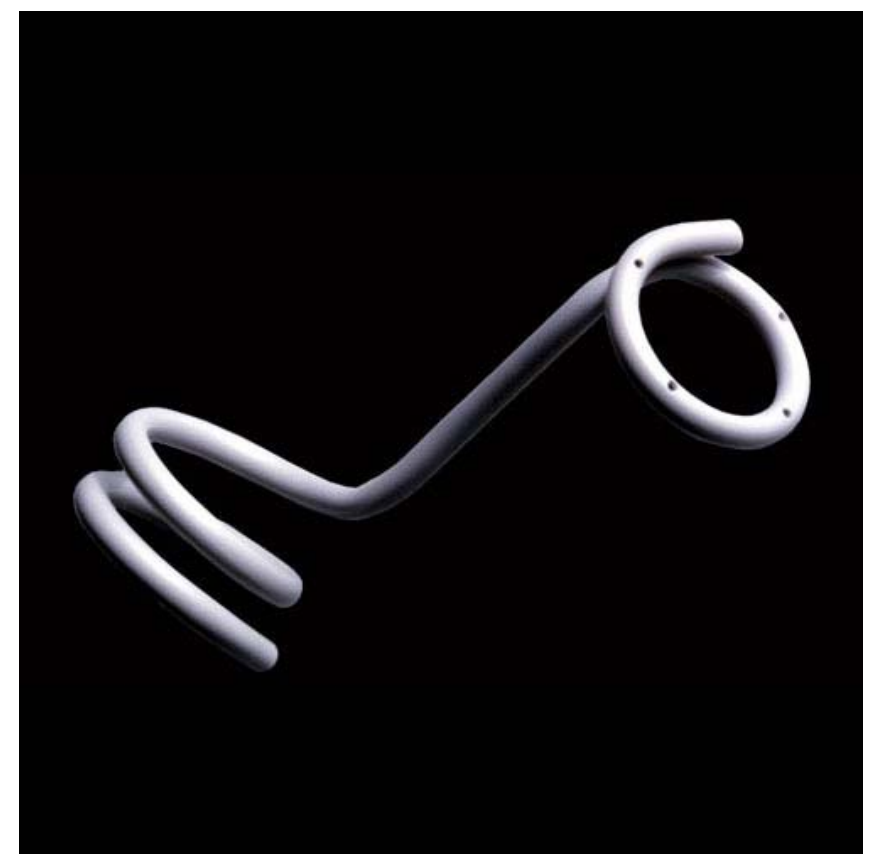

Figura 2: Cateter “double pigtail” (cateter de Harrison, Cook Medical Inc ANVISA $n^{\circ}$ M.S. 10330710004)

Embora não exista nenhum trabalho randomizado que compare as diferentes estratégias terapêuticas fetais, as revisões da literatura, baseadas em série ou relatos de casos, parecem apontar uma superioridade não significativa na derivação tóraco- 
amniótica quando comparado com a toracocentese ${ }^{105}$. Esses estudos apontam para uma taxa de sobrevivência de 60 a 100\% para os fetos não hidrópicos ${ }^{25,50,52,95}$ e de 44 a $66 \%$ para os fetos com hidropisia (Tabela 01$) .9,14,50,52,56,63,98,106$ 
Tabela 1: Taxa de sobrevivência de acordo com a terapêutica escolhida para tratamento do derrame pleural primário - Revisão da literatura.

\begin{tabular}{|c|c|c|c|c|c|c|}
\hline \multirow[t]{3}{*}{ Autor } & \multicolumn{2}{|c|}{$\begin{array}{l}\text { Tratamento } \\
\text { Conservador }\end{array}$} & \multicolumn{2}{|c|}{ Toracocentese } & \multicolumn{2}{|c|}{$\begin{array}{c}\text { Derivação } \\
\text { Tóraco-amniótica }\end{array}$} \\
\hline & \multicolumn{2}{|c|}{ Hidropisia } & \multicolumn{2}{|c|}{ Hidropisia } & \multicolumn{2}{|c|}{ Hidropisia } \\
\hline & Não & Sim & Não & Sim & Não & Sim \\
\hline Pettersen $^{63}$ & $83 \%$ (29) & $12 \%(3)$ & $50 \%(4)$ & $33 \%(3)$ & $100 \%(28)$ & $46,3 \%$ (19) \\
\hline Aubard $^{14}$ & $21,3 \%(48)$ & $24 \%(48)$ & $60 \%(10)$ & $10 \%(19)$ & $100 \%(17)$ & $66,6 \%(63)$ \\
\hline Picone $^{106}$ & $*$ & * & * & * & * & $66 \%(31)$ \\
\hline Smith $^{52}$ & $*$ & * & $*$ & $*$ & $60 \%(3)$ & $44 \%(7)$ \\
\hline Rústico $^{50}$ & $73 \%(25)$ & $35 \%(7)$ & $77 \%(10)$ & $50 \%(11)$ & $82 \%(27)$ & $62 \%(77)$ \\
\hline Deurloo $^{9}$ & $*$ & $*$ & * & $61 \%(19)$ & $*$ & $62,5 \%(85)$ \\
\hline Yinon $^{56}$ & $*$ & $*$ & * & $*$ & $72 \%(21)$ & $53 \%(31)$ \\
\hline Favre $^{98}$ & $75 \%(4)$ & * & $85,7 \%(7)$ & $33,3 \%(3)$ & $75 \%(8)$ & $52,9 \%(17)$ \\
\hline
\end{tabular}

* Estudos não realizados pelo método terapêutico. 


\subsubsection{4 - Pleurodese}

A pleurodese é uma técnica invasiva do espaço pleural onde se introduz substância irritativa que irá provocar o colabamento dos folhetos pleurais (visceral e parietal), dificultando o acúmulo de líquido. ${ }^{107}$

Publicações têm descrito a pleurodese com sangue materno ou OK-432 como tratamento experimental em fetos com derrame pleural volumoso.

O OK-432 é derivado de cepas de origem humana de baixa virulência do Streptococcus pyogenes do grupo A, tipo 3, encubado com benzilpenicilina. O uso nos fetos ocorreu após experiência adquirida no tratamento em adultos, baseado nas propriedades inflamatórias do liofilizado de células e de suas propriedades enzimáticas e glicolíticas.

Seu primeiro uso em fetos para tratamento do derrame pleural foi descrito por Tanemura et al. e Okawa et al. ${ }^{26,108}$ (2001). Após isso, diversas terapias experimentais com OK-432 para a pleurodese do derrame pleural fetal têm sido descritas $^{29,96,109-113}$, embora a experiência quanto ao seu uso seja bastante limitada e seus resultados, discrepantes. ${ }^{96}$

Rústico et $a l .{ }^{50}$, em sua revisão com 10 casos, observaram sucesso em $60 \%$ dos casos. Em uma série dinamarquesa de casos ${ }^{110}$, observou-se êxito em $100 \%$ dos fetos não hidrópicos $(n=07)$ e com derrame pleural bilateral tratado. Outro estudo aponta uma taxa de $100 \%$ de sobrevivência em fetos não hidrópicos $(\mathrm{n}=7)$, porém uma taxa de $0 \%$ de sobrevivência em fetos hidrópicos $(n=5) .{ }^{114}$ 
A explicação para os diferentes resultados é que o derrame pleural "isolado" poderia apresentar diferentes mecanismos etiológicos, sendo dividido em processo de origem inflamatório local e em processo de origem genética. ${ }^{67,113,114}$

Assim, Yu-Shih Yang et al. ${ }^{96}$, estudaram o uso do OK-432 no derrame pleural primário, pesquisando possíveis fatores genéticos associados. Eles encontraram que a eficácia do OK-432 é de 35,6\% após um ano de tratamento, com taxa de sucesso de $67 \%$ para os fetos não hidrópicos e de $15 \%$ para os hidrópicos. Notaram que o derrame pleural pode apresentar diferentes comportamentos e que o tipo inflamatório responde melhor ao tratamento estudado.

Outra estratégia para a pleurodese é a inserção intrapleural de sangue fetal ou de sangue materno. Parra et al. (2003) descrevem um relato de caso em que utilizaram sangue materno com sucesso em um caso de derrame pleural com ascite. $^{115}$

\subsubsection{5 - Complicações dos procedimentos fetais}

Os dados literários a respeito das complicações relacionadas ao procedimento para tratamento do derrame pleural são escassos.

Estudos descrevem que os riscos relacionados à toracocentese são semelhantes às taxas de complicações encontradas para amniocentese, sendo de 1,0 a $1,6 \%$ para a ruptura das membranas ovulares e de 0,5 a $1 \%$ para a perda fetal.

A derivação tóraco-amniótica apresenta como principal complicação o não funcionamento do dreno, seja por sua obstrução ou por migração, ocorrendo em 4,5 a 
$33 \%$ dos $\operatorname{casos}^{4,102}$. Tem-se descrito a ruptura prematura das membranas, o trabalho prematuro e a corioamnionite em $17 \%$ dos $\operatorname{casos}^{106}$, e uma taxa de 5 a $10 \%$ para a perda fetal $^{4,102}$. Outras complicações menos comuns à derivação tóraco-amniótica são o sangramento no local da punção, a constricção de membros ${ }^{116}$ e cordão umbilical (semelhante à banda amniótica), drenagem reversa pelo "shunt" tóracoamniótico (drena o líquido amniótico para o espaço pleural) ${ }^{22}$, alteração na morfologia de $\operatorname{arcos}$ costais ${ }^{117}$ e pele sobrejacente no local da punção, além da hipoplasia mamária. ${ }^{118}$

Outro risco hipotético relacionado aos procedimentos de drenagem da cavidade pleural (toracocentese ou derivação tóraco-amniótica) seria a perda de proteína no líquido pleural, levando a um possível quadro de hipoproteinemia, o qual favoreceria o desenvolvimento da hidropisia. ${ }^{119,120}$

As complicações referentes ao procedimento com OK-432 parecem ser semelhantes às descritas para a toracocentese, porém, dados sobre a sua segurança e toxicidade durante o período perinatal são escassos ${ }^{4}$. Estudos com OK-432 em animais têm demonstrado a supressão da atividade elétrica cardíaca no eletrocardiograma, da respiração e dos movimentos corporais ${ }^{28}$. Outro modelo experimental sugeriu que o OK-432 pudesse levar ao sofrimento cerebral, colocando em risco o seu uso quanto ao futuro ${ }^{27}$. Quanto ao seu estudo em humanos, tem-se o relato de uma morte materna por embolia do líquido amniótico, oito semanas após o uso do OK-432 $2^{112}$, embora nenhuma causa direta tenha sido encontrada. Também foi evidenciada, em uma série de $45 \operatorname{casos}{ }^{96}$, a ocorrência maior de corioamnionite em $6,8 \%$ dos casos. Em outro estudo, não foi observado nenhum efeito tóxico em fetos tratados com OK-432 para o higroma cístico. ${ }^{121}$ 


\subsection{7 - O derrame pleural “isolado" no período pós-natal}

O derrame pleural "isolado" (primário) é a principal causa de quilotórax congênito no período pós-natal. A falha na conexão entre o ducto torácico e o sistema venoso-linfático leva ao extravasamento do quilo para o espaço pleural.

O quilo presente no líquido pleural é proveniente da linfa que é absorvida no intestino. Essa linfa, rica em lipídeos, após o início da dieta enteral (p. ex. amamentação), é drenada para o ducto torácico, que é a principal via de escoamento da gordura alimentar absorvida nos intestinos. Como o ducto torácico no derrame pleural primário apresenta um desequilíbrio em seu processo de drenagem, o quilo é extravasado para o interior da cavidade pleural formando o quilotórax congênito ${ }^{64}$, 122.

O diagnóstico do quilotórax no período pós-natal se dá pela análise do líquido pleural, a qual evidenciará a presença mais de 1000 células $/ \mathrm{mL}$, mais de $80 \%$ de linfócitos e mais de $110 \mathrm{mg} / \mathrm{dL}$ dos triglicerídeos. ${ }^{122}$

A conduta no quilotórax congênito, no período neonatal, consiste no tratamento sintomático, tais como: suporte ventilatório para os recém-nascidos com dificuldade respiratória; toracocentese ou drenagem contínua para os recém-nascidos com derrame moderado ou volumoso; e, em casos refratários a esses tratamentos, pode-se combinar a dietoterapia. ${ }^{123}$ Este tratamento clínico pós-natal apresenta taxas de sucesso acima dos $50 \% .^{124}$ 
A terapia nutricional é inicialmente proposta por via parenteral com rápida progressão para a via enteral, devendo ser rica em triglicerídeos de cadeia média, os quais atravessam os vasos linfáticos intestinais e são absorvidos diretamente no sistema porta, diminuindo o fluxo de quilo pelo ducto torácico. Com isso, há uma considerável redução no volume e na concentração de lipídeos no derrame pleural ${ }^{122,}$ $125-128$

Uma minoria de pacientes necessitará de tratamento cirúrgico para a ligadura dos ductos linfáticos ${ }^{129}$, sendo indicado para os recém-nascidos que apresentarem volumosos quilotórax (drenagem acima de $50 \mathrm{~mL} / \mathrm{kg} / \mathrm{dia}$ ) ou falha do tratamento clínico após 10 dias. Recém-nascido com baixo peso para a idade gestacional e quilotórax volumosos se beneficiam do tratamento cirúrgico mais precoce (antes dos 10 dias). ${ }^{124}$

Estudos recentes sugerem que o OK-432 também possa ser usado no período pós-natal, embora faltem evidências quanto ao benefício do seu uso em longo prazo $^{130}$. A pleurodese com iodopovedine deve ser evitada nos RNs e durante a infância. $^{124}$

2.5 - A hipoplasia pulmonar fetal e a sua estimativa por meio do volume pulmonar

A hipoplasia pulmonar é caracterizada pelo desenvolvimento incompleto de um ou ambos os pulmões, resultando na redução do número de dicotomizações da árvore brônquica e seus alvéolos associados. A consequência dessa deformidade é a 
redução no volume do pulmão acometido ${ }^{131}$, levando a condições de alta morbidade e mortalidade $(50-70 \%)$ no período neonatal. ${ }^{132}$

Diversos fatores podem contribuir para a hipoplasia pulmonar, entre os quais destacam-se: ${ }^{132-135}$

- a redução do espaço intratorácico (p.ex. nas hérnias diafragmáticas congênitas, das lesões adenomatoides císticas, no sequestro broncopulmonar, no derrame pleural);

- a redução dos movimentos respiratórios fetais (p. ex. as displasias esqueléticas, distúrbios neuromusculares);

- oligoâmnio crônico e severo (p.ex. amniorrexe em idade gestacional muito precoce, anomalias renais);

- interferência no desenvolvimento pulmonar em idade gestacional precoce, especialmente antes do término da fase canalicular.

Como o diagnóstico definitivo da hipoplasia pulmonar se dá apenas por estudo anatomopatológico, seja pela relação entre o peso pulmonar e o peso corporal, pela contagem de alvéolos radiais ou de DNA detectados no tecido pulmonar ${ }^{136-140}$, faz-se necessário buscar outros métodos que avaliem indiretamente a hipoplasia pulmonar em fetos com risco para o seu desenvolvimento.

A estimativa da hipoplasia pulmonar é de fundamental importância, visto que, auxilia na assistência pré-natal, na predição do prognóstico perinatal, no aconselhamento aos pais, na tomada de decisão em se realizar tratamento fetal de uma forma mais agressiva e no planejamento quanto aos melhores cuidados e assistência necessária no período pós-natal. ${ }^{141}$ 
Uma vez que a hipoplasia pulmonar pode ser caracterizada pelo tamanho reduzido dos pulmões fetais, muitos estudos foram realizados com o intuito de se aferir o tamanho e o volume pulmonar ${ }^{90,132,140-143}$ na tentativa de estimar a probabilidade do seu desenvolvimento ${ }^{141-144}$. Para esse fim, utilizou-se a ultrassonografia bidimensional, ultrassonografia tridimensional e a ressonância nuclear magnética (RNM).

\subsection{1 - Avaliação pulmonar fetal pela ultrassonografia bidimensional}

Na década de 1990, diversas curvas de normalidade, utilizando parâmetros bidimensionais e suas relações, foram construídas na tentativa de se estimar a hipoplasia pulmonar. Na literatura, encontramos curvas de normalidades bidimensionais, utilizando o comprimento $\operatorname{pulmonar}^{145}$, a área $\operatorname{pulmonar}^{94,}{ }^{143}$, a circunferência torácica, o diâmetro pulmonar $^{146}$, a circunferência pulmonar $^{147}$, as relações comprimento pulmonar pelo diâmetro médio, comprimento pulmonar pela circunferência torácica, comprimento pulmonar pela circunferência cefálica, área pulmonar pela circunferência cefálica (LHR - "lung head ratio") ${ }^{148-150}$, entre outras.

Apesar da importância desses normogramas, muitos trabalhos demonstram que os parâmetros bidimensionais tiveram moderada especificidade e baixa sensibilidade para a detecção da hipoplasia pulmonar, não sendo indicado o seu uso na prática clínica ${ }^{37}$. Exceção se faz para as medidas bidimensionais da área pulmonar pela circunferência cefálica (LHR) como método preditor da hipoplasia pulmonar 
apenas nos casos de hérnia diafragmática congênita ${ }^{151,152}$, embora isso não seja consenso na literatura.

Raríssimos trabalhos descrevem a avaliação do volume pulmonar nos casos de derrame pleural pela ultrassonografia bidimensional. Vergani et al. ${ }^{37}$ (2010) compararam a técnica ultrassonográfica tridimensional com a bidimensional e demonstraram que esta é inadequada para a estimativa da hipoplasia pulmonar, principalmente nos casos de hidrotórax fetal e das displasias esqueléticas.

\subsection{2 - Avaliação pulmonar fetal por técnicas tridimensionais: a} ressonância magnética e a ultrassonografia tridimensional

Atualmente, o volume pulmonar fetal pode ser medido por meio da US $3 \mathrm{D}^{31}$, $33,34,36,153-158$ e por RNM ${ }^{159-161}$.

Estudos com a ressonância magnética fetal (RNM) mostraram a superioridade do método tridimensional quando comparados com o método bidimensional (US 2D) na estimativa de volumes. Duncan et al. ${ }^{162}$, em 1999, construíram uma das primeiras curvas de volume pulmonar pela idade gestacional utilizando a RNM. Diversos normogramas e estudos posteriores validaram essa técnica como método "padrãoouro" para a avaliação pulmonar e estimativa do risco para a hipoplasia nos fetos com patologias pulmonares. Mesmo assim, o uso da RNM na prática clínica mostrou-se bastante limitado, em virtude dos altos custos, da baixa disponibilidade do método, da claustrofobia e a não tolerância materna ao decúbito prolongado, além dos artefatos da movimentação fetal durante a realização do exame. ${ }^{163}$ 
Devido às limitações da RNM, outros métodos de imagem mais práticos, baratos e acessíveis começaram a ser estudados com o intuito de avaliar o volume pulmonar. Darcy et al. ${ }^{164}$, publicaram um dos primeiros estudos na estimativa do volume pulmonar pela ultrassonografia tridimensional. Estudos posteriores vieram para validar a aplicação desse método, o qual demonstra ser de maior confiança para

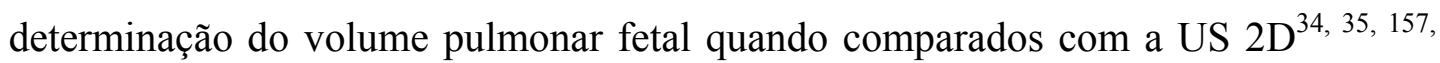
165, 166, além de apresentar boa acurácia quando comparados com a ressonância magnética fetal. ${ }^{34,156,159}$

Uma das primeiras curvas do volume pulmonar obtida pela US 3D utilizava a técnica multiplanar ${ }^{166,167}$, a qual avaliava o volume pulmonar delineando o órgão em planos sucessivos e sequenciais. Entre as vantagens deste método destaca-se a maior facilidade na delimitação do objeto de estudo, visto que são planos subsequentes e pertencem a um mesmo eixo. Entretanto, apresentam como desvantagem a dificuldade em mensurar estruturas irregulares, principalmente as estruturas próximas à cúpula diafragmática e mediastinal, superestimando o volume pulmonar.

A busca por métodos mais precisos para a mensuração pulmonar fez com que surgissem técnicas mais semelhantes às utilizadas pela ressonância magnética fetal, tais como a avaliação volumétrica pela ultrassonografia tridimensional pela técnica rotacional (VOCAL).

A técnica volumétrica de rotação do volume tridimensional (VOCAL Virtual Organ Computer-aided AnaLysis ) mensurado pela ultrassonografia consiste na rotação da imagem volumétrica em três dimensões sobre um eixo inicial, previamente definido pelo operador. A cada rotação da imagem, pode-se circundar o órgão em estudo e, no final de uma rotação completa $\left(360^{\circ}\right)$, o volume é calculado 
automaticamente pelo programa. Apresenta como vantagem a possibilidade de mensurar os pulmões isoladamente ${ }^{155}$, avaliar pulmões pequenos e irregulares ${ }^{155}$, melhor avaliar o ápice pulmonar e obter um volume pulmonar mais próximo do real 157. Uma possível desvantagem do método VOCAL, quando comparado com o método multiplanar, é que na rotação dos planos pelo método VOCAL, a delimitação do pulmão muda de plano a cada medida, exigindo um maior treinamento do operador quando comparado com a técnica multiplanar, para que se execute a mensuração correta. ${ }^{157}$

Em 2003, Raine-Fenning et al. ${ }^{168}$ avaliaram a validade dessa técnica in vitro. Nesse estudo, observa-se maior validade estatisticamente significante nas medidas volumétricas obtidas pela técnica rotacional (VOCAL) em comparação com as obtidas pela multiplanar.

Kalache et al. ${ }^{165}$, ao compararem essas técnicas, na medida do volume pulmonar de fetos normais e com suspeita de hipoplasia pulmonar, observaram concordância entre as duas técnicas, embora a diferença tenha sido estatisticamente insignificante.

Ruano et al ${ }^{34,159}$ ao estudarem por meio das duas técnicas fetos com hérnia diafragmática congênita observaram que a técnica VOCAL se aproxima mais do volume pulmonar real, principalmente pelas dificuldades na delimitação do volume pulmonar contralateral. Esses mesmos autores observaram que a determinação do volume pulmonar pela técnica de VOCAL tem boa acurácia com as imagens de RNM e com o volume real estimado em peças de necropsia. 
Estudos recentes validaram o cálculo do volume pulmonar pela técnica VOCAL como método preditor da função pulmonar no período pós-natal, por meio da mensuração da capacidade funcional pulmonar, utilizando a técnica de diluição do gás Hélio em recém-nascidos normais e com risco para hipoplasia pulmonar. ${ }^{153}$

Dessa forma, diversos normogramas para o volume pulmonar, utilizando a técnica VOCAL por meio da US 3D, foram descritos ${ }^{32,157,158,169}$, impulsionando os estudos na estimativa da hipoplasia pulmonar e do prognóstico perinatal dos fetos com patologias pulmonares. Devido à maior incidência, os trabalhos concentraram a avaliação dessa técnica no estudo de fetos com hérnia diafragmática. ${ }^{33,34,170}$

Apesar de validada a técnica VOCAL pela US 3D para a mensuração do volume pulmonar fetal, não há relatos, na literatura, sobre a utilização dessa técnica para a avaliação prognóstica nos fetos portadores de derrame pleural, provavelmente devido à raridade dessa manifestação clínica. Vergani et $a l^{37}$ descrevem, em sua série de casos, o uso satisfatório do US 3D - técnica VOCAL - na avaliação pulmonar em sete fetos com derrame pleural. 


\section{OBJETIVOS}




\section{OBJETIVOS}

Avaliar o volume pulmonar fetal por meio da US 3D como método preditor dos resultados perinatais em fetos com derrame pleural "isolado":

a) Quanto à mortalidade perinatal

b) Quanto à morbidade neonatal (necessidade de cuidados neonatais intensivos e de ventilação mecânica assistida) 
CASUÍSTICA E MÉTODO 


\section{CASUÍSTICA E MÉTODO}

\section{1 - Local do estudo}

O estudo foi realizado no Setor de Medicina Fetal da Clínica Obstétrica e na Neonatologia do Hospital das Clínicas da Faculdade de Medicina da Universidade de São Paulo (HCFMUSP).

\section{2 - Coleta de dados}

Realizou-se estudo retrospectivo em base de dados eletrônica da Clínica Obstétrica do Hospital das Clínicas da Faculdade de Medicina da Universidade de São Paulo e livro de parto (quando realizados no HCFMUSP) de fetos portadores de derrame pleural de etiologia não imune, encaminhados a esse centro de referência por diversas regiões do País, no período de janeiro de 2005 a julho de 2010, complementado por entrevistas direcionadas realizadas pessoalmente ou por contato telefônico.

Foram utilizados os seguintes descritores na busca em banco de dados eletrônicos: "derrame pleural", "hidrotórax", “quilotórax" ou "hidropisia”. A lista de dados obtida retrospectivamente com esses descritores foi comparada com o rol dos 
dados colhidos prospectivamente pelo examinador (RR), a fim de verificar se todos os casos foram analisados.

\section{3 - Casuística}

Foram selecionadas para participar do estudo pacientes cujos fetos apresentaram derrame pleural de etiologia não imune diagnosticado pela ultrassonografia obstétrica, em qualquer período da gestação, e que preencheram os seguintes critérios de inclusão:

a) Fetos vivos;

b) Idade gestacional confirmada por exame ultrassonográfico realizado até 20 semanas;

c) Fetos sem anomalias estruturais e com dopplerfluxometria do pico da velocidade sistólica da artéria cerebral média dentro da normalidade, rastreados pela ultrassonografia obstétrica morfológica com Doppler do segundo trimestre, realizado por profissional experiente (RR) vinculado ao Setor de Medicina Fetal HCFMUSP;

d) Fetos com ecocardiograma dentro da normalidade realizado por cardiologistas pediátricos experientes vinculados ao HCFMUSP;

e) Cariótipo fetal normal, pesquisado no líquido amniótico, sangue fetal ou líquido pleural; 
f) Pesquisa de infecção materna negativa para parvovirose, citomegalovírus, toxoplasmose, herpes vírus, rubéola e sífilis, mediante a dosagem de imunoglobulinas (IgM e IgG) ou do VDRL (para sífilis) no sangue materno;

g) Pesquisa de infecção fetal negativa, realizada por PCR ou cultura do líquido amniótico somente em casos suspeitos ou confirmados de infecção materna;

h) Pacientes cujos fetos tiveram o volume pulmonar estimados pela US 3D utilizando a técnica rotacional (VOCAL) por único examinador (RR) no momento da confirmação do diagnóstico de derrame pleural no HCFMUSP e próximo ao parto (até a $36^{\mathrm{a}}$ semana de gestação ou duas últimas semanas antecedentes ao parto);

i) Celularidade do líquido pleural fetal apresentando predomínio de linfócitos;

j) Ausência de alterações estruturais verificadas após o parto;

k) Informações completas a respeito do parto e das condições do recém-nascido no período neonatal.

\section{4 - Método}

\subsection{1 - Estimativa do volume pulmonar fetal total pela ultrassonografia em três dimensões (US 3D) e outros parâmetros ultrassonográficos}

Todos os exames foram realizados por um único examinador experiente (RR) do Serviço de Medicina Fetal da Clínica Obstétrica da Faculdade de Medicina do Hospital das Clínicas da Universidade de São Paulo. 
Para a avaliação do volume pulmonar total de cada feto, foi utilizado aparelho de ultrassonografia Voluson 730 Expert (General Eletric, Kretzechnick, Zipf, Áustria) com sonda abdominal 3D/4D de frequência $4-8 \mathrm{MHz}$ com varredura automática, utilizando técnicas de aquisição e medida do volume pulmonar uniformes em todos os casos. Para a aquisição do volume da caixa torácica fetal, foi realizado corte transversal do tórax, com o ápice do coração do feto localizado próximo ao transdutor (dorso fetal posteriormente), com o intuito de evitar a sombra acústica causada pela coluna vertebral. A aquisição do bloco tridimensional dos pulmões foi obtida durante a apneia materna e repouso do feto. A janela volumétrica ("volume box") foi ajustada para captar todo o tórax do feto, assim como a resolução máxima de captura foi estabelecida. O ângulo de varredura automático foi ajustado entre $60^{\circ}$ e $85^{\circ}$ de forma a capturar todo o tórax fetal, no sentido longitudinal, durante quatro a oito segundos de varredura. Após a varredura automática e captura da imagem volumétrica do tórax fetal, a imagem foi cuidadosamente avaliada pelo módulo multiplanar com o intuito de verificar se ambos os pulmões foram completamente capturados nessa imagem volumétrica e se não houve movimentação fetal causando artefatos de imagem. Arquivaram-se esses blocos de volumetria sendo realizada medida volumétrica de cada pulmão (Figura 3). 


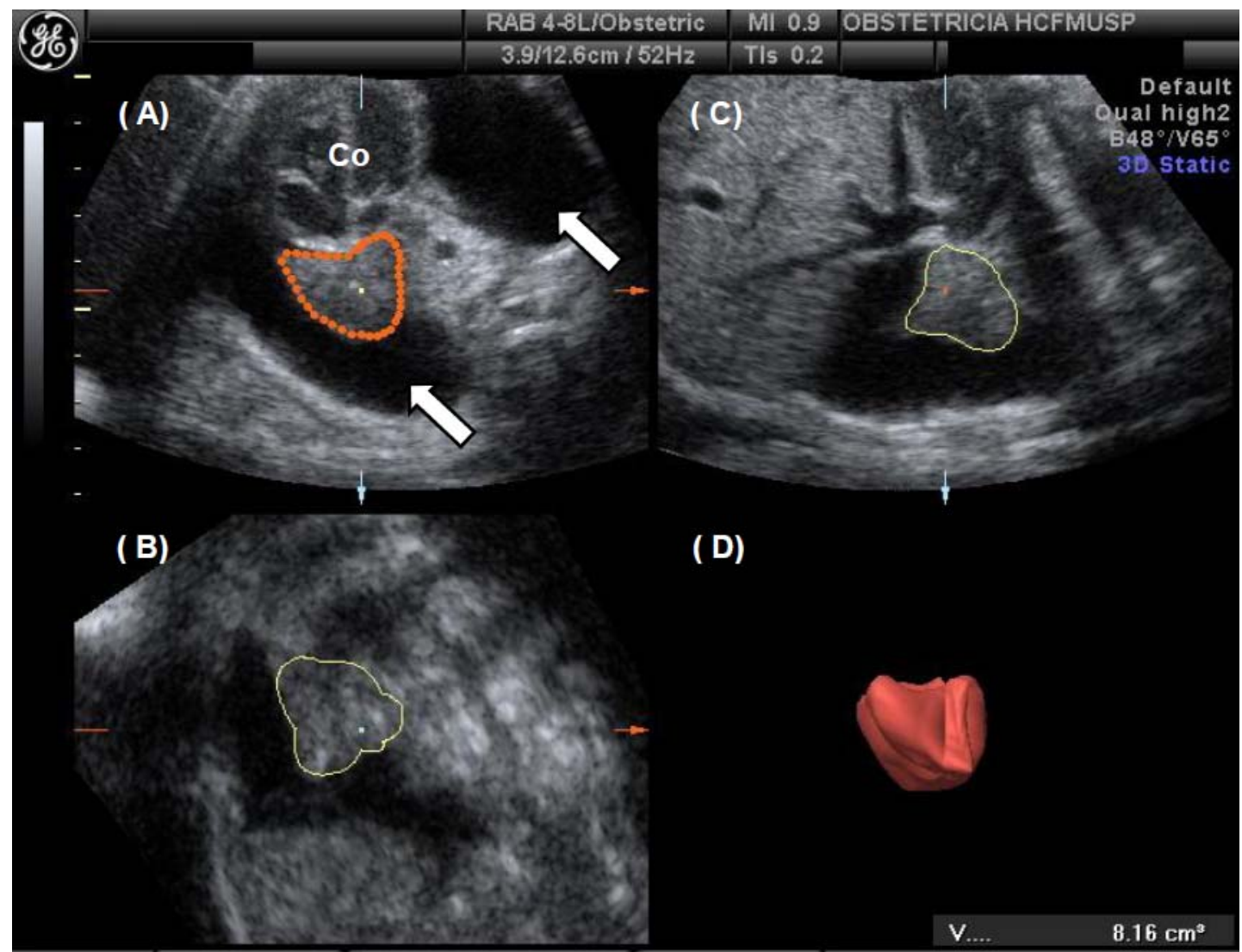

Figura 3: A imagem tridimensional do volume pulmonar de feto com derrame pleural e idade gestacional de 28 semanas obtida nos três planos ortogonais: (A) transversal ou axial. Coração fetal (Co), derrame pleural bilateral (setas brancas) e a delineação do pulmão direito (pontilhado vermelho). (B) longitudinal ou sagital e (C) frontal ou coronal. (D) Imagem tridimensional renderizada do volume do pulmão direito.

Para estimar o volume pulmonar total fetal, escolheu-se o corte transversal da imagem multiplanar com ponto de plano de referência. O volume pulmonar foi mensurado utilizando-se o software VOCAL (Virtual Organ Computer-Aided analysis - Tridimensional Sonoview; GE Healthcare; Zipf, Áustria) pelo modo de delineação manual, sendo fixados previamente os pólos superiores e inferiores pelos marcadores de medida. Ambos os pulmões foram medidos isoladamente pela técnica 
de rotação de imagem em $30^{\circ}$, a qual contornava consecutivamente seis vezes a área do pulmão, em estudo, após a rotação do mesmo em $30^{\circ}$ (VOCAL). O aparelho reconstruía a imagem e fornecia diretamente o volume $\mathrm{em}^{\mathrm{cm}^{3}}$ do pulmão analisado. Em seguida, verificavam-se os contornos da área pulmonar em cada plano previamente analisado. ${ }^{165}$

O volume pulmonar fetal total foi obtido pelo somatório do volume pulmonar direito e esquerdo em cada feto, sendo denominado como volume pulmonar total observado, o qual era comparado com a medida esperada em fetos normais para a mesma idade gestacional (volume pulmonar total esperado), de acordo com a curva de normalidade para volume pulmonar fetal publicada por Ruano et al. ${ }^{169}(2006)$, estabelecendo assim a relação entre o volume pulmonar observado pelo volume pulmonar esperado para determinada idade gestacional (VPT o/e). Optou-se escolher pelo normograma do volume pulmonar fetal publicada por Ruano et al. ${ }^{169} \mathrm{em}$ razão dos seguintes motivos: a) varredura automática no momento da aquisição do bloco tridimensional; b) técnica VOCAL utilizada; c) reprodutibilidade do método; d) validação obtida com peças de autópsias e outros métodos de imagem; e) representatividade da amostra estudada.

Neste estudo, todas as gestantes incluídas foram acompanhadas quinzenalmente no Setor de Medicina Fetal do HCFMUSP, sendo submetidas ao exame ultrassonográfico detalhado. Para estimativa do prognóstico fetal, este estudo considerou a razão entre o volume pulmonar total observado/esperado em dois períodos determinantes da gestação, sendo o primeiro no momento do diagnóstico, denominado $1^{\circ}$ VPT o/e, realizado no $1^{\circ}$ US 3D no HCFMUSP, o qual permite a noção da gravidade inicial do caso; e o segundo, no período antecedente ao parto, 
denominado $2^{\circ}$ VPT o/e, realizado duas semanas antecedentes ao parto ou até a $36^{\mathrm{a}}$ semana de gestação, o qual fornece parâmetros indiretos da severidade da hipoplasia pulmonar ao nascimento.

Outros parâmetros ultrassonográficos bidimensionais foram coletados nos exames realizados nesses períodos, tais como:

a) presença de hidropisia (definida por derrame pleural acompanhado por edema de subcutâneo; ou acúmulo de líquidos em duas ou mais cavidades corporais, tais como: derrame pleural acompanhado de derrame pericárdico ou ascite) ${ }^{9}$;

b) lateralidade do derrame pleural (unilateral à direita, unilateral à esquerda ou bilateral);

c) poli-hidrâmnio grave (definido em nosso protocolo por ILA $>25 \mathrm{~cm}$ ) ;

d) regressão completa do derrame (verificado no último exame ultrassonográfico tridimensional).

\subsection{2. - Procedimentos fetais invasivos}

Todos os procedimentos foram realizados com rigorosa técnica de assepsia e antissepsia, na Clínica Obstétrica do HCFMUSP, após obtenção do Termo de Consentimento Livre e Esclarecido, conforme o protocolo da Clínica Obstétrica. As pesquisas do cariótipo fetal, infecção fetal, amniodrenagem e toracocentese foram 
realizadas ambulatorialmente. As derivações tóraco-amnióticas foram realizadas na sala de procedimentos invasivos fetais.

Não fez parte do objetivo principal deste estudo avaliar a melhor estratégia terapêutica para os casos de derrame pleural "isolado". Além disso, não foi observada nessa análise retrospectiva, a randomização para os casos tratados. O que se verificou foi que os critérios para a escolha do método terapêutico (derivação tóraco-amniótica ou toracocentese) objetivaram única e exclusivamente o tratamento fetal, quando indicado, individualizando a melhor estratégia terapêutica para cada caso.

Dessa forma, o protocolo para tratamento do derrame pleural isolado no período antenatal (toracocentese ou derivação tóraco-amniótica) foi baseado na gravidade do derrame, no grau de comprometimento fetal e na idade gestacional em que foi realizado o diagnóstico, sendo observada a intervenção quando preenchesse um dos seguintes critérios:

1) Fetos com derrame pleural "isolado" associados à hidropisia;

2) Fetos com derrame pleural "isolado" bilateral;

3) Fetos com derrame pleural "isolado" unilateral, com derrame ocupando área maior que $50 \%$ da cavidade torácica, causando importante desvio do mediastino, documentado pelo rápido aumento do derrame em exames subsequentes, associado com poli-hidrâmnio (ILA $>25 \mathrm{~cm}$ ). 
A toracocentese foi realizada sob visão direta ultrassonográfica, com a utilização de agulha BD 20 gauge com $15 \mathrm{~cm}$ de comprimento. O "shunt" tóracoamniótico foi inserido conforme técnica previamente descrita por Rodeck et al. ${ }^{22}$, sob orientação da ultrassonografia, por meio de punção abdominal materna. O cateter "double pigtail” (cateter de Harrison, Cook Medical Inc., USA) (Figura 2) foi inserido por meio da cânula, acomodando a sua extremidade distal no espaço pleural e a sua extremidade proximal na cavidade amniótica. Para evitar o pneumotórax fetal, todos os "shunts" foram removidos imediatamente após o parto.

Esses procedimentos eram realizados apenas com anestesia materna no local da punção com Xylocaína a 2\% (sem vasoconstritor), dispensada a anestesia fetal. Apenas as derivações tóraco-amnióticas receberam antibiótico profilaxia com Cefalotina $1 \mathrm{~g}$, endovenosa, 30 minutos antes do procedimento. A corticoterapia não foi indicada em nenhum caso por conta do procedimento fetal.

\subsection{3 - Assistência ao parto}

O parto normal foi incentivado em todos os casos, exceto naqueles em que se verificou o comprometimento da vitalidade fetal ou houvesse indicação obstétrica ou materna, sendo então optado pela interrupção por via alta. 


\subsection{4 - Cuidados neonatais imediatos}

Todos os recém-nascidos foram imediatamente encaminhados aos cuidados da equipe de neonatologia, a qual avaliava as repercussões do derrame pleural sobre o parâmetro respiratório fetal imediatamente após o nascimento, bem como a necessidade de suporte ventilatório.

\subsection{5 - Variáveis analisadas}

\section{Variáveis maternas:}
a) Idade
b) Tipagem sanguínea e fator $\mathrm{Rh}$
c) Paridade

\section{Variáveis ultrassonográficas fetais:}

a) Idade gestacional no diagnóstico de derrame pleural e nas ultrassonografias subsequentes.

b) Lateralidade do derrame pleural

a. Unilateral (direita ou esquerda)

b. Bilateral

c) Hidropisia fetal (presente ou ausente) 
d) Índice de líquido amniótico (mensurado em $\mathrm{cm}$ )

e) Relação entre o Volume Pulmonar Total Observado / Volume Pulmonar Esperado para a idade gestacional (VPT o/e)

a. $1^{\circ}$ VPT o/e - no momento do $1^{\circ}$ US 3D - HCFMUSP

b. $2^{\circ} \mathrm{VPT}$ o/e - duas semanas antecedentes ao parto ou até a $36^{\mathrm{a}}$ semana gestação

f) Local de pesquisa do cariótipo
a) Líquido amniótico,
b) Sangue Fetal
c) Líquido pleural

\section{Variáveis obstétricas e perinatais:}
a) Idade gestacional do parto
b) Via e indicação de parto
c) Sexo fetal
d) Peso ao nascimento
e) Apgar
f) Resultado perinatal
a. Óbito intrauterino
b. Óbito pós-natal ${ }^{*}$
c. Sobrevida período pós-natal ${ }^{*}$

* O período pós-natal considerado foi até o momento da alta hospitalar. 
g) Cuidados no período neonatal

a. Berçário de baixo risco

b. Unidade de Terapia Intensiva neonatal (UTI)

i. Tempo de internação na UTI

ii. Necessidade de suporte ventilatório (IOT)

\subsection{6 - Análise estatística}

As informações coletadas foram armazenadas em planilha eletrônica do programa Excel e analisadas por métodos estatísticos, utilizando o programa SPSS 17 (Statistical Package for Social Sciences - Microsoft Corporation, Chicago, Il, USA) e MedCalc 11.6 (Mariakerke, Belgium) para a obtenção dos resultados.

Inicialmente, realizou-se uma análise exploratória dos dados, com a confecção de tabelas de distribuição de frequência e calculo de medidas de tendência central e de dispersão para as variáveis (medida de variabilidade individual). As variáveis numéricas foram resumidas por meio de média e desvio padrão; as variáveis categóricas, pelas de porcentagens.

A normalidade dos dados de cada grupo foi testada pelo teste de ShapiroWilk não se observando nenhum desvio significativo em relação à normalidade entre os grupos.

Para a análise estatística descritiva, foi utilizado o teste de $t$-Students para comparação entre dois grupos e o teste ANOVA (Análise de Variância) para a 
comparação entre mais de duas variáveis contínuas. O teste exato de Fisher foi utilizado para comparação dos dados nominais. Para comparação múltipla, utilizouse o pós-teste de Tukey.

Em todas as etapas da análise foi adotado o nível de significância de 5\% $(p<0,05)$. 


\subsection{7 - Aspectos éticos}

O presente estudo obedeceu aos postulados da Declaração de Helsinque, bem como as normas da Resolução 196/96 do Conselho Nacional de Saúde.

Os exames ultrassonográficos e os procedimentos fetais foram realizados na própria instituição (HCFMUSP), seguindo as normas já existentes para isso (p. ex. preenchimento do Termo de Consentimento Livre e Esclarecido padronizado pela Clínica Obstétrica HCFMUSP prévio a qualquer procedimento invasivo fetal).

O presente estudo foi submetido e aprovado pelo Comitê de Ética em Pesquisa (CAPPesq 0867/08). 
RESULTADOS 


\section{5 - RESULTADOS}

\section{1 - Resultados gerais}

Pesquisando os descritores "hidrotórax", “derrame pleural”, "quilotórax" ou "hidropisia" no banco de dados da Clínica Obstétrica do HCFMUSP, foi constatado a existência de 132 fetos com derrame pleural de etiologia não imune, no período de janeiro de 2005 a julho de 2010. Desse universo, 43 apresentaram malformações estruturais (com cariótipo normal ou desconhecido); 36, alterações no cariótipo (associadas ou não à malformação estrutural); 24, hidrotórax "isolado"; dois, hidrotórax por causa infecciosa (Parvovírus B 19) e 27, hidrotórax sem ter sido a sua etiologia adequadamente investigada (Gráfico 1). Considerou-se hidrotórax sem etiologia adequadamente investigada os casos em que não se obteve o resultado do cariótipo, do ecocardiograma fetal ou das sorologias maternas no banco de dados eletrônico ou em prontuário. 


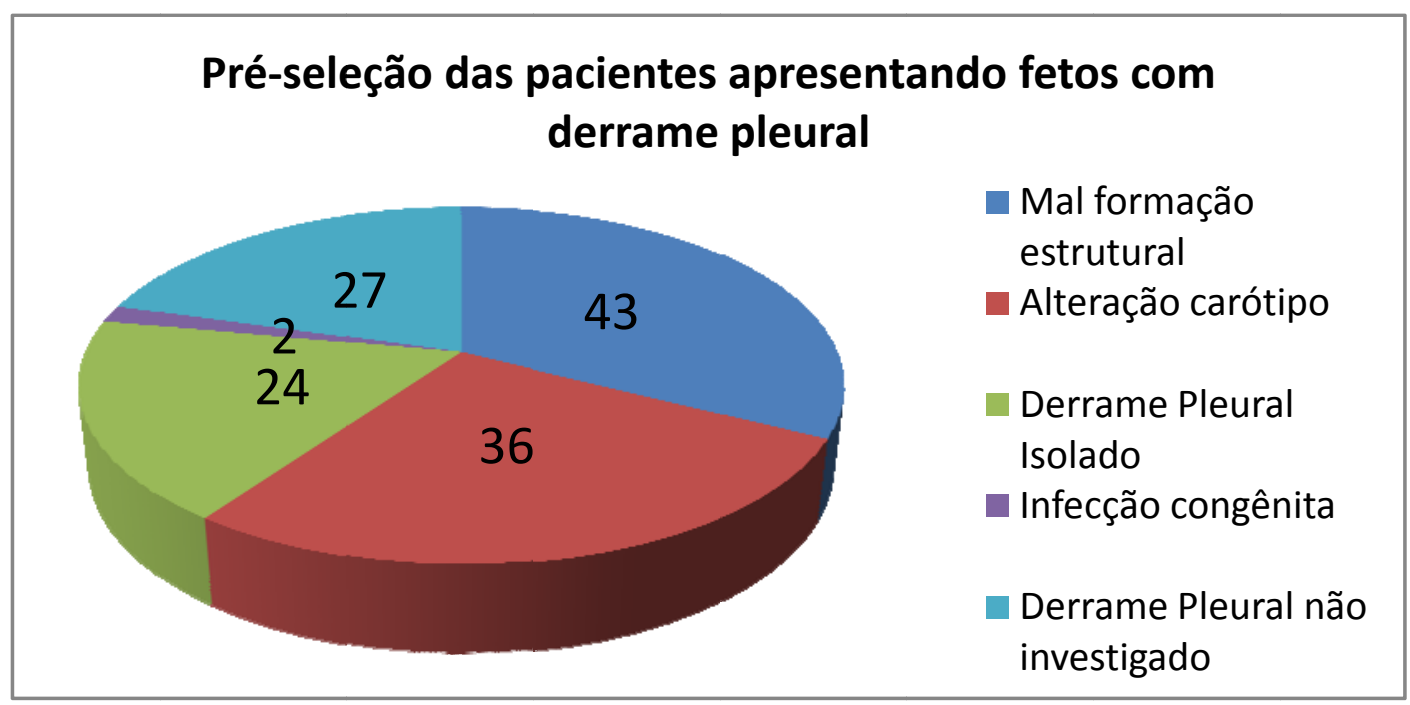

Gráfico 1: Distribuição dos 132 fetos com derrame pleural de etiologia não imune encaminhados ao HCFMUSP, entre janeiro de 2005 a julho de 2010.

Aplicando os critérios de inclusão nos 24 fetos com derrame pleural “isolado", selecionou-se para o presente estudo 19 fetos. Cinco fetos não foram incluídos devido à perda no seguimento pós-natal $(\mathrm{n}=1)$ ou por não terem o volume pulmonar mensurado pela US 3D $(n=4)$. 


\section{2 - Caracterização da amostra estudada}

Foram selecionados 19 fetos para participar do presente estudo. As características maternas e obstétricas da amostra estudada estão apresentadas na Tabela 2.

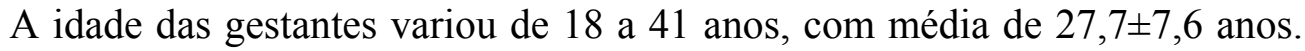
O número de gestações variou de um a seis, com média de $2,2 \pm 1,5$. Houve um caso de gestação gemelar dicoriônica diamniótica (paciente $n^{0} 5$ - Anexo C), em que o derrame acometeu apenas um dos fetos. Apenas duas (10,5\%) das 19 pacientes apresentavam fator $\mathrm{Rh}$ negativo e necessitaram receber imunoglobulina anti-D, imediatamente após a realização dos procedimentos invasivos.

A pesquisa do cariótipo foi realizada no líquido amniótico (amniocentese) em $11(57,9 \%)$ casos e no sangue fetal (por cordocentese) em 07 (36,9\%) fetos. Houve um $(5,3 \%)$ caso em que se optou por analisar o cariótipo em duplo sítio de punção, sendo confirmada sua normalidade no líquido pleural (toracocentese) bem como no líquido amniótico (amniocentese) (Tabela 2).

A idade gestacional média do diagnóstico de derrame pleural foi de 25,2 semanas (variando de 16,4 a 31,4 semanas) e a idade gestacional média da primeira ultrassonografia realizada no HCFMUSP foi de 26,0 semanas (variando de 18,3 a 31,4 semanas) (Tabela 2).

Os achados da primeira ecografia no HCFMUSP mostraram $10(52,6 \%)$ fetos com derrame pleural "isolado" bilateral, 12 (63,2\%), apresentando hidropisia e 09 
(47,4\%), gestações com poli-hidrâmnio. Todos os fetos com a bilateralidade do derrame pleural apresentavam hidropisia no momento do diagnóstico, porém nem todos os casos de hidropisia apresentavam bilateralidade (02 fetos eram hidrópicos com importante derrame pleural unilateral). Dos nove casos de derrame pleural unilateral, cinco $(55,6 \%)$ localizavam à esquerda e quatro $(43,4 \%)$ à direita da cavidade torácica. Dos fetos acometidos, sete $(36,8 \%)$ eram do sexo masculino e 12 (63,2\%), feminino (Tabela 2).

A via de parto foi predominantemente cesariana, ocorrendo em $11(57,8 \%)$ casos. As indicações para a cesariana foram: duas por iteratividade, quatro por comprometimento na vitalidade fetal, uma por se tratar de uma gestação gemelar com um dos fetos em situação transversa, uma por desproporção céfalo-pélvica e três cesarianas com as indicações não bem definidas (p. ex. feto com derrame pleural, amniorrexe prematura). Dos oito partos via baixa, quatro foram induzidos quando constatado previamente o óbito fetal.

Dos 19 casos, $14(73,7 \%)$ partos ocorreram no HCFMUSP, sendo sete normais (quatro óbitos fetal) e sete cesarianas (quatro por comprometimento da vitalidade fetal, um por gestação gemelar com um dos fetos em situação transversa, uma desproporção céfalo-pélvica e um parto por iteratividade).

A corticoterapia antenatal foi indicada em quatro casos pelo risco da prematuridade em gestações com idade gestacional inferior a 34 semanas, com o ciclo completo realizado em apenas três desses (paciente número 07, 10, 14 - Anexo C). Houve a necessidade de antecipar o parto em um dos quatro casos (paciente $16-$ Anexo C) em virtude do comprometimento da vitalidade fetal. 
Tabela 2: Características do grupo de estudo $(\mathrm{n}=19)$

\begin{tabular}{|c|c|}
\hline Características & Valor \\
\hline Idade Materna (anos) & $27,7(18-41)$ \\
\hline Paridade & $2,2(1-6)$ \\
\hline Gestação Gemelar & $1(5,2 \%)$ \\
\hline Fator Rh negativo (materno) & $2(10,5 \%)$ \\
\hline \multicolumn{2}{|l|}{ Cariótipo } \\
\hline Líquido Amnitótico & $11(57,9 \%)$ \\
\hline Sangue Fetal & $7(36,9 \%)$ \\
\hline Líquido amniótico e líquido pleural & $1(5,3 \%)$ \\
\hline IG diagnóstico (semanas) & $25,2(16,4-31,4)$ \\
\hline IG $1^{\circ}$ US HC-FMUSP (semanas) & $26,0(18,3-31,4)$ \\
\hline \multicolumn{2}{|l|}{ Achados da $1^{\circ}$ US - HCFMUSP } \\
\hline Bilateralidade & $10(52,6 \%)$ \\
\hline Unilateral & $9(47,4 \%)$ \\
\hline Esquerda & $5(55,5 \%)$ \\
\hline Direita & $4(44,5 \%)$ \\
\hline Hidropisia & $12(63,2 \%)$ \\
\hline Poli-hidrâmnio & $9(47,4 \%)$ \\
\hline Sexo fetal (Masculino: Feminino) & $7: 12$ \\
\hline Via de parto (Cesariana : Via baixa) & $11: 8$ \\
\hline Local do parto (HCFMUSP : Outros) & $14: 5$ \\
\hline
\end{tabular}

Dados são descritos em média (variação), $n$ (\%) ou razão. 
Dos 19 fetos portadores de derrame pleural "isolado" submetidos a tratamento intrauterino, nove $(47,4 \%)$ foram submetidos à toracocentese e 10 $(52,6 \%)$ à derivação tóraco-amniótica (com ou sem a toracocentese prévia). Ocorreu o óbito de dois fetos hidrópicos antes da inserção do "shunt" tóraco-amniótico programado. Nenhum "shunt" tóraco-amniótico foi inserido sem o resultado prévio do cariótipo. A idade gestacional média para a toracocentese foi de 27,6 semanas (variando de 20 a 33,0 semanas) e para a derivação tóraco-amniótica foi de 27,1 semanas (variando de 23,6 a 31,1 semanas).

$\mathrm{Na}$ ultrassonografia realizada antes do parto, observou-se que o derrame pleural desapareceu completamente em seis $(31,6 \%)$ casos; a hidropisia reduziu de $12(63,2 \%)$ para $10(52,6 \%)$ fetos; a bilateralidade do derrame reduziu de $10(52,6 \%)$ para nove $(47,4 \%)$ casos; e o poli-hidrâmnio reduziu de nove $(47,4 \%)$ para seis $(31$, $6 \%$ ) após o tratamento (Tabela 3$)$. Seis $(60 \%)$ dos 10 casos que receberam o cateter tóraco-amniótico sobreviveram. 


\section{3 - Predição da mortalidade perinatal em fetos com derrame pleural} “isolado” pelo volume pulmonar

Dos 19 fetos com derrame pleural "isolado" submetidos a tratamento, sete (36,8\%) evoluíram a óbito e $12(63,2 \%)$ sobreviveram (Tabela 3). Dos que foram a óbito, quatro ocorreram intraútero e três no período neonatal. Em todos eles, a hipoplasia pulmonar foi confirmada pela necropsia. Os fetos sobreviventes receberam alta hospitalar sem a necessidade imediata de suporte ventilatório com oxigênio, realizando acompanhamento com a equipe da Pediatria no pós-natal. (Gráfico 2).

A predição da mortalidade ou da hipoplasia pulmonar não foi possível quando se analisou o $1^{\circ}$ VPT o/e. Não se observou diferença estatisticamente significante entre as razões médias do $1^{\circ} \mathrm{VPT}$ o/e para estabelecimento do prognóstico fetal entre os fetos que apresentaram óbito intraútero $(0,26 \pm 0,03)$, óbito neonatal $(0,34 \pm 0,12)$ e os que sobreviveram no período perinatal $(0,42 \pm 0,18 ; p=0,24)$ (Gráfico 3).

Quando agrupados os óbitos intraúteros e neonatais, observa-se que o $1^{\circ} \mathrm{VPT}$ o/e também não foi estatisticamente significante para predizer o desfecho perinatal, apresentando a média de $0,29 \pm 0,08$ para os casos que foram a óbito contra a média de $0,42 \pm 0,18$ ( $\mathrm{p}=0,11)$, para o os fetos que sobreviveram (Gráfico 4 e Tabela 3 ). 


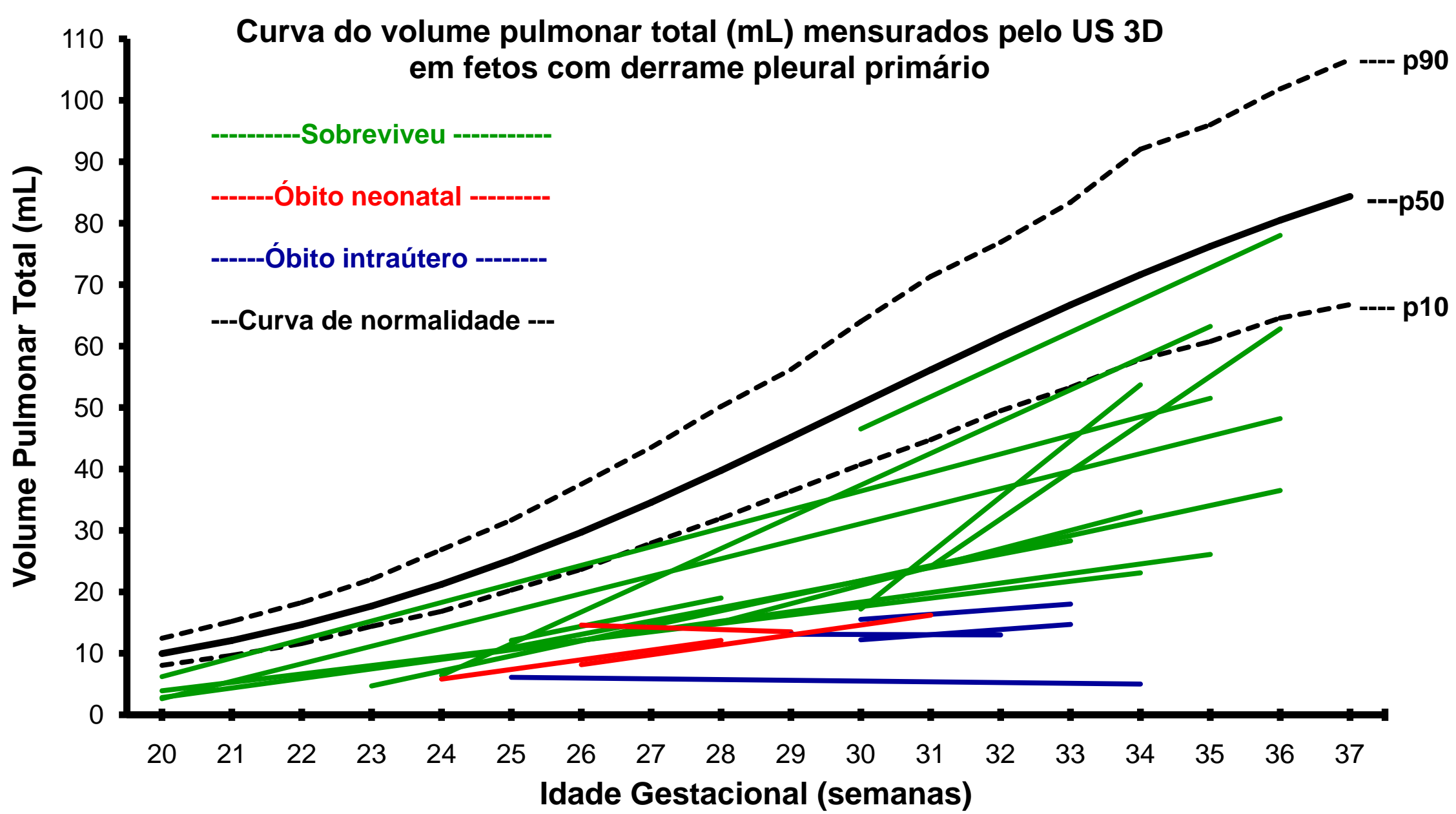

Gráfico 2: Volume pulmonar total mensurado (no diagnóstico e próximo ao parto) utilizando o US 3D em fetos com derrame pleural

“isolado" plotados na curva de normalidade para volume pulmonar fetal em cada idade gestacional publicada por Ruano et al ${ }^{169}$. 


\section{Razão entre o volume pulmonar total observado / esperado (VPT o/e) de fetos com derrame pleural "isolado"}

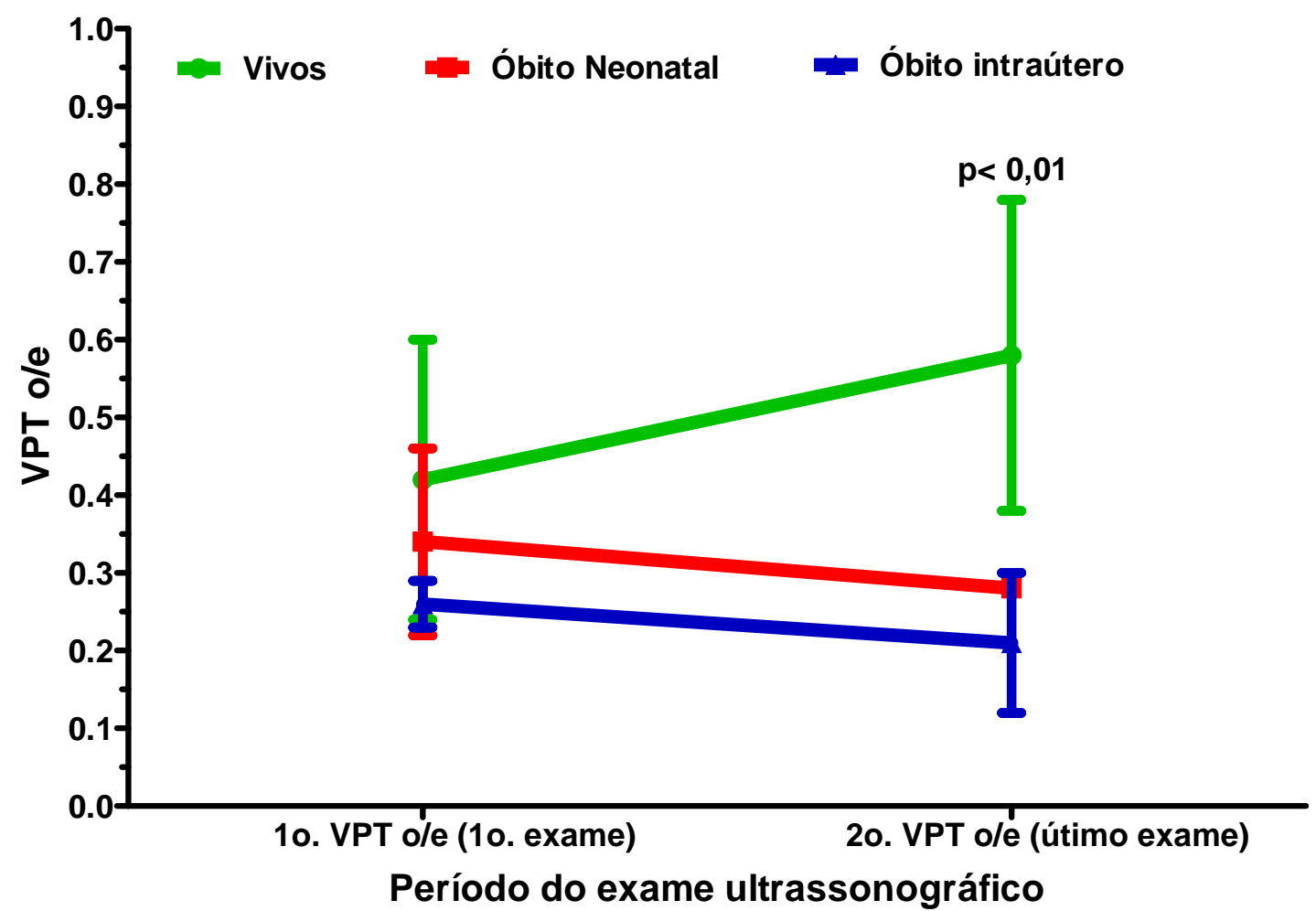

Gráfico 3: Evolução da razão entre o volume pulmonar observado sobre o volume pulmonar esperado (VPT o/e) estimados pela US 3D no momento do diagnóstico ( $1^{\circ}$. VPT o/e) e próximo ao parto ( $2^{\circ}$. VPT o/e) em fetos sobreviventes, fetos com óbito intraútero e neonatal portadores de derrame pleural "isolado". 
Razão entre o volume pulmonar total observado / esperado (VPT ole) de fetos com derrame pleural "isolado" (sobreviventes X não sobreviventes)

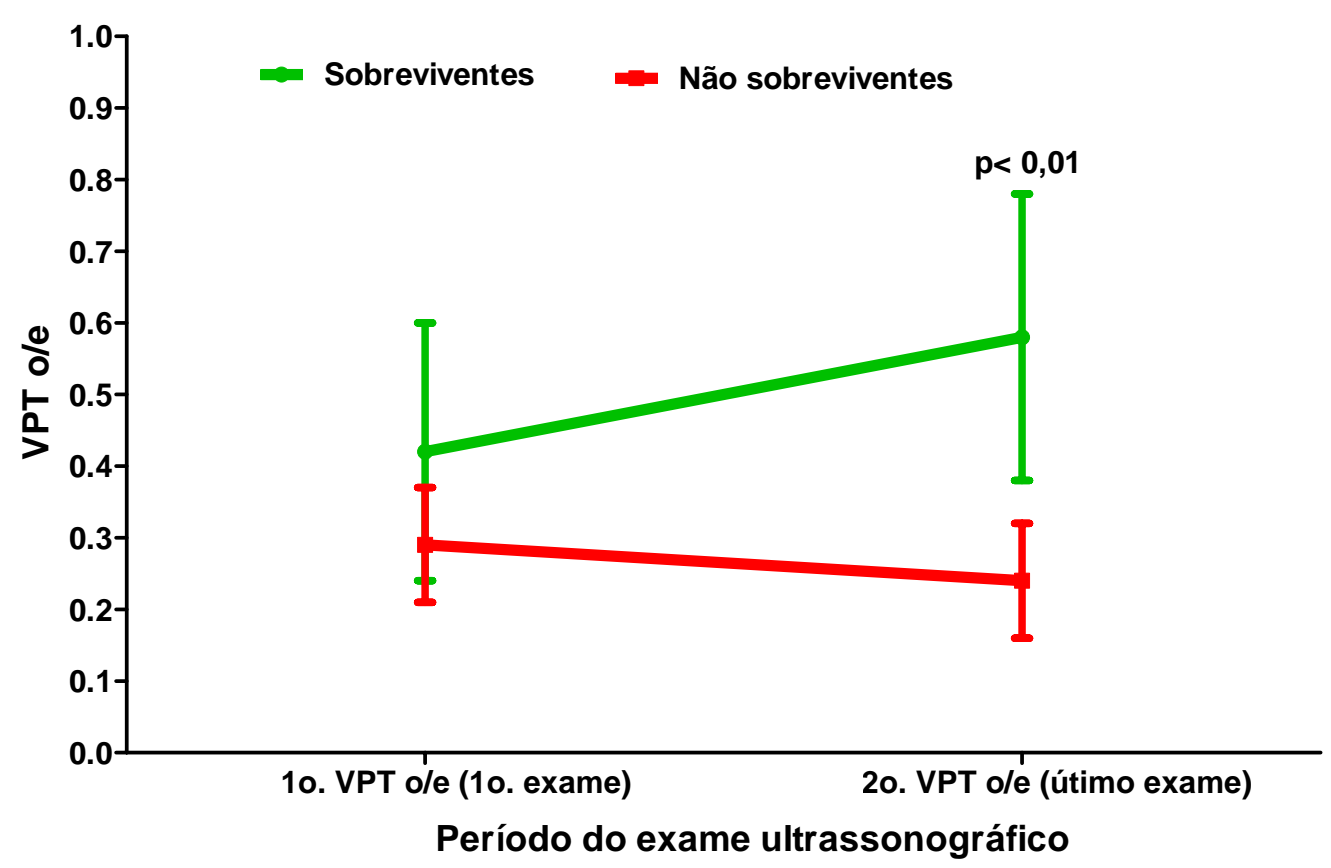

Gráfico 4: Evolução da razão entre o volume pulmonar observado sobre o volume pulmonar esperado (VPT o/e) estimados pela US 3D no momento do diagnóstico $\left(1^{\circ}\right.$ VPT o/e) e próximo ao parto $\left(2^{\circ} \mathrm{VPT}\right.$ o/e $)$ em fetos sobreviventes e não sobreviventes portadores de derrame pleural "isolado". 
Entretanto, observa-se que o $2^{\circ}$ VPT o/e (último US 3D realizado antes do parto) pode predizer a gravidade do desfecho e indiretamente o grau de hipoplasia pulmonar. Nota-se que o mesmo foi significativamente menor nos casos com óbito intraútero $(0,21 \pm 0,09)$ e óbito neonatal $(0,28 \pm 0,01)$ quando comparados com os fetos sobreviventes $(0,58 \pm 0,20 ; p<0,01)$ (Gráfico 3).

De forma semelhante, quando agrupados os óbitos intraúteros e neonatais, observa-se que o $2^{\circ} \mathrm{VPT}$ o/e foi significativamente menor nos sete casos que não sobreviveram $(0,24 \pm 0,08)$ quando comparados com os 12 fetos sobreviventes $(0,58 \pm 0,20 ; \mathrm{p}<0,01)$ (Gráfico 4 e Tabela 3).

Em uma análise mais específica, observa-se que todos os fetos que tiveram valores do $2^{\circ} \mathrm{VPT}$ o/e inferior a 0,33 morreram e os fetos com valores do $2^{\circ} \mathrm{VPT}$ o/e superiores a 0,33 sobreviveram $(\mathrm{p}<0,01)$ (linha tracejada vermelha do Gráfico 5).

Quando subtraído o $2^{\circ}$ VPT o/e do $1^{\circ}$ VPT o/e $(\Delta V P T$ o/e) para cada caso, observa que os fetos sobreviventes apresentam maior média do $\triangle \mathrm{VPT}$ o/e quando comparados com os fetos não sobreviventes ( $\triangle \mathrm{VPT}$ sobreviventes $=0,16 \pm 0,05$ contra $\triangle$ VPT não sobreviventes $=-0,05 \pm 0,03, \mathrm{p}<0,01$, respectivamente) (Gráfico 6).

Observou-se que os fetos não sobreviventes apresentaram pequenas variações entre o $1^{\circ} \mathrm{VPT}$ o/e e o $2^{\circ} \mathrm{VPT}$ o/e com curvas decrescentes para a evolução da razão entre o volume pulmonar (Gráfico 3 e 4). 
Predição do óbito perinatal pelo volume pulmonar (20. VPT ole) em fetos com derrame pleural "isolado"

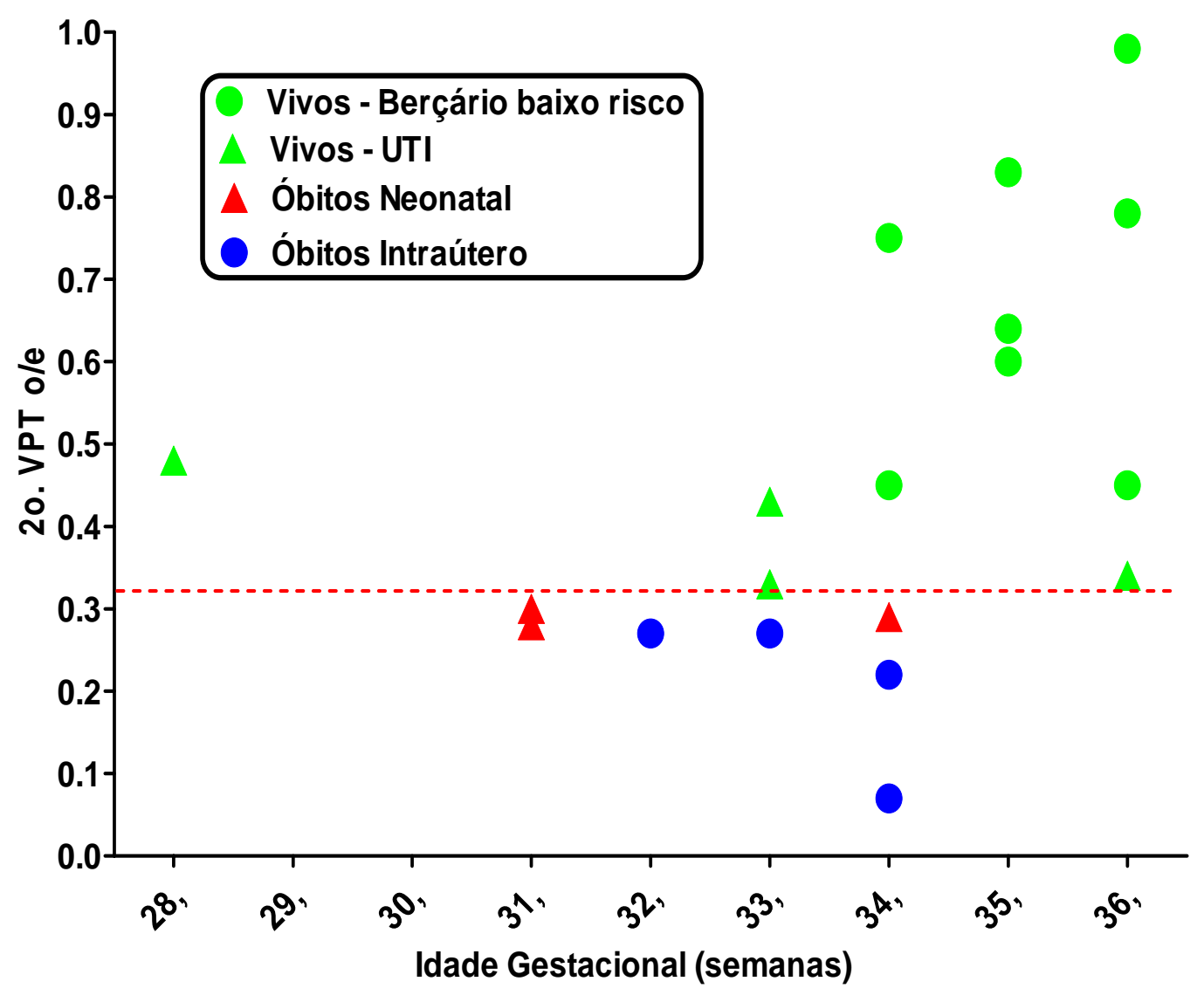

Gráfico 5: Dispersão da razão entre o $2^{\circ}$ volume pulmonar observado /esperado $\left(2^{\circ}\right.$ VPT o/e) pela idade gestacional e o desfecho perinatal em fetos portadores de derrame pleural "isolado". 

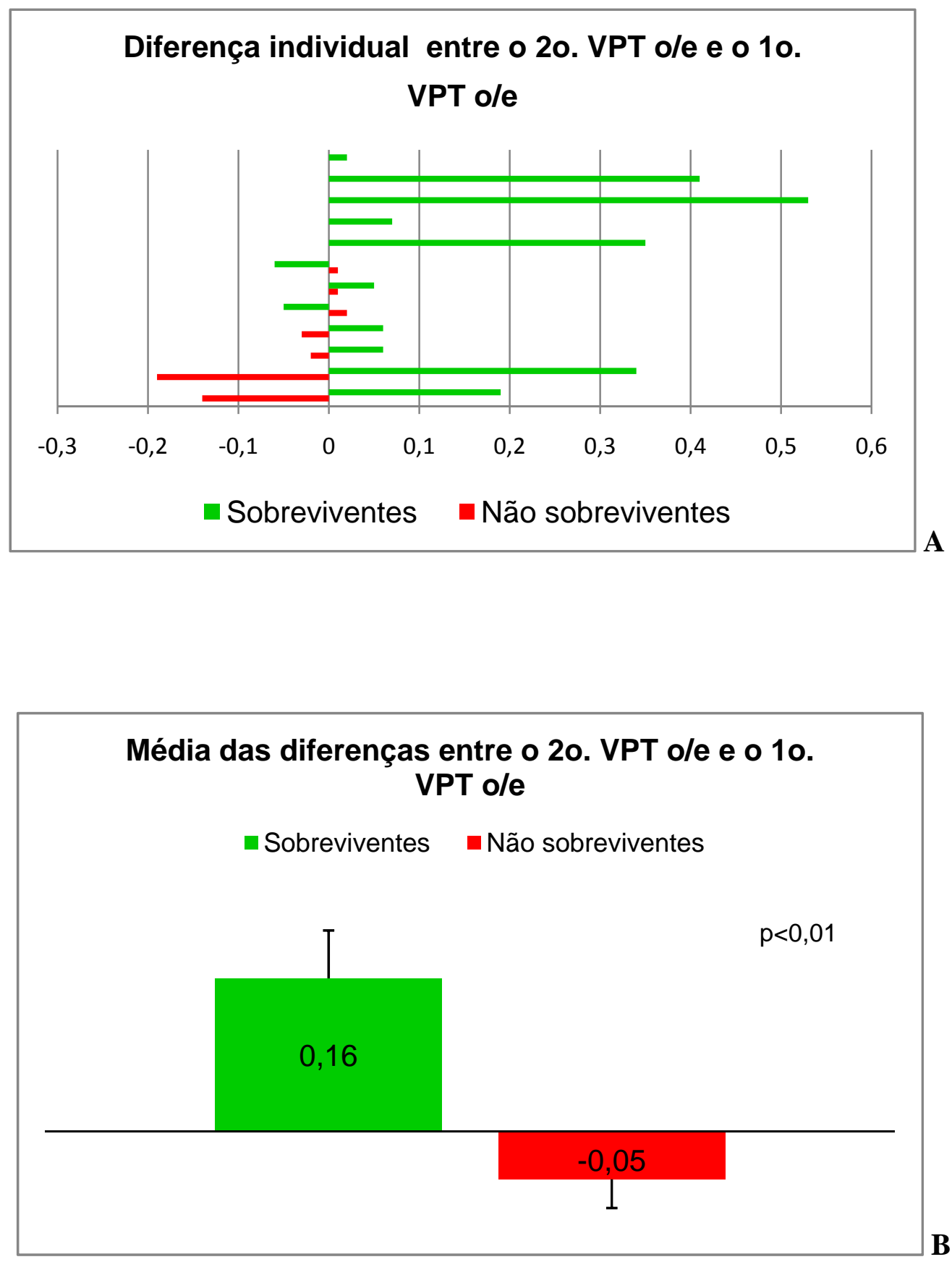

Gráfico 6: Diferença numérica entre o $2^{\circ} \mathrm{VPT}$ o/e do $1^{\circ} \mathrm{VPT}$ o/e $(\Delta \mathrm{VPT}$ o/e) nos fetos com derrame pleural "isolado". (A) $\triangle \mathrm{VPT}$ o/e para cada caso. (B) Média do $\Delta \mathrm{VPT}$ o/e para os fetos sobreviventes x não-sobreviventes. 
Tabela 3: Características obstétricas e ultrassonográficas de acordo com a sobrevida perinatal em fetos com derrame pleural "isolado"

Fetos com derrame pleural “isolado”

Óbito $(n=7) \quad$ Vivos $(n=12) \quad p$

\begin{tabular}{|c|c|c|c|}
\hline IG diagnóstico (semanas) & $26,9 \pm 4,0$ & $24,2 \pm 5,6$ & 0.27 \\
\hline Idade materna (anos) & $30,9 \pm 7,8$ & $25,9 \pm 7,3$ & 0,18 \\
\hline IG $1^{\circ}$ US (semanas) & $27,9 \pm 3,1$ & $24,9 \pm 4,8$ & 0,16 \\
\hline Bilateralidade $1^{\circ}$ US $(n=10)$ & $7(100.0 \%)$ & $3(25.0 \%)$ & $<0.01^{*}$ \\
\hline Hidropisia $1^{\circ}$ US ( $\left.n=12\right)$ & $7(100.0 \%)$ & $5(41.7 \%)$ & $0.02 *$ \\
\hline Poli-hidrâmnio $1^{o}$ US $(n=9)$ & $5(71.4 \%)$ & $4(33.3 \%)$ & 0.17 \\
\hline $1^{o} \mathrm{VPT}$ o/e & $0.29 \pm 0.08$ & $0.42 \pm 0.18$ & 0.11 \\
\hline Desaparecimento do DP $(n=6)$ & 0 & $6(50.0 \%)$ & $0,04 *$ \\
\hline Bilateralidade $2^{\circ}$ US $(n=9)$ & $7(100 \%)$ & $2(16.7 \%)$ & $<0.01^{*}$ \\
\hline Hidropisia $2^{o}$ US $(n=10)$ & $7(100 \%)$ & $3(25.0 \%)$ & $<0,01^{*}$ \\
\hline Poli-hidrâmnio $2^{o}$ US $(n=6)$ & $5(71,42 \%)$ & $1(8,3 \%)$ & $0,01 *$ \\
\hline $2^{o} \mathrm{VPT} \mathrm{o} / \mathrm{e}$ & $0.24 \pm 0.08$ & $0.58 \pm 0.20$ & $<0.01^{*}$ \\
\hline IG parto (semanas) & $32,4 \pm 1,9$ & $37,2 \pm 3,5$ & $<0,01^{*}$ \\
\hline Peso ao nascimento (gramas) & $2587.7 \pm 676.5$ & $2833.6 \pm 790.9$ & 0.53 \\
\hline
\end{tabular}




\section{4 - Predição da necessidade de UTI Neonatal / Suporte Ventilatório pelo volume pulmonar em fetos com derrame pleural "isolado"}

Dos 15 recém-natos portadores de derrame pleural "isolado" (excluindo quatro casos que evoluíram ao óbito fetal), 11 (73,3\%) nasceram de parto cesariana e quatro $(26,7 \%)$, de parto normal. Oito $(53,3 \%)$ foram encaminhados ao berçário de baixo risco e sete $(46,7 \%)$, à Unidade Terapêutica Intensiva Neonatal (UTI). Dos encaminhados à UTI todos necessitaram receber oxigênio suplementar por meio da intubação oro-traqueal (IOT) como estratégia inicial de tratamento. O Apgar do $5^{\circ}$ minuto foi menor que 5 em cinco $(33,3 \%)$ dos 15 casos, sendo que apenas dois $(40 \%)$ sobreviveram.

Dos sete RNs encaminhados à UTI, três $(42,9 \%)$ vieram a óbito nas primeiras 48 horas de vida e quatro $(57,1 \%)$ sobreviveram. O tempo de internação médio na UTI para os RNs que sobreviveram foi de 38,5 dias (variando de 14 a 60 dias) com necessidade de 18,7 dias ( 7 - 40) de IOT. Em nenhum caso houve a necessidade de otimizar o tratamento para o derrame pleural com nutrição parenteral especial. Nenhum dos oito RNs encaminhados ao berçário de baixo risco apresentou complicações no período neonatal.

Quando analisada a idade gestacional do parto observa-se que esta foi significativamente menor no grupo encaminhado à UTI (média: 32,8 $\pm 3,6$ semanas) em relação ao grupo encaminhado ao berçário de baixo risco (média 38,7 $\pm 1,8$ semanas, $\mathrm{p}<0,01)$. Quando divididos os grupos entre sobreviventes e não sobreviventes, no período neonatal, observa-se que a prematuridade foi importante 
para o desfecho negativo (IG parto sobrevivente: $37,2 \pm 3,5$ semanas e IG parto óbito neonatal: $31,0 \pm 1,7$ semanas, $\mathrm{p}=0,01)$.

A análise dos volumes pulmonares, permitiu observar que $1^{\circ}$. VPT o/e não se

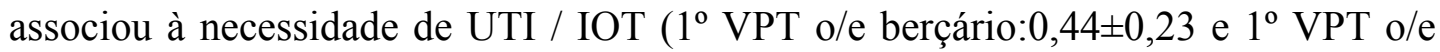
UTI/IOT: $0,37 \pm 0,10 ; p=0,50)$. Já o $2^{\circ} \mathrm{VPT}$ o/e mostrou-se importante na predição dos fetos que necessitariam de UTI/IOT demonstrada pela redução do $2^{\circ}$. VPT o/e $(0,35 \pm 0,07)$ quando comparado com os $\mathrm{RNs}$ encaminhados ao berçário de baixo risco $\left(2^{\circ}\right.$ VPT o/e $\left.0,68 \pm 0,18 ; p<0,01\right)$ (Gráfico 7).

Em relação ao $2^{\circ}$. VPT o/e dos 12 fetos sobreviventes, notou-se que todos apresentavam o $2^{\circ}$. VPT o/e entre 0,33 e 0,98 . Observou-se que aqueles recémnascidos que necessitaram de IOT e UTI, no período neonatal, apresentavam o $2^{\circ}$. VPT o/e entre 0,33 e 0,48 . Todos os fetos que foram encaminhados para o berçário de baixo risco apresentavam o $2^{\circ}$. VPT o/e acima de 0,45 (linha tracejada vermelha do Gráfico 8). Nesta casuística, apenas um RN que apresentava o $2^{\circ} \mathrm{VPT}$ o/e acima de 0,45 necessitou de UTI / IOT, provavelmente devido a sua prematuridade (IG parto $=28$ semanas - paciente $\mathrm{n}^{\circ} 07-$ Anexo C) (Gráfico 8) 
Avaliação do volume pulmonar observado / esperado (VPT ole) em fetos com derrame pleural "isolados" associado à morbidade respiratória

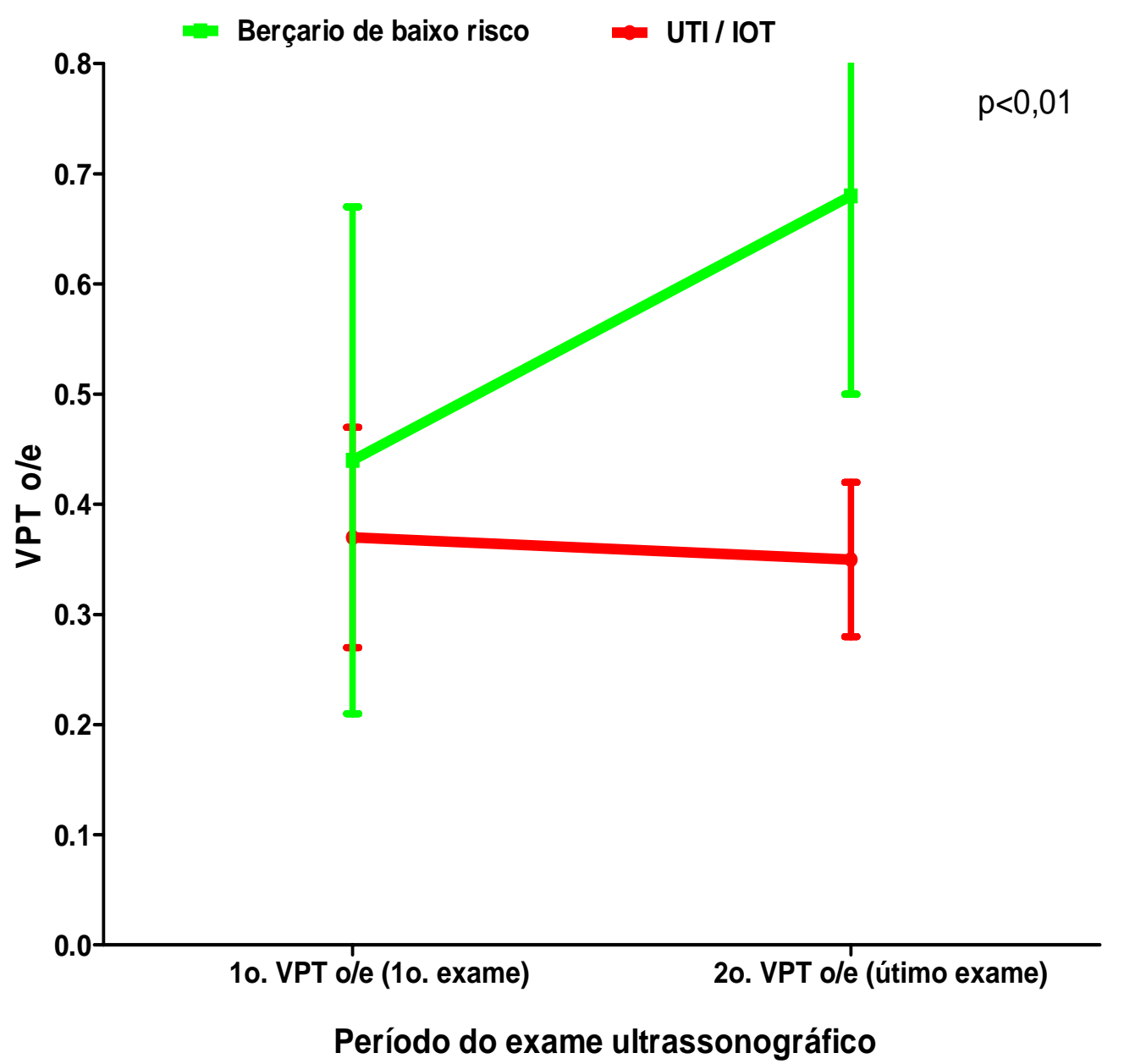

Gráfico 7: Variação do volume pulmonar observado /esperado em fetos com derrame pleural "isolado" associados à morbidade respiratória. 
Predição da necessidade de UTI Neonatal / IOT pelo volume pulmonar

(2o. VPT ole) em fetos com derrame pleural "isolado"

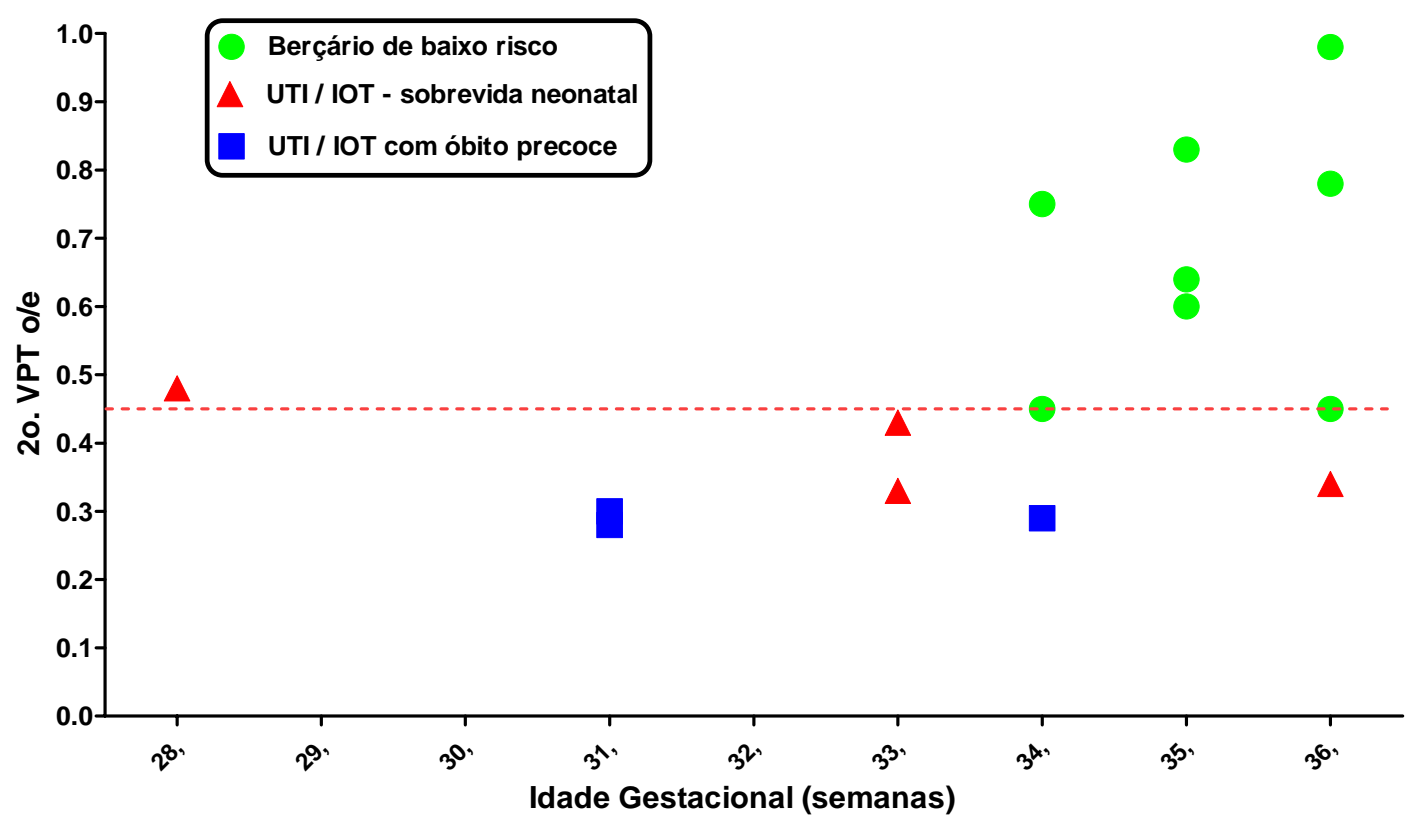

Gráfico 8: Dispersão da razão entre o $2^{\circ}$ volume pulmonar observado /esperado $\left(2^{\circ}\right.$ VPT o/e) pela idade gestacional e mortalidade perinatal em fetos portadores de derrame pleural "isolado". 
Tabela 4: Características obstétricas e perinatais relacionadas à morbidade pós-natal em 15 recém-nascidos com derrame pleural "isolado"

\section{RN que necessitaram de UTI / IOT}

\begin{tabular}{|c|c|c|c|}
\hline & Não (n=8) & $\operatorname{Sim}(n=7)$ & $p$ \\
\hline IG diagnóstico (semanas) & $25,3 \pm 5,7$ & $22,6 \pm 4,1$ & 0,32 \\
\hline Idade materna (anos) & $26.0 \pm 8.1$ & $26.0 \pm 4.9$ & 1.00 \\
\hline IG $1^{\circ}$ US (semanas) & $26,0 \pm 5,0$ & $23,7 \pm 3,2$ & 0,30 \\
\hline Bilateralidade $1^{\circ}$ US $(n=6)$ & $3(37.5 \%)$ & $3(42.9 \%)$ & 1.00 \\
\hline Hidropisia $1^{o}$ US $(n=8)$ & $3(37.5 \%)$ & $5(71.4 \%)$ & 0.32 \\
\hline Poli-hidrâmnio $1^{\circ}$ US $(n=6)$ & $3(37.5 \%)$ & $3(42.9 \%)$ & 1.00 \\
\hline $1^{o} \mathrm{VPT}$ o/e & $0.44 \pm 0.23$ & $0.37 \pm 0.10$ & 0.50 \\
\hline Desaparecimento do DP $(n=6)$ & $5(62,5 \%)$ & $1(14,28 \%)$ & 0.12 \\
\hline Bilateralidade $2^{\circ}$ US $(n=5)$ & $2(25.0 \%)$ & $3(42.9 \%)$ & 0.61 \\
\hline Hidropisia $2^{\circ}$ US $(n=6)$ & $1(12.5 \%)$ & $5(71.4 \%)$ & $0.04 *$ \\
\hline Poli-hidrâmnio $2^{o}$ US $(n=3)$ & $1(12.5 \%)$ & $2(28.6 \%)$ & 0.57 \\
\hline $2^{o} \mathrm{VPT}$ o/e & $0.68 \pm 0.18$ & $0.35 \pm 0.07$ & $<0.01 *$ \\
\hline IG parto (semanas) & $38.7 \pm 1.8$ & $32.8 \pm 3.6$ & $<0.01^{*}$ \\
\hline Peso ao nascimento (gramas) & $3245.0 \pm 304.3$ & $2442.0 \pm 878.3$ & $0.03 *$ \\
\hline
\end{tabular}




\section{5 - Volume pulmonar fetal e outros fatores preditores do prognóstico perinatal em fetos com derrame pleural “isolado"}

Outros parâmetros ecográficos podem nos fornecer informações importantes a respeito da gravidade e possíveis predições quanto ao derrame pleural "isolado".

A primeira ultrassonografia (ultrassonografia diagnóstica) já nos fornece parâmetros importantes quanto à gravidade e possíveis desfechos negativos que poderão advir nos fetos com derrame pleural. Observou-se que a presença do derrame pleural bilateral e da hidropisia identificados no momento do diagnóstico $\left(1^{\circ}\right.$. VPT o/e) está associada a maiores taxas de mortalidade perinatal $(\mathrm{p}<0,01 \mathrm{e}$ $\mathrm{p}=0,02$, respectivamente) (Tabela 3 ).

Já a ultrassonografia realizada próxima ao parto (entre 28 - 36 semanas) forneceu uma quantidade maior de parâmetros ecográficos associados ao prognóstico dos recém-natos. Verificou-se que além da bilateralidade e da hidropisia ( $p<0,01$ e $p=0,02$, respectivamente), a presença de poli-hidrâmnio e da prematuridade $(p<0,01$ e $p<0,01)$ esteve associada significativamente aos piores resultados. Nota-se também que o desaparecimento do derrame pleural $(\mathrm{p}=0,04)$ está associado à maior taxa de sobrevida no período neonatal.

Quanto à necessidade de UTI / IOT, observa-se que além dos marcadores indiretos para hipoplasia pulmonar (diminuição do $2^{\circ} \mathrm{VPT}$ o/e), a hidropisia $(\mathrm{p}=0,04)$ e a prematuridade $(\mathrm{p}<0,01)$ são fatores agravantes das morbidades respiratórias no período perinatal (Tabela 4). 
Ao correlacionar todos esses parâmetros, observa-se que o $2^{\circ}$ VPT o/e está estatisticamente associado à hidropisia $(\mathrm{p}<0.01)$, à bilateralidade do derrame $(\mathrm{p}=0.01)$ e ao poli-hidrâmnio $(p=0.01)($ Tabela 5$)$.

Tabela 5: Associação entre o volume pulmonar fetal próximo ao parto e outros achados ultrassonográficos em 19 fetos com derrame pleural "isolado".

$2^{\circ}$ VPT o/e p

\begin{tabular}{lccc}
\hline Hidropisia fetal & Sim & $0,28 \pm 0,10$ & \\
& & & \\
& Não & $0,65 \pm 0,20$ & $<0,01$ \\
Derrame Pleural Bilateral & Sim & $0.31 \pm 0.18$ & \\
& Não & $0.59 \pm 0.21$ & 0.01 \\
\hline Poli-hidrâmnio & Sim & $0.26 \pm 0.10$ & \\
& & & \\
& Não & $0.55 \pm 0.23$ & 0.01 \\
\hline Desaparecimento do & Sim & $0.61 \pm 0.19$ & \\
derrame pleural & & & \\
& Não & $0.39 \pm 0.24$ & 0.07 \\
\hline
\end{tabular}

Dados são descritos em média ( \pm desvio padrão) 


\section{DISCUSSÃO}




\section{DISCUSSÃO}

$\mathrm{Na}$ avaliação de fetos com derrame pleural há dois desafios. O primeiro é identificar a etiologia do derrame. O segundo é estimar o prognóstico para cada feto.

Sabe-se que o prognóstico fetal está intimamente relacionado com a causa base e que os derrames associados à malformação estrutural e /ou cromossomopatia apresentam os piores resultados. ${ }^{4,16,52}$

Entretanto, desafio maior é estimar o prognóstico em fetos com derrame pleural sem etiologia identificável, definidos neste estudo por fetos com derrame pleural "isolado". A estimativa do prognóstico nesse grupo é de fundamental importância, visto que poderá haver fetos que se beneficiem do tratamento, alterando a sua história desfavorável. ${ }^{3,18,56,106,171}$

Estudos anteriores demonstraram que a hidropisia fetal é a principal causa de mortalidade no período perinatal ${ }^{3,17}$. Estudos mais recentes apontam a hipoplasia pulmonar associada à hipertensão pulmonar e / ou prematuridade como importantes causas de mortalidade no período pós-natal. ${ }^{15,56,88}$

Dessa forma, a estimativa do volume pulmonar é de fundamental importância para estabelecimento do prognóstico nos fetos com derrame pleural "isolado", visto que auxilia na assistência pré-natal, no aconselhamento aos pais, na tomada de decisão em se realizar o tratamento fetal e no planejamento da assistência neonatal.

Para isso, a ultrassonografia tridimensional tem se mostrado cada vez mais presente no aconselhamento nos casos de fetos com risco para hipoplasia pulmonar. Essa experiência foi adquirida com os estudos de fetos com hérnia diafragmática 
congênita "isolada", que é a doença mais prevalente para a hipoplasia pulmonar ${ }^{34,153}$. Porém, essa ferramenta diagnóstica (US 3D) nunca foi estudada para a predição da hipoplasia pulmonar nos fetos com derrame pleural "isolado".

Assim, o presente estudo se propôs a demonstrar que o volume pulmonar fetal estimado pela US 3D pode ser útil na predição da morbidade e mortalidade perinatal em fetos com derrame pleural "isolado". Além disso, também analisou a relação entre o volume pulmonar reduzido (hipoplasia pulmonar) com outros critérios de gravidade já estabelecidos, tais como a hidropisia fetal e a bilateralidade. ${ }^{3,18,56,106,171}$

\section{Caracterização da amostra estudada}

A principal característica da amostra estudada foi a rigorosa seleção de fetos com derrame pleural "isolado". A grande vantagem dessa seleção se faz pela possibilidade de avaliar os fatores prognósticos intrínsecos da história natural do derrame pleural "isolado" (hidropisia e bilateralidade), relacionando-os com outro fator prognóstico conhecido, mas ainda não estimado, que é a hipoplasia pulmonar.

Além disso, há de se levar em conta que na casuística deste trabalho, não houve interferências, tais como a interrupção da gestação (fato este verificado em muitos trabalhos da literatura), não permitida pelas leis brasileiras para esses casos, o que faz com que sejam incluídos, no presente estudo, alguns fetos com prognóstico bastante reservado. Isso pôde ser observado pela ocorrência de dois óbitos fetais, antes mesmo de receberem o tratamento mais indicado (derivação tóraco-amniótica) e pelo predomínio de fetos hidrópicos (12 entre os 19 selecionados) no número total de casos. 
Outro fato importante que se deve destacar é que a casuística deste trabalho é diferenciada em relação à da maioria das publicações literárias sobre o derrame pleural fetal, visto que elas geralmente avaliam o prognóstico em fetos com derrame pleural "primário", que, por vezes é referido inadequadamente por quilotórax fetal. Os estudos do derrame pleural "isolado" devem ser diferenciados das publicações do derrame pleural primário, para evitar possíveis vieses na interpretação dos resultados. Sabe-se que o derrame pleural primário apresenta como critério diagnóstico o predomínio de linfócitos na celularidade do líquido pleural (acima de 70 a $80 \%$ de linfócitos), na ausência de processo infeccioso materno ou fetal; enquanto o derrame pleural "isolado" é definido por ausência de alterações estruturais, cromossômica, infecções e causas imunes ${ }^{3,15}$. Dessa forma, observa-se que muitos trabalhos da literatura discorrem sobre o prognóstico nos fetos com derrame pleural primário, incluindo, em sua casuística, fetos com alterações estruturais ou cromossômicas. Essas alterações são sabidamente fatores preditores de piores resultados ${ }^{16,50}$. Assim, deve-se ter cautela ao analisar os estudos de derrame pleural primário, para não incluir os fetos com anomalias estruturais ou cromossômicas, quando for comparálos com os estudos de derrame pleural "isolado".

Outro termo encontrado em publicações literárias, utilizado como sinônimo de derrame pleural fetal primário é o quilotórax fetal ${ }^{26,96,108,110,113,115}$, que, a nosso ver, não deve ser utilizado, visto que a formação do quilo só se concretizará após o recebimento da dieta no período pós-natal. ${ }^{98,122,129}$

Ao se analisar a casuística do presente estudo, observou-se que o diagnóstico pré-natal do derrame pleural "isolado" foi tardio (idade gestacional média 25,2 semanas) quando comparado com série de estudos mais recentes. ${ }^{52}$ 
O diagnóstico tardio contribuiu para uma considerável taxa (37\%) de pesquisa do cariótipo em sangue fetal (procedimento de maior risco quando comparado com a amniocentese), em virtude da necessidade de se conhecer mais rapidamente o seu resultado, e, dessa forma, propor o tratamento mais adequado (derivação tóraco-amniótica).

Outro fato observado é que, apesar de não significativo, os fetos que foram a óbito apresentaram maior idade gestacional do diagnóstico e menor volume pulmonar quando comparados com os fetos sobreviventes (IG: 27,9 $\pm 3,1$ semanas e $24,9 \pm 4,8$ semanas; $p=0,16$, respectivamente $)$ e $\left(1^{\circ}\right.$ VPT o/e: $0,29 \pm 0,08$ e $0,42 \pm 0,18$; $\mathrm{p}=0,11$, respectivamente). Esses achados associados à hidropisia e bilateralidade, os quais foram significantes para o desfecho negativo $(\mathrm{p}<0,05)$, podem indicar que o diagnóstico tardio pode ter contribuído para a maior mortalidade. Essa suposição é baseada na avaliação da história natural do derrame pleural, a qual indica que o seu volume e o tempo em que o pulmão fica submetido ao regime de aumento da pressão intratorácica, podem contribuir para uma maior taxa de hidropisia e hipoplasia pulmonar, que são fatores sabidamente conhecidos como agravantes do prognóstico perinatal. Laudy e Wladimiroff ${ }^{132}$ mencionaram a importância em realizar o diagnóstico precoce do derrame pleural com o objetivo de melhor selecionar os fetos e o momento adequado em que poderão se beneficiar do tratamento. Acredita-se que essa suposição não foi significativa no presente trabalho provavelmente pelo número reduzido da amostra.

Quanto às características iniciais do derrame pleural primário, não se observou o predomínio da bilateralidade, da lateralidade à direita ou do maior acometimento de fetos do sexo masculino, como apontado por alguns estudos ${ }^{14,50,51}$. 
Os resultados encontrados foram: 12 derrames bilaterais, nove unilaterais (cinco à esquerda e quatro à direita), sete fetos do sexo masculino e 12 do sexo feminino.

Em relação à regressão do derrame pleural, observou-se que ocorreu em seis $(31,6 \%)$ dos 19 fetos que receberam tratamento. Dessas, cinco ocorreram nos derrames unilaterais não acompanhados de hidropisia. Esses achados são compatíveis com o estudo publicado por Klam et al. ${ }^{15}$, o qual demonstra que a regressão é mais comum nos fetos com derrame pleural unilateral não acompanhado de hidropisia. A taxa de regressão encontrada nesse trabalho foi inferior à descrita na série publicada por Yinon et al. ${ }^{56}$, os quais descreveram a regressão em $47 \%$ dos fetos que receberam tratamento.

Por fim, no presente estudo, a hidropisia e a bilateralidade do derrame pleural, após a $28^{\mathrm{a}}$ semana, estiveram estatisticamente associadas com o pior resultado perinatal. A mortalidade perinatal foi de $36,8 \%(n=07)$ casos, compatível com os resultados encontrados em fetos que receberam tratamentos publicados na literatura $7-9,105$

Apesar desses resultados, têm-se a consciência de que os estudos na literatura a respeito do derrame pleural fetal têm evidências limitadas devido a sua raridade, e a maioria dessas consiste em relatos de casos, série de casos, geralmente originado de centros únicos. As poucas revisões a respeito desse tema apresentam limitações quanto a sua interpretação, visto a heterogeneidade dos dados apresentados ${ }^{9}$. Um inevitável viés encontrado nas revisões literárias é a maior publicação dos sucessos do tratamento quando comparados com as falhas de tratamento. Isso pode ser evidenciado com as altas taxas de sucesso publicado nos relatos de casos quando 
comparados com o sucesso publicado em série de casos. Deurloo et al. ${ }^{9}$ publicam em sua revisão uma taxa de sucesso de até $81 \%$ no tratamento do hidrotórax isolado em fetos hidrópicos quando se consideram os relatos de caso, caindo essa taxa para $63 \%$ quando incluídas as séries de casos.

\section{Considerações sobre a metodologia usada para estimar o volume pulmonar fetal}

O volume pulmonar fetal foi estimado, neste estudo, pela técnica rotacional da imagem multiplanar (VOCAL). Optou-se por essa técnica devido a sua superioridade comprovada em relação aos métodos bidimensionais ${ }^{31,37}$ para a mensuração do volume, pela reprodutibilidade in vitro ${ }^{172}$ e in vivo ${ }^{34}$, por sua acurácia comprovada em estudos pos mortem $^{34}$, por apresentar reprodutibilidade e maior benefício (menor custo, maior tolerância e disponibilidade) quando comparado à $\mathrm{RNM}^{34}$, por sua reprodutibilidade na avaliação de estruturas irregulares quando comparado com o método multiplanar ${ }^{32,157}$, por avaliar o volume de cada pulmão separadamente $32,34,165,169$ (fato importante para o derrame pleural, visto que a técnica de subtração tornaria o método menos reprodutível) e por ter sido a técnica validada nos estudos da hipoplasia pulmonar em fetos com hérnia diafragmática congênita. ${ }^{33,34,155,169,173}$

Optou-se por escolher o normograma do volume pulmonar fetal, publicado por Ruano et al. ${ }^{169}$, em relação a outros ${ }^{156-158,}{ }^{165}$, pelos seguintes motivos: a) varredura automática no momento da aquisição do bloco tridimensional; b) técnica VOCAL utilizada; c) reprodutibilidade do método; d) validação obtida com peças de autópsias e outros métodos de imagem $(\mathrm{RNM})$; e) representatividade da amostra 
estudada; f) pelo intervalo gestacional analisado (entre 20 e 37 semanas); e g) pela uniformidade na metodologia.

Dessa forma, o presente estudo prezou pela uniformidade metodológica. Utilizou os exames de apenas um único operador (RR) com experiência prévia comprovada, o qual aplicou a mesma metodologia descrita para a confecção do normograma de referência.

A não utilização da mesma metodologia para análises comparativas pode acarretar em discrepâncias nos resultados encontrados. Em uma recente revisão ${ }^{174}$, diversas curvas de normalidade para o volume pulmonar fetal foram comparadas, utilizando o exame considerado "padrão-ouro" (RNM). Nessa revisão, verificou-se que os normogramas para o volume pulmonar fetal apresentavam resultados discrepantes, em virtude da técnica diferente utilizada, das diversas metodologias aplicadas, relacionados com a experiência dos examinadores ${ }^{174}$. Resultado semelhante foi descrito por Peralta et al. ${ }^{157}$ (2006), os quais compararam diferentes normogramas construídos pela ultrassonografia tridimensional e observou a influência de técnicas (p. ex. técnica VOCAL comparada com a técnica multiplanar) e da não padronização da metodologia, na divergência das curvas de normalidade para os volumes pulmonares fetais publicados.

Assim sendo, uma importante característica do presente estudo é a uniformidade na metodologia em relação ao normograma de referência, com a utilização do ângulo de rotação em $30^{\circ}$ para a estimativa do volume. Essa angulação mostrou-se satisfatória e adequada quando comparada a outros métodos ${ }^{34}$, embora se saiba que algumas publicações descrevem que angulações menores $\left(6^{\circ}, 9^{\circ}\right.$ e $\left.18^{\circ}\right)$ possam ser mais representativas da avaliação volumétrica. ${ }^{160,161,175}$ 
Outro ponto a se destacar é que, no presente estudo, optou-se por escolher o último volume pulmonar mensurado antes do parto $\left(2^{\circ} \mathrm{VPT}\right.$ o/e) por considerá-lo mais fidedigno às condições pulmonares ao nascimento, visto que o derrame pleural apresenta comportamento incerto. $\mathrm{Na}$ nossa casuística, considerou-se a idade gestacional de 36 semanas como o limite superior para a mensuração do volume pulmonar. Trabalhos na literatura sugerem que a mensuração pulmonar após a $32^{\mathrm{a}}$ semana pode apresentar maior dificuldade técnica, principalmente pela posição fetal e interposição acústica ocasionada pelas estruturas ósseas no momento do exame ${ }^{32}$, 167, 176 , representados por uma maior variabilidade inter e intraobservador e por maior dificuldade em se estabelecer os contornos pulmonares. ${ }^{156,157,177}$

De fato, estimar volumes de pulmão fetal pelo US 3D em idades gestacionais avançadas é tecnicamente mais difícil. Porém, no presente estudo, a experiência do operador, o emprego da metodologia correta e a avaliação volumétrica seriada (avaliações quinzenais) fizeram com que os resultados deste trabalho não fossem comprometidos. As dificuldades técnicas foram superadas pela avaliação criteriosa dos traçados nos três planos ortogonais na imagem multiplanar e padronização do método de aquisição da imagem (sempre com o coração fetal voltado para o transdutor). Nos fetos com derrame pleural, essa avaliação é facilitada pela janela acústica criada pelo líquido pleural, permitindo boa avaliação dos limites pulmonares, bem como pela maior facilidade em mobilizar estruturas fetais, em virtude do poli-hidrâmnio, resultando no melhor posicionamento fetal (o ápice cardíaco mais próximo ao transdutor). 


\section{Relação entre o volume pulmonar fetal estimado pela US 3D e o prognóstico neonatal dos casos de derrame pleural "isolado"}

O presente estudo comparou o volume observado com o volume previsto para a idade gestacional determinada, formando a relação observado/esperado para o volume pulmonar de acordo com a idade gestacional (VPT o/e) no momento do diagnóstico ( $1^{\circ} \mathrm{VPT}$ o/e) e no último exame volumétrico após o parto ( $2^{\circ} \mathrm{VPT}$ o/e). Com isso, demonstrou-se que o volume pulmonar mensurado pelo US 3D foi significativamente reduzido nos fetos com derrame pleural "isolado" que morreram ou que apresentaram morbidade respiratória severa após o nascimento.

A análise do $1^{\circ}$ VPT o/e demonstrou que ele não foi significante na predição da mortalidade ou morbidade perinatal. Apesar desse resultado negativo, acredita-se que a mensuração do $1^{\circ} \mathrm{VPT}$ o/e possa ser útil para outros objetivos, tais como no auxílio à assistência pré-natal, no aconselhamento aos pais, no estabelecimento da gravidade inicial do caso, na tomada de decisões em se realizar o tratamento fetal invasivo e na avaliação inicial do tratamento invasivo.

O baixo VPT o/e no momento do diagnóstico $\left(1^{\mathrm{o}} \mathrm{VPT}\right.$ o/e) pode ser indicativo do inadequado desenvolvimento pulmonar ocasionado pelo aumento da pressão intra-torácica, em virtude do derrame pleural. Acredita-se que essa informação associada a outros dados, tais como a presença da hidropisia e da bilateralidade do derrame pleural, possa ser útil na orientação ao pré-natalista e no aconselhamento aos pais, auxiliando-os na escolha pelo mais adequado tratamento fetal. 
Além disso, a avaliação do $1^{\circ}$ VPT o/e poderá ser útil numa estratificação de riscos quando associados aos marcadores clássicos, tais como a hidropisia e a bilateralidade. A avaliação dos fatores de risco, utilizando critérios quantitativos (cálculo do volume pulmonar) associados aos critérios qualitativos (presença ou não da bilateralidade e hidropisia fetal) poderá ser útil para estratificar grupos com gravidades diferentes. Dessa maneira, será possível avaliar, de forma mais objetiva, os resultados do tratamento fetal, de acordo com a gravidade, bem como selecionar os grupos que melhor poderão se beneficiar com o tratamento. Assim, reduzir-se-iam os vieses de seleção na publicação dos resultados, podendo ser útil até para comparação entre as diferentes modalidades de tratamento, já que, até o presente momento, não se tem o melhor tratamento estabelecido.

Com o mesmo propósito, acredita-se que a mensuração do volume pulmonar, no momento do diagnóstico ( $1^{\circ} \mathrm{VPT}$ o/e), poderá contribuir na avaliação inicial da resposta ao tratamento. No presente estudo, observou-se que os fetos que apresentavam baixo volume pulmonar no momento do diagnóstico ( $1^{\mathrm{o}} \mathrm{VPT}$ o/e reduzido) e que apresentaram boa expansão do volume pulmonar após a intervenção fetal (toracocentese ou derivação tóraco-amniótica) apresentaram melhor prognóstico quando comparados com aqueles cujos pulmões pouco se expandiram. Esses achados podem sugerir que os fetos que apresentaram pequena variação da relação VPTo/e, após o tratamento (pequena expansão pulmonar), podem apresentar grau de hipoplasia pulmonar mais severo, e, por consequência, maior taxa de morbidade ou mortalidade perinatal.

De maneira em geral, acredita-se que o $1^{\circ}$ VPT o/e poderá ser útil na avaliação da gravidade e do prognóstico nos fetos com derrame pleural "isolado". 
Talvez, o grande fator limitante para encontrar essas suposições no presente estudo, foi o número reduzido de casos. Estudos futuros, multicêntricos e com casuísticas bem estabelecidas, são necessários para avaliar se o volume pulmonar mensurado no momento do diagnóstico $\left(1^{\mathrm{o}} \mathrm{VPT}\right.$ o/e) poderá ser utilizado como critério de gravidade e na avaliação da resposta inicial ao tratamento.

Em relação ao volume pulmonar próximo ao parto $\left(2^{\circ} \mathrm{VPT}\right.$ o/e), o presente estudo demonstrou que foi significativamente reduzido nos fetos com derrame pleural "isolado" que morreram ou que apresentaram dificuldade respiratória severa ao nascimento. Isso sugere que a hipoplasia pulmonar é uma das principais causas do aumento da mortalidade e morbidade em fetos com derrame pleural "isolado". Esses achados foram confirmados pelas necropsias publicados no estudo de Yinom et al. ${ }^{56}$. Ao nosso conhecimento, esse é o primeiro trabalho que utiliza o volume pulmonar como método preditor da hipoplasia em fetos com derrame pleural "isolado".

Fato interessante observado no presente estudo é que o volume pulmonar mensurado próximo ao parto pode ser útil na predição da morte perinatal no derrame pleural "isolado" $\left(2^{\circ}\right.$ VPT o/e $\left.<0,33\right)$ com o valor muito próximo daqueles observados para a mesma relação, em trabalhos publicados com fetos com hérnia diafragmática congênita “isolada” (VPT o/e < 0,35). ${ }^{33,154,178-180}$

Também se observou que os fetos que apresentaram o $2^{\circ}$ VPT $>0,45$ não associados à prematuridade, tiveram menor morbidade respiratória no período neonatal. Esses achados sugerem que o $2^{\circ} \mathrm{VPT}$ o/e pode auxiliar no melhor preparo para a assistência neonatal.

O grande viés e fator limitante para o uso do $2^{\circ}$ VPT o/e como método preditor "isolado" da morbidade e mortalidade perinatal nos fetos com derrame 
pleural "isolado" é a prematuridade. Sabe-se que ela pode ser influenciada pela técnica fetal invasiva (maior risco para trabalho de parto prematuro e amniorrexe prematura nas derivações tóraco-amnióticas), pelo número de procedimentos invasivos (maior risco de corioamnionite), pelo volume do líquido amniótico, por causas infecciosas diversas, entre outras.

Mesmo assim, o $2^{\circ}$ VPT o/e não perde o seu valor ao tentar predizer a hipoplasia pulmonar que é um importante fator prognóstico perinatal. Recentemente, Prendergast et al. ${ }^{153}$ (2011) sugeriram a importância do volume pulmonar prévio ao parto ao comparar com testes que avaliam a função pulmonar no pós-parto, tais como a mensuração da capacidade residual funcional no pós-parto, utilizando a técnica de diluição do gás Hélio.

O principal problema do estudo atual foi o tamanho reduzido da série, que pode ser explicado pela raridade da malformação, especialmente quando se considera apenas os casos de derrame pleural "isolado". Consequentemente, o presente estudo tem algumas limitações, como por exemplo, não ser possível realizar a análise de regressão múltipla em virtude do tamanho reduzido da série.

Estudos futuros são necessários para avaliar as estratégias de tratamento, as suas complicações, os riscos para parto prematuro, a interferência do poli-hidrâmnio e a estimativa da hipoplasia pulmonar no prognóstico perinatal. 


\section{Perspectivas futuras:}

A avaliação do volume pulmonar fetal teria como principal consequência o melhor aconselhamento pré-natal nos fetos portadores de derrame pleural "isolado". Dessa forma, espera-se, com o volume pulmonar, a criação de critérios quantitativos para a estratificação da gravidade. Acredita-se que o uso do volume pulmonar associado a outros fatores prognósticos, tais como à bilateralidade do derrame e à hidropisia fetal, possa estabelecer esses diferentes níveis.

Essa estratificação dos riscos seria o primeiro passo para melhor se compreender a história natural do derrame pleural, o melhor momento para se propor o tratamento, as diferentes respostas ao tratamento e a repercussão de suas complicações no prognóstico perinatal.

Dessa forma, uma possível aplicação futura da medida do volume pulmonar pela US 3D seria a determinação da gravidade inicial e o seguimento do crescimento pulmonar após o feto ser submetido à terapia invasiva. Com isso, poder-se-ia avaliar, de forma mais segura, os resultados iniciais em futuros protocolos controlados e randomizados, selecionando o feto que poderá se beneficiar do tratamento, estabelecendo a vantagem de cada modalidade terapêutica e traçando a melhor estratégia ainda não definida. Talvez a US 3D possa preencher a lacuna que existe nas indicações para a terapia fetal no derrame pleural.

Também se espera que estudos futuros sejam capazes de predizer outros dois importantes fatores prognósticos, que são a hipertensão pulmonar e a hidropsia fetal. Acredita-se que estudos dopplervelocimétricos, avaliando a sobrecarga no aparelho 
cardiovascular $^{49,} 75,89$ e a vascularização pulmonar fetal ${ }^{170}$, poderão trazer informações adicionais na compreensão do comportamento e do prognóstico em fetos com derrame pleural "isolado", auxiliando na determinação da melhor estratégia terapêutica, antes que essas complicações se instalem.

Também é de fundamental importância, o acompanhamento, a longo prazo, desses pacientes, para avaliar as interferências da intervenção fetal no desenvolvimento pulmonar, e suas repercussões na vida adulta. Esse acompanhamento no pós-parto é fundamental para buscar possíveis fatores genéticos, imunológicos ou ambientais que possam estar relacionados com a etiologia obscura do derrame pleural isolado.

Novas pesquisas, multicêntricas, com maior número de casos, avaliando a variabilidade inter e intraobservador, nas diversas idades gestacionais, são necessárias para consolidar cada vez mais essa ferramenta poderosa e subutilizada que é a ultrassonografia tridimensional. A incorporação da mensuração do volume pulmonar nos fetos com risco para hipoplasia pulmonar poderá trazer respostas futuras para muitas questões levantadas. A padronização do método e o treinamento dos ultrassonografistas são condições necessárias para o avanço nessas pesquisas.

Não se pretende, com este trabalho, desvalorizar marcadores clássicos, tais como a hidropisia e a bilateralidade, verificados pelos parâmetros bidimensionais. Por mais clássica que seja a definição que a ultrassonografia tridimensional advém do estudo bidimensional, não se pode ignorar a tecnologia e a utilidade desses recursos em fontes de pesquisa para futuras aplicações clínicas. Somente assim se faz o crescimento científico, que é o resultado do somatório entre o conhecimento, domínio de técnicas e tecnologia, e a ética. 
CONCLUSÕES

$\bar{~}$




\section{CONCLUSÕES}

O presente estudo permitiu realizar as seguintes conclusões quanto à predição dos resultados perinatais:

1. O volume pulmonar total reduzido aferido próximo ao parto $\left(2^{\circ} \mathrm{VPT}\right.$ o/e $)$ se relaciona estatisticamente com o óbito perinatal.

2. O volume pulmonar total reduzido aferido próximo ao parto $\left(2^{\circ} \mathrm{VPT}\right.$ o/e $)$ também se relaciona com a necessidade de UTI e suporte ventilatório neonatal. 
ANEXOS 


\section{ANEXO}

\section{ANEXO A}

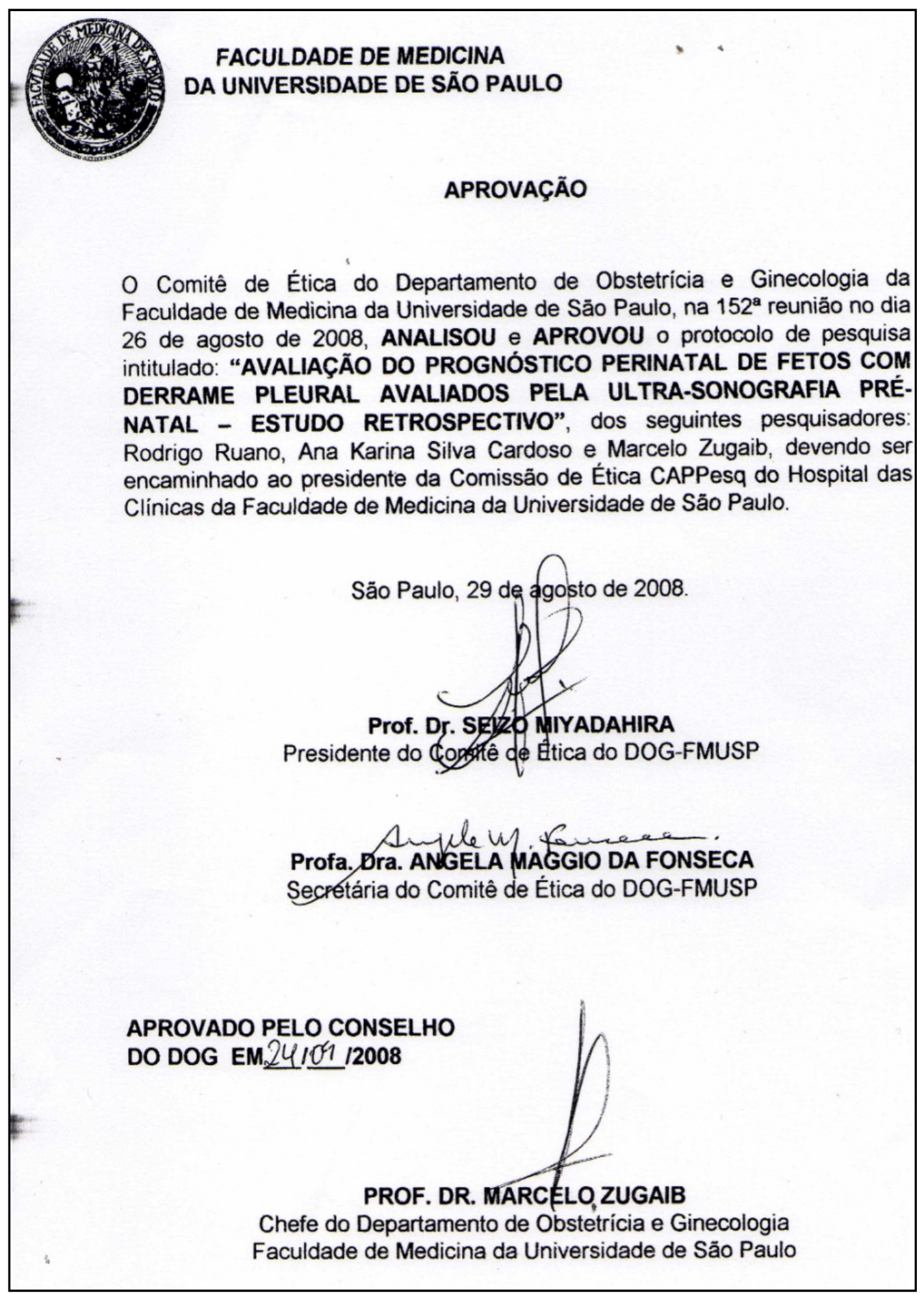




\section{ANEXO B}

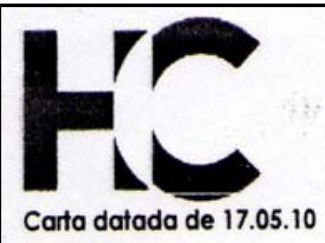

Ao

Departamento de Obstetrícia e Ginecologia

A Comissão de Ética para Análise de Projetos de Pesquisa - CAPPesa da Diretoria Clínica do Hospital das Clínicas e da Faculdade de Medicina da Universidade de São Paulo, em sessão de $07 / 07 / 10$ tomou conhecimento que o Protocolo de Pesquisa $n^{\circ}$ 0867/08 intitulado "AVALIAÇÃO DO PROGNÓSTICO PERINATAL DE FETOS COM DERRAME PLEURAL AVALIADOS PELA ULTRA-SONOGRAFIA PRÉ-NATAL - ESTUDO RETROSPECTIVO", ap ROVado em 19.11.98 será dissertação de mestrado do aluno ROGÉRIO CAIXETA MORAES DE FREITAS, tendo como orientador DR. RODRIGO RUONO.

CAPPesq, 08 de julho de 2009.

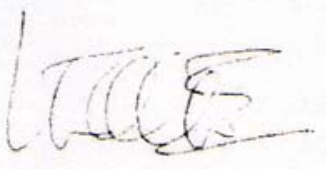

PROF. DR. CLAUDIO LEONE

Vice-Presidente da Comissc̄o Ética para Análise de Projetos de Pesquisa 


\begin{tabular}{|c|c|c|c|c|c|c|c|c|c|c|c|c|}
\hline $\begin{array}{c}\text { Paciente } \\
\mathrm{N}^{\mathrm{o}}\end{array}$ & $\begin{array}{c}\text { Idade } \\
\text { Materna } \\
\text { (anos) }\end{array}$ & $\begin{array}{l}\text { IG Diagn. } \\
\text { (semanas) }\end{array}$ & $\begin{array}{c}\text { IG } 1^{\circ} \text {. US } \\
\text { HCFMUSP } \\
\text { (semanas) }\end{array}$ & $\begin{array}{l}\text { Hidropisia } \\
\text { (10. US ) }\end{array}$ & $\begin{array}{c}\text { Lateral. } \\
\text { DP } \\
1^{\circ} \mathrm{US}\end{array}$ & $\begin{array}{l}\text { ILA > } \\
25 \mathrm{~cm} \\
10 . \text { US }\end{array}$ & $\begin{array}{c}10 . \\
\text { VPTo/e }\end{array}$ & $\begin{array}{c}\text { Tipo } \\
\text { Tratamento }\end{array}$ & $\begin{array}{c}\text { IG } 2^{\circ} \text { US } \\
\text { HCFMUSP } \\
\text { (semanas) }\end{array}$ & $\begin{array}{c}\text { Desaparecimento } \\
\text { DP }\end{array}$ & $\begin{array}{l}\text { Hidropisia } \\
\text { (2o. US ) }\end{array}$ & $\begin{array}{c}\text { Lateral } \\
\text { DP } \\
1^{\circ} \mathrm{US}\end{array}$ \\
\hline 1 & 33 & 25,3 & 25,4 & Sim & Bilat. & Sim & 0,24 & Shunt & 34,1 & Não & Sim & Bilat. \\
\hline 2 & 22 & 23,1 & 23,6 & Não & Esq & Não & 0,26 & Shunt & 36,0 & Sim & Não & - \\
\hline 3 & 37 & 19,0 & 19,0 & Não & Esq & Não & 0,26 & Toraco & 36,2 & Sim & Não & - \\
\hline 4 & 38 & 30,6 & 30,6 & Não & Esq & Sim & 0,92 & Toraco & 36,0 & Não & Não & Esq \\
\hline 5 & 20 & 16,4 & 18,3 & Não & Esq & Não & 0,28 & Shunt & 35 & Sim & Não & - \\
\hline 6 & 31 & 25,7 & 25,7 & Sim & Dir & Sim & 0,43 & Shunt & 33 & Não & Sim & Dir \\
\hline 7 & 32 & 26,9 & 25,0 & Não & Dir & Não & 0,48 & Toraco & 28,0 & Não & Não & Dir \\
\hline 8 & 20 & 18,7 & 20,0 & Sim & Dir & Não & 0,39 & Shunt & 34 & Não & Sim & Dir \\
\hline 9 & 18 & 31,1 & 31,1 & Não & Dir & Não & 0,43 & Toraco & 36,1 & Sim & Não & - \\
\hline 10 & 26 & 26,4 & 26,4 & Sim & Bilat. & Não & 0,49 & Shunt & 28,7 & Não & Sim & Bilat. \\
\hline 11 & 31 & 28,6 & 28,7 & Sim & Bilat. & Sim & 0,38 & Shunt & 34 & Não & Sim & Bilat. \\
\hline 12 & 22 & 29,7 & 29,9 & Sim & Bilat. & Sim & 0,29 & Shunt & 31,9 & Não & Sim & Bilat. \\
\hline 13 & 41 & 31,4 & 31,4 & Sim & Bilat. & Sim & 0,30 & Toraco & 32,7 & Não & Sim & Bilat. \\
\hline 14 & 29 & 20,3 & 26,3 & Sim & Bilat. & Sim & 0,27 & Shunt & 31,3 & Não & Sim & Bilat. \\
\hline 15 & 21 & 20,0 & 24,0 & Sim & Bilat. & Não & 0,30 & Shunt & 34,6 & Sim & Não & - \\
\hline 16 & 24 & 24,0 & 24,0 & Sim & Bilat. & Sim & 0,27 & Toraco & 28,0 & Não & Sim & Bilat. \\
\hline 17 & 20 & 31,2 & 31,2 & Sim & Bilat. & Sim & 0,34 & Toraco & 34,0 & Não & Não & Bilat. \\
\hline 18 & 41 & 32,0 & 32,0 & Sim & Bilat. & Não & 0,23 & Toraco & 33,0 & Não & Sim & Bilat. \\
\hline 19 & 21 & 18,6 & 20,0 & Não & Esq & Não & 0,62 & Toraco & 35,6 & Sim & Não & - \\
\hline
\end{tabular}

ANEXO C: $\mathrm{N}^{\circ}=$ número, IG Diagn. = idade gestacional do diagnóstico, IG $1^{\circ}$. US HCFMUSP - idade gestacional do $1^{\circ}$. US 3D no HCFMUSP, Lateral. DP $1^{\circ}$ US $=$ lateralidade do derrame pleural no $1^{\circ}$ US (Bilat = bilateral; Dir= Direita; Esq= Esquerda), ILA= índice de líquido amniótico, $1^{\circ} \mathrm{VPT}$ o/e $=$ relação entre o volume pulmonar total observado e volume pulmonar total esperado por idade gestacional no momento do diagnóstico HCFMUSP, Shunt $=$ derivação tóraco-amniótica, Toraco $=$ toracocentese, IG $2^{\circ}$. US HCFMUSP - idade gestacional do último. US 3D no HCFMUSP prévio ao pato ( 2 semanas antes do parto ou 36 semanas), DP = derrame pleural 


\begin{tabular}{|c|c|c|c|c|c|c|c|c|c|c|c|c|c|}
\hline $\begin{array}{c}\text { Paciente } \\
\mathrm{N}^{\mathbf{o}}\end{array}$ & $\begin{array}{l}\text { ILA }>25 \\
\text { cm } 2^{\circ} . \text { US }\end{array}$ & $\begin{array}{c}20 . \\
\text { VPTo/e }\end{array}$ & Corticóide & Desfecho & $\begin{array}{c}\text { IG } \\
\text { parto }\end{array}$ & $\begin{array}{c}\text { Via } \\
\text { parto }\end{array}$ & $\begin{array}{c}\text { Parto no } \\
\text { HCFMUSP }\end{array}$ & $\begin{array}{c}\text { Indicação } \\
\text { Parto }\end{array}$ & $\begin{array}{l}\text { Sexo } \\
\text { fetal }\end{array}$ & IOT & $\begin{array}{c}\text { Tempo } \\
\text { IOT (dias) }\end{array}$ & UTI & $\begin{array}{c}\text { Tempo UTI } \\
\text { (dias) }\end{array}$ \\
\hline 1 & Sim & 0,07 & - & Natimorto & 34,7 & Normal & Sim & $\mathrm{OF}$ & Fem & NA & $*$ & NA & * \\
\hline 2 & Não & 0,45 & Não & Vivo & 40,6 & Cesárea & Sim & $\mathrm{DCP}$ & masc & Não & $*$ & Não & $*$ \\
\hline 3 & Não & 0,60 & Não & Vivo & 39,0 & Cesárea & Não & Iterativa & Fem & Não & * & Não & * \\
\hline 4 & Não & 0,98 & Não & Vivo & 39,3 & Cesárea & Sim & Iterativa & Fem & Não & $*$ & Não & * \\
\hline 5 & Não & 0,34 & Não & Vivo & 37,1 & Cesárea & Sim & Gemelar & masc & Sim & 7 & Sim & 20 \\
\hline 6 & Não & 0,43 & Não & Vivo & 34,6 & Cesárea & Sim & SFA & masc & Sim & 7 & Sim & 14 \\
\hline 7 & Não & 0,48 & Sim & Vivo & 28,0 & Cesárea & Sim & SFA & Fem & Sim & 21 & Sim & 60 \\
\hline 8 & Não & 0,33 & Não & Vivo & 36,9 & Cesárea & Sim & SFA & Fem & Sim & 40 & Sim & 60 \\
\hline 9 & Não & 0,78 & Não & Vivo & 41,0 & Cesárea & Não & Eletiva? & Fem & Não & * & Não & $*$ \\
\hline 10 & Não & 0,30 & Sim & Neomorto & 30,0 & Cesárea & Não ${ }^{A}$ & $\begin{array}{c}\text { RPMO+ } \\
\text { Hidropisia }\end{array}$ & Fem & Sim & 1 & $\mathrm{Sim}$ & 1 \\
\hline 11 & Sim & 0,45 & Não & Vivo & 36,9 & Cesárea & Não & Eletiva? & Masc & Não & $*$ & Não & * \\
\hline 12 & Sim & 0,27 & - & Natimorto & 32,0 & Normal & Sim & OF & Masc & NA & $*$ & NA & $*$ \\
\hline 13 & Sim & 0,27 & - & Natimorto & 33,3 & Normal & Sim & $\mathrm{OF}$ & Fem & NA & $*$ & NA & $*$ \\
\hline 14 & Sim & 0,29 & Sim & Neomorto & 32,9 & Normal & Sim & $*$ & Fem & Sim & 1 & Sim & 1 \\
\hline 15 & Não & 0,83 & Não & Vivo & 37,0 & Normal & Não & $*$ & Masc & Não & $*$ & Não & $*$ \\
\hline 16 & Sim & 0,28 & Não ${ }^{B}$ & Neomoto & 30,0 & Cesárea & Sim & SFA & Masc & Sim & 1 & Sim & 1 \\
\hline 17 & Não & 0,75 & Não & Vivo & 36,1 & Normal & Sim & $*$ & Fem & Não & $*$ & Não & * \\
\hline 18 & Não & 0,22 & - & Natimorto & 34,0 & Normal & Sim & $\mathrm{OF}$ & Fem & NA & * & NA & $*$ \\
\hline 19 & Não & 0,64 & Não & Vivo & 40,0 & Normal & Sim & $*$ & Fem & Não & $*$ & Não & $*$ \\
\hline
\end{tabular}

ANEXO C: $\mathrm{N}^{\mathrm{o}}=$ número, ILA= índice de líquido amniótico, $2^{\circ}$ VPT o/e = relação entre o volume pulmonar total observado e volume pulmonar total esperado por idade gestacional próximo ao parto (duas semanas antes do parto ou 36 semanas). OF = óbito fetal, DCP = desproporção céfalo-pélvica, SFA $=$ Sofrimento fetal agudo, RPMO = ruptura prematura das membranas ovulares, $\mathrm{Fem}=$ feminino, Masc $=$ masculino, IOT $=$ intubação oro-traqueal, UTI $=$ Unidade de Terapia Intensiva. ${ }^{\mathrm{A}}-\mathrm{Necropsia} \mathrm{realizada} \mathrm{em} \mathrm{outro} \mathrm{serviço.}$ 
REFERÊNCIAS BIBLIOGRÁFICAS

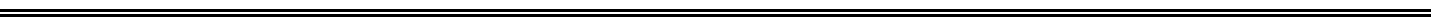




\section{REFERÊNCIAS BIBLIOGRÁFICAS:}

1. Carrol B. Pulmonary hypoplasia and pleural effusions associated with fetal death in utero. Ultrasonographic findings. AJR; 1977. p. 749 - 50.

2. Eddleman KA, Levine AB, Chitkara U, Berkowitz RL. Realiability of pleural fluid lymphocyte counts in the antenatal diagnosis of congenital chylothorax. Obstetrics and Gynecology. 1991; 78(3): 530-2.

3. Longaker MT, Laberge JM, Dansereau J, Langer JC, Crombleholme TM, Callen PW, et al. Primary fetal hydrothorax - Natural history and management. Journal of Pediatric Surgery. 1989; 24(6): 573-6.

4. Yinon Y, Kelly E, Ryan G. Fetal pleural effusions. Best Practice \& Research in Clinical Obstetrics \& Gynaecology. 2008; 22(1): 77-96.

5. Pijpers L, Reuss A, Stewart PA, Wladimiroff JW. Noninvasive management of bilateral fetal hydrothorax.. American Journal of Obstetrics and Gynecology. 1989; 161(2): 330-2.

6. Hwang JY, Yoo JH, Suh JS, Rhee CS. Isolated non-chylous pleural effusion in two neonates. Journal of Korean Medical Science. 2003; 18(4): 603-5.

7. Hagay Z, Reece EA, Roberts A, Hobbins JC. Isolated fetal pleural effusion - A prenatal management dilemma. Obstetrics and Gynecology. 1993; 81(1): 14752.

8. Estroff JA, Parad RB, Frigoletto FD, Benacerraf BR. The natural history of isolated hydrothorax. Ultrasound in Obstetrics \& Gynecology. 1992; 2(3): 1625. 
9. Deurloo KL, Devlieger R, Lopriore E, Klumper FJ, Oepkes D. Isolated fetal hydrothorax with hydrops: a systematic review of prenatal treatment options. Prenatal Diagnosis. 2007; 27(10): 893-9.

10. Nicolaides KH, Azar GB. Thoraco-amniotic shunting. Fetal Diagn Ther. 1990; 5(3-4): 153-64.

11. Chernick V, Reed MH. Pneumothorax and chylothorax in the neonatal period. J Pediatr. 1970; 76(4): 624-32.

12. Yamamoto M, Insunza A, Carrillo J, Caicedo LA, Paiva E, Ville Y. Intrathoracic pressure in congenital chylothorax: Keystone for the rationale of thoracoamniotic shunting? Fetal Diagnosis and Therapy. 2007; 22(3): 169-71.

13. Benacerraf BR, Frigoletto FD, Wilson M. Successful midtrimester thoracentesis with analysis of the lymphocyte population in the pleural effusion. Am J Obstet Gynecol. 1986; 155(2): 398-9.

14. Aubard Y, Derouineau I, Aubard V, Chalifour V, Preux PM. Primary fetal hydrothorax: A literature review and proposed antenatal clinical strategy. Fetal Diagnosis and Therapy. 1998; 13(6): 325-33.

15. Klam S, Bigras JL, Hudon L. Predicting outcome in primary fetal hydrothorax. Fetal Diagnosis and Therapy. 2005; 20(5): 366-70.

16. Ruano R, Ramalho AS, Cardoso AK, Moise K, Zugaib M. Prenatal diagnosis and natural history of fetuses presenting with pleural effusion. Prenat Diagn. 2011; 31(5): 496-9.

17. Weber AM, Philipson EH. Fetal pleural effusion: a review and meta-analysis for prognostic indicators. Obstet Gynecol. 1992; 79(2): 281-6. 
18. Mandelbrot L, Dommergues M, Aubry MC, Mussat P, Dumez Y. Reversal of fetal distress by emergency in-utero descompression of hydrothorax. American Journal of Obstetrics and Gynecology. 1992; 167(5): 1278-83.

19. Devine PC, Malone FD. Noncardiac thoracic anomalies. Clinics in Perinatology. 2000; 27(4): 865-71.

20. Petres RE, Redwine FO, Cruikshank DP. Congenital bilateral chylothorax. Antepartum diagnosis and successful intrauterine surgical management. JAMA. 1982; 248(11): 1360-1.

21. Seeds JW, Bowes WA. Results of treatment of severe fetal hydrothorax with bilateral pleuroamniotic catheters. Obstetrics and Gynecology. 1986; 68(4): 57780.

22. Rodeck CH, Fisk NM, Fraser DI, Nicolini U. Long-term inutero drainage of fetal hydrothorax. New England Journal of Medicine. 1988; 319(17): 1135-8.

23. Mann S, Johnson MP, Wilson RD. Fetal thoracic and bladder shunts. Seminars in Fetal \& Neonatal Medicine. 2010; 15(1): 28-33.

24. Cavoretto P, Molina F, Poggi S, Davenport M, Nicolaides KH. Prenatal diagnosis and outcome of echogenic fetal lung lesions. Ultrasound Obstet Gynecol. 2008; 32(6): 769-83.

25. Wilson RD, Baxter JK, Johnson MP, King M, Kasperski S, Crombleholme TM, et al. Thoracoamniotic shunts: Fetal treatment of pleural effusions and congenital cystic adenomatoid malformations. Fetal Diagnosis and Therapy. 2004; 19(5): 413-20. 
26. Okawa T, Takano Y, Fujimori K, Yanagida K, Sato A. A new fetal therapy for chylothorax: pleurodesis with OK-432. Ultrasound in Obstetrics \& Gynecology. 2001; 18(4): 376-7.

27. Bennet L, Cowie RV, Stone PR, Barrett R, Naylor AS, Blood AB, et al. The neural and vascular effects of killed Su-Streptococcus pyogenes (OK-432) in preterm fetal sheep. Am J Physiol Regul Integr Comp Physiol. 2010; 299(2): R664-72.

28. Cowie RV, Stone PR, Parry E, Jensen EC, Gunn AJ, Bennet L. Acute Behavioral Effects of Intrapleural OK-432 (Picibanil) Administration in Preterm Fetal Sheep. Fetal Diagnosis and Therapy. 2009; 25(3): 304-13.

29. Ma GC, Liu CS, Chang SP, Yeh KT, Ke YY, Chen TH, et al. A recurrent ITGA9 missense mutation in human fetuses with severe chylothorax: possible correlation with poor response to fetal therapy. Prenatal Diagnosis. 2008; 28(11): 1057-63.

30. Gerards FA, Twisk JW, Fetter WP, Wijnaendts LC, Van Vugt JM. Two- or three-dimensional ultrasonography to predict pulmonary hypoplasia in pregnancies complicated by preterm premature rupture of the membranes. Prenat Diagn. 2007; 27(3): 216-21.

31. Gerards FA, Twisk JW, Fetter WP, Wijnaendts LC, van Vugt JM. Predicting pulmonary hypoplasia with 2- or 3-dimensional ultrasonography in complicated pregnancies. Am J Obstet Gynecol. 2008; 198(1): 140-6.

32. Moeglin D, Talmant C, Duyme M, Lopez AC, CFEF. Fetal lung volumetry using two- and three-dimensional ultrasound. Ultrasound Obstet Gynecol. 2005; 25(2): 119-27. 
33. Ruano R, Benachi A, Joubin L, Aubry MC, Thalabard JC, Dumez Y, et al. Three-dimensional ultrasonographic assessment of fetal lung volume as prognostic factor in isolated congenital diaphragmatic hernia. BJOG. 2004; 111(5): 423-9.

34. Ruano R, Martinovic J, Dommergues M, Aubry MC, Dumez Y, Benachi A. Accuracy of fetal lung volume assessed by three-dimensional sonography. Ultrasound Obstet Gynecol. 2005; 26(7): 725-30.

35. Ruano R, Martinovic J, Aubry MC, Dumez Y, Benachi A. Predicting pulmonary hypoplasia using the sonographic fetal lung volume to body weight ratio--how precise and accurate is it? Ultrasound Obstet Gynecol. 2006; 28(7): 958-62.

36. Ruano R, Aubry MC, Dumez Y, Zugaib M, Benachi A. Predicting neonatal deaths and pulmonary hypoplasia in isolated congenital diaphragmatic hernia using the sonographic fetal lung volume-body weight ratio. AJR Am J Roentgenol. 2008; 190(5): 1216-9.

37. Vergani P, Andreani M, Greco M, Farina G, Fedeli T, Cuttin S. Two- or threedimensional ultrasonography: which is the best predictor of pulmonary hypoplasia? Prenatal Diagnosis. 2010; 30(9): 834-8.

38. Moore KL, Persaud TVN. Embriologia pulmonar. In: Embriologia Clínica. $8^{\mathrm{a}}$ ed; Elsevier, 2008; 256-60.

39. Rozas A, Oshiro, CGS. Desenvolvimento pulmonar. In: Neme B., Obstetrícia Básica. 3ª ed.. São Paulo: Sarvier; 2006; 963 - 6.

40. Zugaib, M. Desenvolvimento pulmonar. In: Zugaib M., Obstetrícia, $1^{\mathrm{a}}$ ed.. Barueri: Manole; 2008; 126-30. 
41. Boyden EA. Development of the pulmonary airways. Minn Med. 1971; 54(11): 894-7.

42. Burri PH. Fetal and postnatal development of the lung. Annu Rev Physiol. 1984; 46: $617-28$.

43. Pasquali R, Potier A, Gorincour G. [Fetal lung imaging]. Gynecol Obstet Fertil. 2008; 36(6): 587-602.

44. Tschanz SA, Damke BM, Burri PH. Influence of postnatally administered glucocorticoids on rat lung growth. Biol Neonate. 1995; 68(4): 229-45.

45. Laudy JA, Wladimiroff JW. The fetal lung. 1: Developmental aspects. Ultrasound Obstet Gynecol. 2000; 16(3): 284-90.

46. Sahn SA. State of the art. The pleura. Am Rev Respir Dis. 1988; 138(1): 184234.

47. Sahn SA. The pathophysiology of pleural effusions. Annu Rev Med. 1990; 41: 7-13.

48. Fahimi H, Casselman FP, Mariani MA, van Boven WJ, Knaepen PJ, van Swieten HA. Current management of postoperative chylothorax. Ann Thorac Surg. 2001; 71(2): 448-50; discussion 50-1.

49. Bigras JL, Ryan G, Suda K, Silva AE, Seaward PGR, Windrim R, et al. Echocardiographic evaluation of fetal hydrothorax: the effusion ratio as a diagnostic tool. Ultrasound in Obstetrics \& Gynecology. 2003; 21(1): 37-40.

50. Rustico MA, Lanna M, Coviello D, Smoleniec J, Nicolini U. Fetal pleural effusion. Prenatal Diagnosis. 2007; 27(9): 793-9.

51. Sanders RC. Prenatal diagnosis of structural abnormalities. Curr Opin Obstet Gynecol. 1991; 3(2): 259-65. 
52. Smith RP, Illanes S, Denbow ML, Soothill PW. Outcome of fetal pleural effusions treated by thoracoamniotic shunting. Ultrasound in Obstetrics \& Gynecology. 2005; 26(1): 63-6.

53. Medina O, Gomez J, Mejia C, Ramirez J. First-trimester diagnosis of pleural effusion. Ultrasound Obstet Gynecol. 2002; 19(4): 423-4.

54. Shimizu T, Hashimoto K, Shimizu M, Ozaki M, Murata Y. Bilateral pleural effusion in the first trimester: a predictor of chromosomal abnormality and embryonic death? Am J Obstet Gynecol. 1997; 177(2): 470-1.

55. Hashimoto K, Shimizu T, Fukuda M, Ozaki M, Shimoya K, Koyama M, et al. Pregnancy outcome of embryonic/fetal pleural effusion in the first trimester. J Ultrasound Med. 2003; 22(5): 501-5.

56. Yinon Y, Grisaru-Granovsky S, Chaddha V, Windrim R, Seaward PGR, Kelly EN, et al. Perinatal outcome following fetal chest shunt insertion for pleural effusion. Ultrasound in Obstetrics \& Gynecology. 2010; 36(1): 58-64.

57. Dupre AR, Morrison JC, Martin JN, Floyd RC, Blake PG. Clinical application of the Kleihauer-Betke test. J Reprod Med. 1993; 38(8): 621-4.

58. Lam H, Yates R, Jauniaux E. Successful early in utero management of fetal hydrothorax in a twin pregnancy. Prenatal Diagnosis. 2003; 23(3): 221-4.

59. Chen CH, Chen TH, Kuo SJ, Chen CP, Lee DJ, Ke YY, et al. Genetic evaluation and management of fetal chylothorax: review and insights from a case of Noonan Syndrome. Lymphology. 2009; 42(3): 134-8.

60. Goldstein RB, Callen WP. Ultrasound Evaluation of the Fetal Thorax. Ultrasonography in Obstetrics and Gynecology. Philadelphia: Saunders; 2000. p. 426-55. 
61. Achiron R, Weissman A, Lipitz S, Mashiach S, Goldman B. Fetal pleural effusion: the risk of fetal trisomy. Gynecol Obstet Invest. 1995; 39(3): 153-6.

62. Waller K, Chaithongwongwatthana S, Yamasmit W, Donnenfield AE. Chromosomal abnormalities among 246 fetuses with pleural effusions detected on prenatal ultrasound examination: Factors associated with an increased risk of aneuploidy. Genetics in Medicine. 2005; 7(6): 417-21.

63. Nicolaides K, Pettersen H. Fetal therapy. Curr Opin Obstet Gynecol. 1994; 6(5): 468-71.

64. Al-Tawil K, Ahmed G, Al-Hathal M, Al-Jarallah Y, Campbell N. Congenital chylothorax. Am J Perinatol. 2000; 17(3): 121-6.

65. Hodges CC, Fossum TW, Evering W. Evaluation of thoracic duct healing after experimental laceration and transection. Vet Surg. 1993; 22(6): 431-5.

66. Riquet M, Le Pimpec Barthes F, Souilamas R, Hidden G. Thoracic duct tributaries from intrathoracic organs. Ann Thorac Surg. 2002; 73(3): 892-8; discussion 8-9.

67. Chen M, Hsieh CY, Shih JC, Chou CH, Ma GC, Chen TH, et al. Proinflammatory macrophage migratory inhibition factor and interleukin-6 are concentrated in pleural effusion of human fetuses with prenatal chylothorax. Prenat Diagn. 2007; 27(5): 435-41.

68. Moerman P, Vandenberghe K, Devlieger H, Van Hole C, Fryns JP, Lauweryns JM. Congenital pulmonary lymphangiectasis with chylothorax: a heterogeneous lymphatic vessel abnormality. Am J Med Genet. 1993; 47(1): 54-8.

69. Fox GF, Challis D, O'Brien KK, Kelly EN, Ryan G. Congenital chylothorax in siblings. Acta Paediatr. 1998; 87(9): 1010-2. 
70. Huang XZ, Wu JF, Ferrando R, Lee JH, Wang YL, Farese RV, et al. Fatal bilateral chylothorax in mice lacking the integrin alpha9beta1. Mol Cell Biol. 2000; 20(14): 5208-15.

71. Adzick NS, Harrison MR. Fetal surgical therapy. Lancet. 1994; 343(8902): 897902.

72. Adzick NS, Harrison MR, Crombleholme TM, Flake AW, Howell LJ. Fetal lung lesions: Management and outcome. American Journal of Obstetrics and Gynecology. 1998; 179(4): 884-9.

73. Smoleniec J, James D. Predictive value of pleural effusions in fetal hydrops. Fetal Diagn Ther. 1995; 10(2): 95-100.

74. Ibrahim H, Asamoah A, Krouskop RW, Lewis D, Webster P, Pramanik AK. Congenital chylothorax in neonatal thyrotoxicosis. J Perinatol. 1999; 19(1): 6871.

75. Skoll MA, Sharland GK, Allan LD. Is the ultrasound definition of fluid collections in non-immune hydrops fetalis helpful in defining the underlying cause or predicting outcome? Ultrasound Obstet Gynecol. 1991; 1(5): 309-12.

76. Barron SD, Pass RF. Infectious causes of hydrops fetalis. Semin Perinatol. 1995; 19(6): 493-501.

77. Savarese I, De Carolis MP, Costa S, De Rosa G, De Carolis S, Lacerenza S, et al. Atypical manifestations of congenital parvovirus B19 infection. European Journal of Pediatrics. 2008; 167(12): 1463-6.

78. Parilla BV, Tamura RK, Ginsberg NA. Association of parvovirus infection with isolated fetal effusions. Am J Perinatol. 1997; 14(6): 357-8. 
79. Dubois-Lebbe C, Houfflin-Debarge V, Dewilde A, Devisme L, Subtil D. Nonimmune hydrops fetalis due to herpes simplex virus type 1. Prenat Diagn. 2007; 27(2): 188-9.

80. Huang HC, Wang TJ, Huang CB. Noonan syndrome presented with cystic hygroma and chylothorax: case report. Changgeng Yi Xue Za Zhi. 1999; 22(2): $313-8$

81. Patton MA, Baraitser M, Nickolaides K, Rodeck CH, Gamsu H. Prenatal treatment of fetal hydrops associated with the hypertelorism-dysphagia syndrome (Opitz-G syndrome). Prenat Diagn. 1986; 6(2): 109-15.

82. Van Aerde J. Spontaneous chylothorax in newborns. In: Campbell N, editor. Am J Dis Child; 1984. p. 961 - 4.

83. Thurlbeck WM. Prematurity and the developing lung. Clin Perinatol. 1992; 19(3): 497-519.

84. Castillo RA, Devoe LD, Falls G, Holzman GB, Hadi HA, Fadel HE. Pleural effusions and pulmonary hypoplasia. Am J Obstet Gynecol. 1987; 157(5): 12525.

85. Maeda H, Shimokawa H, Yamaguchi Y, Sueishi K, Nakano H. The influence of pleural effusion on pulmonary growth in the human fetus. J Perinat Med. 1989; 17(3): 231-6.

86. Chinoy MR. Pulmonary hypoplasia and congenital diaphragmatic hernia: advances in the pathogenetics and regulation of lung development. J Surg Res. 2002; 106(1): 209-23. 
87. Dillon PW, Cilley RE, Mauger D, Zachary C, Meier A. The relationship of pulmonary artery pressure and survival in congenital diaphragmatic hernia. J Pediatr Surg. 2004; 39(3): 307-12..

88. Yonemoto H, Itoh S, Nakamura Y, Yoshida K, Kinoshita K. Hemodynamic evaluation of a prenatal thoracoamniotic shunt for fetal pleural effusion. Early Human Development. 2006; 82(6): 411-4.

89. Gonen R, Degani S, Shapiro I, Samberg I, Sharf M. The effect of drainage of fetal chylothorax on cardiac and blood vessel hemodynamics. J Clin Ultrasound. 1993; 21(4): 265-8.

90. Laudy JA, Tibboel D, Robben SG, de Krijger RR, de Ridder MA, Wladimiroff JW. Prenatal prediction of pulmonary hypoplasia: clinical, biometric, and Doppler velocity correlates. Pediatrics. 2002; 109(2): 250-8.

91. Kugelman A, Gonen R, Bader D. Potential role of high-frequency ventilation in the treatment of severe congenital pleural effusion. Pediatric Pulmonology. 2000; 29(5): 404-8.

92. Paternoster DM, Manganelli F, Minucci D, Nanhornguè KN, Memmo A, Bertoldini M, et al. Ballantyne syndrome: a case report. Fetal Diagn Ther. 2006; 21(1): 92-5.

93. Cardwell MS. Polyhydramnios: a review. Obstet Gynecol Surv. 1987; 42(10): $612-7$

94. Maeda H, Nagata H, Tsukimori K, Satoh S, Koyanagi T, Nakano H. Prenatal evaluation and obstetrical management of fetuses at risk of developing lung hypoplasia. J Perinat Med. 1993; 21(5): 355-61. 
95. Bianchi S, Lista G, Castoldi F, Rustico M. Congenital primary hydrothorax: effect of thoracoamniotic shunting on neonatal clinical outcome. Journal of Maternal-Fetal \& Neonatal Medicine. 2010; 23(10): 1225-9.

96. Yang YS, Ma GC, Shih JC, Chen CP, Chou CH, Yeh KT, et al. Experimental treatment of bilateral fetal chylothorax using in utero pleurodesis. Ultrasound Obstet Gynecol. 2011; 1 - 31 .

97. Bartha JL, Comino-Delgado R. Fetal chylothorax response to maternal dietary treatment. Obstet Gynecol. 2001; 97(5 Pt 2): 820-3.

98. Favre R. Diagnosis and treatment of fetal pleural effusions. Archives De Pediatrie. 2010; 17(6): 695-6.

99. Picone O, Benachi A, Mandelbrot L, Ruano R, Dumez Y, Dommergues M. [Emergency thoraco amniotic shunting in cases with compressive pleural effusion with hydrops: A retrospective study of 60 cases]. J Gynecol Obstet Biol Reprod (Paris). 2006; 35(7): 652-7.

100.Giazza G, Cosimi MF, Lanero M, Rossi GP, Casagranda I. Cytologic diagnosis and chromosome analysis: sensitivity, specificity, accuracy and predictive value in malignant and benign pleural effusions. Pathologica. 1990; 82(1077): 33-40.

101.Cabral A, Leite H, Corbani M, Pereira A. Toracocentese fetal para cariótipo em líquido pleural. J Bras Ginecol; 1994. p. 104:429-30.

102.Knox EM, Kilby MD, Martin WL, Khan KS. In-utero pulmonary drainage in the management of primary hydrothorax and congenital cystic lung lesion: a systematic review. Ultrasound in Obstetrics \& Gynecology. 2006; 28(5): 726-34. 
103.Pandya P, Rodeck C. Percutaneous sonographically guided interventions: catheters and shunts. In: Harrison M, Evans M, Adzick N, editors. The Unborn Patient 2001. p. 191-7.

104.Harrison M. UCSF fetal treatment center: a Personal Perspective. Fetal Diagn Ther; 2004. p. 19: 513-24.

105.NICE G. Insertion of Pleuro-Amniotic Shunt for Fetal Pleural Effusion. National Institute for Health and Clinical Excellence: London.; 2006. p. 190-3.

106.Picone O, Benachi A, Mandelbrot L, Ruano R, Dumez Y, Dommergues M. Thoracoamniotic shunting for fetal pleural effusions with hydrops. American Journal of Obstetrics and Gynecology. 2004; 191(6): 2047-50.

107.Dikensoy O, Light RW. Alternative widely available, inexpensive agents for pleurodesis. Curr Opin Pulm Med. 2005; 11(4): 340-4.

108.Tanemura M, Nishikawa N, Kojima K, Suzuki Y, Suzumori K. A case of successful fetal therapy for congenital chylothorax by intrapleural injection of OK-432. Ultrasound in Obstetrics \& Gynecology. 2001; 18(4): 371-5.

109.Jorgensen C, Brocks V, Bang J, Jorgensen FS, Ronsbro L. Treatment of severe fetal chylothorax associated with pronounced hydrops with intrapleural injection of OK-432. Ultrasound in Obstetrics \& Gynecology. 2003; 21(1): 66-9.

110.Nygaard U, Sundberg K, Nielsen HS, Hertel S, Jorgensen C. New treatment of early fetal chylothorax. Obstetrics and Gynecology. 2007; 109(5): 1088-92.

111.Chen M, Chen CP, Shih JC, Chou HC, Yu CL, Wang ET, et al. Antenatal treatment of chylothorax and cystic hygroma with OK-432 in nonimmune hydrops fetalis. Fetal Diagnosis and Therapy. 2005; 20(4): 309-15. 
112.Chen M, Shih JC, Wang BT, Chen CP, Yu CL. Fetal OK-432 pleurodesis: complete or incomplete? Ultrasound Obstet Gynecol. 2005; 26(7): 791-3.

113. Chen CH, Chen TH, Kuo SJ, Chen CP, Lee DJ, Ke YY, et al. Genetic evaluation and management of fetal chylothorax: review and insights from a case of Noonan syndrome. Lymphology. 2009; 42(3): 134-8.

114.Ma GC, Liu CS, Chang SP, Yeh KT, Ke YY, Chen TH, et al. A recurrent ITGA9 missense mutation in human fetuses with severe chylothorax: possible correlation with poor response to fetal therapy. Prenat Diagn. 2008; 28(11): 1057-63.

115.Parra J, Amenedo M, Muniz-Diaz E, Ormo F, Simo M, Vega C, et al. A new successful therapy for fetal chylothorax by intrapleural injection of maternal blood. Ultrasound in Obstetrics \& Gynecology. 2003; 22(3): 290-4.

116. Brown R, Nicolaides K. Constriction band of the arm following insertion of a pleuro-amniotic shunt. Ultrasound Obstet Gynecol. 2000; 15(5): 439-40.

117.Chao AS, Chao A, Chang YL, Wang TH, Lien RY, Lee ZL. Chest wall deformities in a newborn infant after in utero thoracoamniotic shunting for massive pleural effusion. European Journal of Obstetrics \& Gynecology and Reproductive Biology. 2010; 151(1): 112-3.

118. Webb RD, Walkinshaw SA, Shaw NJ. Cosmetic sequelae of thoraco-amniotic shunting. Eur J Pediatr. 2000; 159(1-2): 133.

119.Bovicelli L, Rizzo N, Orsini LF, Carderoni P. Ultrasonic real-time diagnosis of fetal hydrothorax and lung hypoplasia. J Clin Ultrasound. 1981; 9(5): 253-4.

120.Lange IR, Manning FA. Antenatal diagnosis of congenital pleural effusions. Am J Obstet Gynecol. 1981; 140(7): 839-40. 
121. Samuel M, McCarthy L, Boddy SA. Efficacy and safety of OK-432 sclerotherapy for giant cystic hygroma in a newborn. Fetal Diagn Ther. 2000; 15(2): 93-6.

122.Caserío S, Gallego C, Martin P, Moral MT, Pallás CR, Galindo A. Congenital chylothorax: from foetal life to adolescence. Acta Paediatr. 2010; 99(10): 15717.

123.Strausser JL, Flye MW. Management of nontraumatic chylothorax. Ann Thorac Surg. 1981; 31(6): 520-6.

124.Le Nué R, Molinaro F, Gomes-Ferreira C, Scheib-Brolly C, Escande B, Kühn P, et al. Surgical management of congenital chylothorax in children. Eur J Pediatr Surg. 2010; 20(5): 307-11.

125.Soffiati M, Bonaldi A, Biban P. [Management of pleural drainage]. Minerva Pediatr. 2010; 62(3 Suppl 1): 165-7.

126.Lahmiti S, Elhoudzi J, Aboussad A. Congenital chylothorax. ScientificWorldJournal. 2009; 9: 431-4.

127.Copons Fernández C, Benítez Segura I, Castillo Salinas F, Salcedo Abizanda S. [Neonatal chylothorax: aetiology, clinical course and efficacy of treatment]. An Pediatr (Barc). 2008; 68(3): 224-31.

128.Rocha G. Pleural effusions in the neonate. Curr Opin Pulm Med. 2007; 13(4): 305-11.

129.Büttiker V, Fanconi S, Burger R. Chylothorax in children: guidelines for diagnosis and management. Chest. 1999; 116(3): 682-7. 
130.Cannizzaro V, Frey B, Bernet-Buettiker V. The role of somatostatin in the treatment of persistent chylothorax in children. Eur J Cardiothorac Surg. 2006; 30(1): 49-53.

131.Winters WD, Effmann EL. Congenital masses of the lung: prenatal and postnatal imaging evaluation. J Thorac Imaging. 2001; 16(4): 196-206.

132.Laudy JA, Wladimiroff JW. The fetal lung. 2: Pulmonary hypoplasia. Ultrasound Obstet Gynecol. 2000; 16(5): 482-94.

133.Shanmugam G, MacArthur K, Pollock JC. Congenital lung malformations-antenatal and postnatal evaluation and management. Eur J Cardiothorac Surg. 2005; 27(1): 45-52.

134.Kilbride HW, Yeast J, Thibeault DW. Defining limits of survival: lethal pulmonary hypoplasia after midtrimester premature rupture of membranes. Am J Obstet Gynecol. 1996; 175(3 Pt 1): 675-81.

135.Thibeault DW, Beatty EC, Hall RT, Bowen SK, O'Neill DH. Neonatal pulmonary hypoplasia with premature rupture of fetal membranes and oligohydramnios. J Pediatr. 1985; 107(2): 273-7.

136.Askenazi SS, Perlman M. Pulmonary hypoplasia: lung weight and radial alveolar count as criteria of diagnosis. Arch Dis Child. 1979; 54(8): 614-8.

137.Wigglesworth JS, Desai R, Guerrini P. Fetal lung hypoplasia: biochemical and structural variations and their possible significance. Arch Dis Child. 1981; 56(8): 606-15.

138. Wigglesworth JS, Desai R. Use of DNA estimation for growth assessment in normal and hypoplastic fetal lungs. Arch Dis Child. 1981; 56(8): 601-5. 
139. Cooney TP, Thurlbeck WM. The radial alveolar count method of Emery and Mithal: a reappraisal 1--postnatal lung growth. Thorax. 1982; 37(8): 572-9.

140.Lauria MR, Gonik B, Romero R. Pulmonary hypoplasia: pathogenesis, diagnosis, and antenatal prediction. Obstet Gynecol. 1995; 86(3): 466-75.

141.Fox HE, Badalian SS. Ultrasound prediction of fetal pulmonary hypoplasia in pregnancies complicated by oligohydramnios and in cases of congenital diaphragmatic hernia: a review. Am J Perinatol. 1994; 11(2): 104-8.

142.Sherer DM, Davis JM, Woods JR. Pulmonary hypoplasia: a review. Obstet Gynecol Surv. 1990; 45(11): 792-803.

143.Yoshimura S, Masuzaki H, Gotoh H, Fukuda H, Ishimaru T. Ultrasonographic prediction of lethal pulmonary hypoplasia: comparison of eight different ultrasonographic parameters. Am J Obstet Gynecol. 1996; 175(2): 477-83.

144.Tanigaki S, Miyakoshi K, Tanaka M, Hattori Y, Matsumoto T, Ueno K, et al. Pulmonary hypoplasia: prediction with use of ratio of MR imaging-measured fetal lung volume to US-estimated fetal body weight. Radiology. 2004; 232(3): 767-72.

145.Roberts AB, Mitchell JM. Direct ultrasonographic measurement of fetal lung length in normal pregnancies and pregnancies complicated by prolonged rupture of membranes. Am J Obstet Gynecol. 1990; 163(5 Pt 1): 1560-6.

146.Merz E, Miric-Tesanic D, Bahlmann F, Weber G, Hallermann C. Prenatal sonographic chest and lung measurements for predicting severe pulmonary hypoplasia. Prenatal Diagnosis. 1999; 19(7): 614-9.

147.Siddiqi TA, Meyer RA, Korfhagen J, Khoury JC, Rosenn B, Miodovnik M. A longitudinal study describing confidence limits of normal fetal cardiac, thoracic, 
and pulmonary dimensions from 20 to 40 weeks' gestation. J Ultrasound Med. 1993; 12(12): 731-6.

148.Keller RL, Glidden DV, Paek BW, Goldstein RB, Feldstein VA, Callen PW, et al. The lung-to-head ratio and fetoscopic temporary tracheal occlusion: prediction of survival in severe left congenital diaphragmatic hernia. Ultrasound Obstet Gynecol. 2003; 21(3): 244-9.

149.Lipshutz GS, Albanese CT, Feldstein VA, Jennings RW, Housley HT, Beech R, et al. Prospective analysis of lung-to-head ratio predicts survival for patients with prenatally diagnosed congenital diaphragmatic hernia. J Pediatr Surg. 1997; 32(11): 1634-6.

150.Jani J, Nicolaides KH, Keller RL, Benachi A, Peralta CF, Favre R, et al. Observed to expected lung area to head circumference ratio in the prediction of survival in fetuses with isolated diaphragmatic hernia. Ultrasound Obstet Gynecol. 2007; 30(1): 67-71.

151.Harstad TW, Twickler DM, Leveno KJ, Brown CE. Antepartum prediction of pulmonary hypoplasia: an elusive goal? Am J Perinatol. 1993; 10(1): 8-11.

152.Ba'ath ME, Jesudason EC, Losty PD. How useful is the lung-to-head ratio in predicting outcome in the fetus with congenital diaphragmatic hernia? A systematic review and meta-analysis. Ultrasound Obstet Gynecol. 2007; 30(6): 897-906.

153.Prendergast M, Rafferty GF, Davenport M, Persico N, Jani J, Nicolaides K, et al. Three-dimensional ultrasound fetal lung volumes and infant respiratory outcome: a prospective observational study. BJOG. 2011; 118(5): 608-14. 
154.Ruano R, Aubry MC, Barthe B, Dumez Y, Zugaib M, Benachi A. Threedimensional sonographic measurement of contralateral lung volume in fetuses with isolated congenital diaphragmatic hernia. J Clin Ultrasound. 2008; 36(5): 273-8.

155.Ruano R, Benachi A, Martinovic J, Grebille AG, Aubry MC, Dumez Y, et al. Can three-dimensional ultrasound be used for the assessment of the fetal lung volume in cases of congenital diaphragmatic hernia? Fetal Diagn Ther. 2004; 19(1): 87-91.

156.Gerards FA, Engels MA, Twisk JW, van Vugt JM. Normal fetal lung volume measured with three-dimensional ultrasound. Ultrasound Obstet Gynecol. 2006; 27(2): 134-44.

157.Peralta CF, Cavoretto P, Csapo B, Falcon O, Nicolaides KH. Lung and heart volumes by three-dimensional ultrasound in normal fetuses at 12-32 weeks' gestation. Ultrasound Obstet Gynecol. 2006; 27(2): 128-33.

158.Werneck Britto IS, de Silva Bussamra LC, Araujo Júnior E, Tedesco GD, Nardozza LM, Moron AF, et al. Reference range of fetal lung volume by 3Dultrasonography using the rotational method (VOCAL). J Perinat Med. 2009; 37(2): 161-7.

159.Ruano R, Joubin L, Sonigo P, Benachi A, Aubry MC, Thalabard JC, et al. Fetal lung volume estimated by 3-dimensional ultrasonography and magnetic resonance imaging in cases with isolated congenital diaphragmatic hernia. $\mathrm{J}$ Ultrasound Med. 2004; 23(3): 353-8.

160.Peralta CF, Kazan-Tannus JF, Bunduki V, Santos EM, de Castro CC, Cerri GG, et al. Evaluation of the agreement between 3-dimensional ultrasonography and 
magnetic resonance imaging for fetal lung volume measurement. J Ultrasound Med. 2006; 25(4): 461-7.

161.Araujo Júnior E, De Oliveira PS, Nardozza LM, Simioni C, Rolo LC, Goldman SM, et al. Fetal lung volume in fetuses with urinary tract malformations: comparison by 2D-, 3D-sonography and magnetic resonance imaging. J Matern Fetal Neonatal Med. 2010; 23(1): 60-8.

162.Duncan KR, Gowland PA, Moore RJ, Baker PN, Johnson IR. Assessment of fetal lung growth in utero with echo-planar MR imaging. Radiology. 1999; 210(1): 197-200.

163.Kehl S, Eckert S, Sütterlin M, Neff KW, Siemer J. Influence of different rotation angles in assessment of lung volumes by 3-dimensional sonography in comparison to magnetic resonance imaging in healthy fetuses. J Ultrasound Med. 2011; 30(6): 819-25.

164.D'Arcy TJ, Hughes SW, Chiu WS, Clark T, Milner AD, Saunders J, et al. Estimation of fetal lung volume using enhanced 3-dimensional ultrasound: a new method and first result. Br J Obstet Gynaecol. 1996; 103(10): 1015-20.

165.Kalache KD, Espinoza J, Chaiworapongsa T, Londono J, Schoen ML, Treadwell $\mathrm{MC}$, et al. Three-dimensional ultrasound fetal lung volume measurement: a systematic study comparing the multiplanar method with the rotational (VOCAL) technique. Ultrasound Obstet Gynecol. 2003; 21(2): 111-8.

166.Lee A, Kratochwil A, Stümpflen I, Deutinger J, Bernaschek G. Fetal lung volume determination by three-dimensional ultrasonography. Am J Obstet Gynecol. 1996; 175(3 Pt 1): 588-92. 
167.Pöhls UG, Rempen A. Fetal lung volumetry by three-dimensional ultrasound. Ultrasound Obstet Gynecol. 1998; 11(1): 6-12.

168.Raine-Fenning NJ, Campbell BK, Clewes JS, Kendall NR, Johnson IR. The reliability of virtual organ computer-aided analysis (VOCAL) for the semiquantification of ovarian, endometrial and subendometrial perfusion. Ultrasound Obstet Gynecol. 2003; 22(6): 633-9.

169.Ruano R, Joubin L, Aubry MC, Thalabard JC, Dommergues M, Dumez Y, et al. A nomogram of fetal lung volumes estimated by 3-dimensional ultrasonography using the rotational technique (virtual organ computer-aided analysis). J Ultrasound Med. 2006; 25(6): 701-9.

170.Ruano R, Aubry MC, Barthe B, Mitanchez D, Dumez Y, Benachi A. Quantitative analysis of fetal pulmonary vasculature by 3-dimensional power Doppler ultrasonography in isolated congenital diaphragmatic hernia. Am J Obstet Gynecol. 2006; 195(6): 1720-8.

171. Mussat P, Dommergues M, Parat S, Mandelbrot L, Degamarra E, Dumez Y, et al. Congenital chylothorax with hydrops - postnatal care and outcome following antenatal diagnosis. Acta Paediatrica. 1995; 84(7): 749-55.

172.Raine-Fenning NJ, Clewes JS, Kendall NR, Bunkheila AK, Campbell BK, Johnson IR. The interobserver reliability and validity of volume calculation from three-dimensional ultrasound datasets in the in vitro setting. Ultrasound Obstet Gynecol. 2003; 21(3): 283-91.

173.Gerards FA, Twisk JW, Bakker M, Barkhof F, van Vugt JM. Fetal lung volume: three-dimensional ultrasonography compared with magnetic resonance imaging. Ultrasound Obstet Gynecol. 2007; 29(5): 533-6. 
174.Deshmukh S, Rubesova E, Barth R. MR assessment of normal fetal lung volumes: a literature review. AJR Am J Roentgenol. 2010; 194(2): W212-7.

175.Raine-Fenning NJ, Campbell BK, Clewes JS, Johnson IR. The interobserver reliability of ovarian volume measurement is improved with three-dimensional ultrasound, but dependent upon technique. Ultrasound Med Biol. 2003; 29(12): 1685-90.

176.Laudy JA, Janssen MM, Struyk PC, Stijnen T, Wladimiroff JW. Threedimensional ultrasonography of normal fetal lung volume: a preliminary study. Ultrasound Obstet Gynecol. 1998; 11(1): 13-6.

177. Sabogal JC, Becker E, Bega G, Komwilaisak R, Berghella V, Weiner S, et al. Reproducibility of fetal lung volume measurements with 3-dimensional ultrasonography. J Ultrasound Med. 2004; 23(3): 347-52.

178.Jani J, Cannie M, Sonigo P, Robert Y, Moreno O, Benachi A, et al. Value of prenatal magnetic resonance imaging in the prediction of postnatal outcome in fetuses with diaphragmatic hernia. Ultrasound Obstet Gynecol. 2008; 32(6): 793-9.

179.Ruano R, Aubry MC, Barthe B, Dumez Y, Benachi A. Three-dimensional ultrasonographic measurements of the fetal lungs for prediction of perinatal outcome in isolated congenital diaphragmatic hernia. J Obstet Gynaecol Res. 2009; 35(6): 1031-41.

180.Ruano R, Takashi E, da Silva MM, Campos JA, Tannuri U, Zugaib M. Prediction and probability of neonatal outcome in isolated congenital diaphragmatic hernia using multiple ultrasound parameters. Ultrasound Obstet Gynecol. 2011. 